INCREASING THE ACADEMIC SUCCESS OF LATINO TRANSFER STUDENTS:

EVALUATING THE GANAS PROGRAM

A dissertation submitted to the faculty of

San Francisco State University

As

In partial fulfillment of

The Requirements for

The Degree

2017

EDD

$\cdot C 47$

Doctor of Education

In

Educational Leadership

By

Melissa Padilla Cervantes

San Francisco, California

December 2017 
Copyright by

Melissa Padilla Cervantes

2017 


\section{CERTIFICATION OF APPROVAL}

I certify that I have read Increasing the Academic Success of Latino Transfer Students:

Evaluating the GANAS Program by Melissa Padilla Cervantes, and that in my opinion this work meets the criteria for approving a dissertation submitted in partial fulfillment of the requirements for the degree: Doctor of Education in Educational Leadership at San Francisco State University.
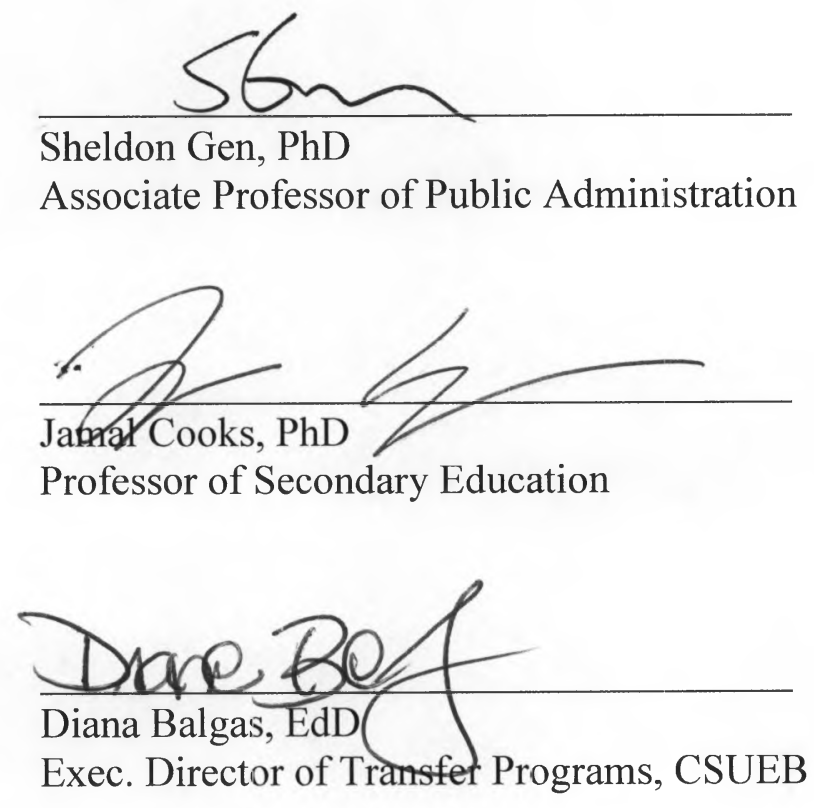


\title{
INCREASING THE ACADEMIC SUCCESS OF LATINO TRANSFER STUDENTS: EVALUATING THE GANAS PROGRAM
}

\author{
Melissa Padilla Cervantes \\ San Francisco, California \\ 2017
}

The largest entry point into higher education for Latino students is through the California Community College system. Only $14 \%$ of those students successfully transfer to a fouryear university to pursue their baccalaureate degree. This study explores one university program offering support to these recent transfer students. The GANAS Program at Cal State East Bay offers an integrated academic and cultural approach, to smooth the transition while increasing the academic success, persistence, and ultimately, baccalaureate degree attainment rates of their students. A mixed methods program evaluation was conducted to examine the following research questions: Does participation in the GANAS Program at Cal State East Bay impact the academic progress of its transfer students? How do the services and activities that the program provides result in satisfactory academic progress? Statistical analysis found that GANAS participants experience higher GPAs and graduate at a higher 2-year and 3-year rate than the larger transfer sample population. Focus group responses revealed that participants attributed their success to the community they developed within GANAS, connecting to the course content, and to staff, faculty, and fellow students in a way that felt like family.

I certify that the Abstract is a correct representation of the content of this dissertation.

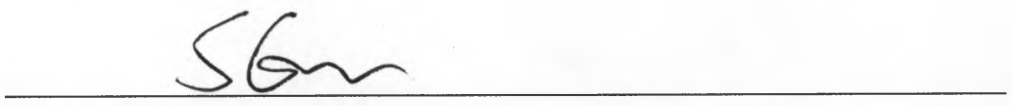

Chair, Dissertation Committee

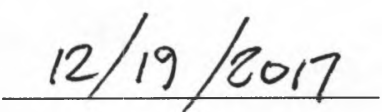

Date 


\section{PREFACE}

From the depths of my heart, I would like to thank the village that has carried me on their shoulders for longer than I could ever have asked for - my family, my friends, my colleagues, my mentors, and my students. I am the result of your love and I share this accomplishment with all of you.

To my ancestors, the original dreamers, who fought to provide more for the generations ahead of them, I am your dreams come true.

To my parents, Manuel and Alexandra Padilla, who loved me more than they loved themselves and who sacrificed so that I could have every opportunity, my strength, my passion, and my vocation to be of service to others came from both of you.

To Manuel, Michelle, Andrue, Alex, Anthony, Gabriel, and Lucas, your love and resilience as a family will forever be the standard by which I measure my own.

To my boys Fernando and Anthony, you revealed in me a capacity to love that I never knew I had, and I am humbled to be able to call you my sons.

To my husband Poncho, you've been at my side every moment of this journey. You were there to pick me up when I fell, and you were there to celebrate when I succeeded. I'm so proud to be loved by you. 


\section{ACKNOWLEDGMENTS}

This dissertation would not have been possible without the GANAS community, especially the students who so generously shared their time with me. Your stories of struggle and of triumph will forever live in the pages of this study. Thank you for ensuring I had everything I needed to tell the story of GANAS. With the utmost respect and gratitude, I would like to thank my dissertation chair, Dr. Sheldon Gen, and my committee members, Dr. Jamal Cooks and Dr. Diana Balgas. Having a team of first generation doctors behind me was a special experience, thank you for your guidance and for blazing a path for the rest of us to follow. To my study group (EBSG4L), Dr. Janine Saunders and Dr. Vanessa Mercado, some of the smartest and most powerful women of color I will ever have the privilege to call my friends, you will never know how just being in your presence inspired me. To my sister in the struggle, my biggest fan, and my best friend, Dr. Nancy Martinsen, we finally did it. Forever more we will be known as Doctor Best Friends. Finally, to all of the brown girls who have been told they aren't college material, that they don't belong, or who have been silenced - Calladita no te ves mas bonita. Be Chingona.

A woman who writes has power. $\sim$ Gloria Anzaldúa 


\section{TABLE OF CONTENTS}

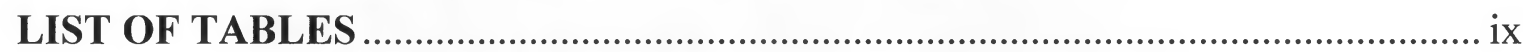

LIST OF FIGURES .............................................................................................

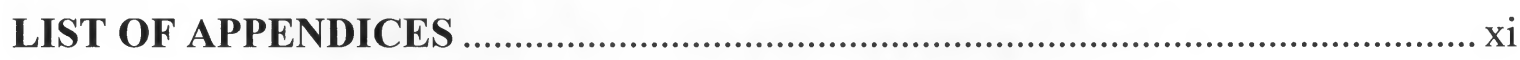

Chapter One: Purpose of the Study …….................................................................... 1

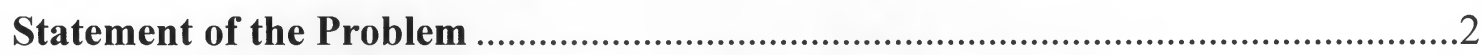

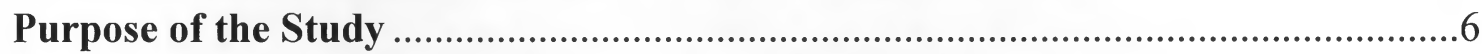

Research Questions and Design .............................................................................6

Significance of Study .................................................................................................10

Chapter Two: Literature Review ……………………............................................ 12

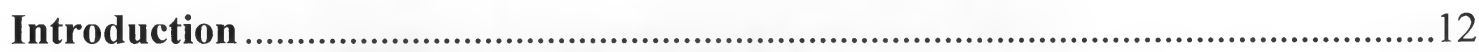

GANAS Program Selection and Participation ....................................................14

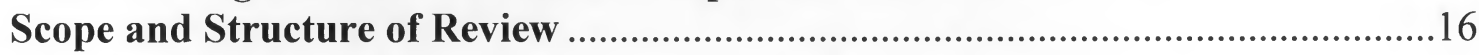

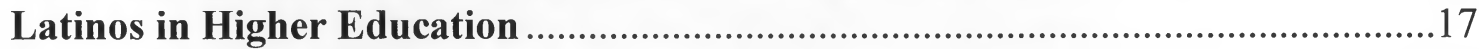

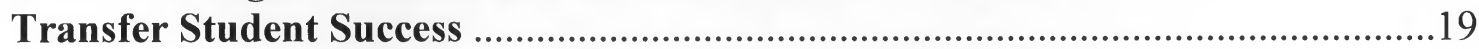

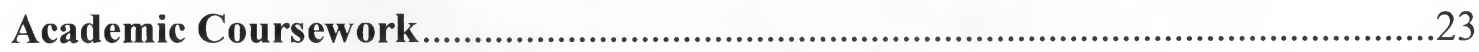

Learning community model................................................................................ 24

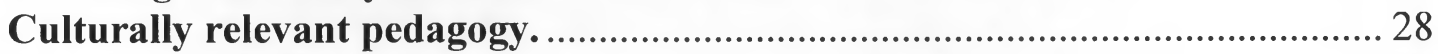

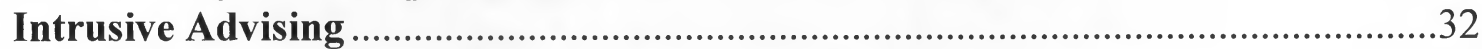

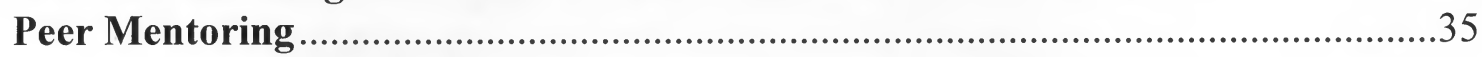

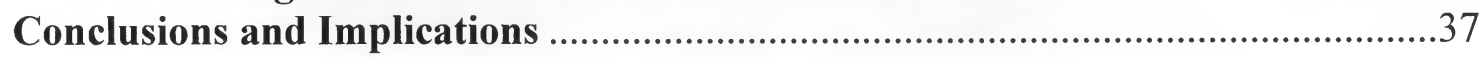

Chapter Three: Methodology ................................................................................... 39

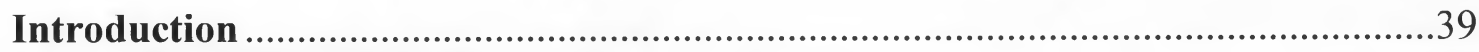

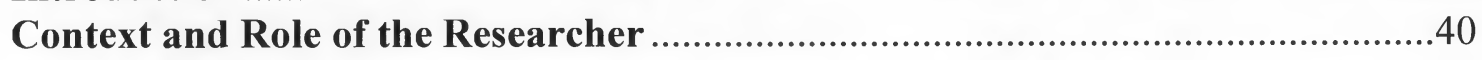

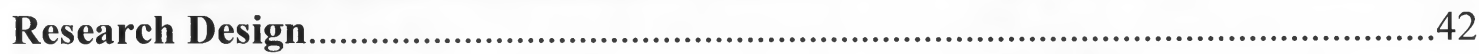

Setting and Sample

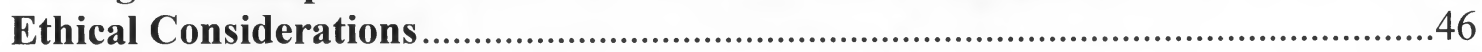

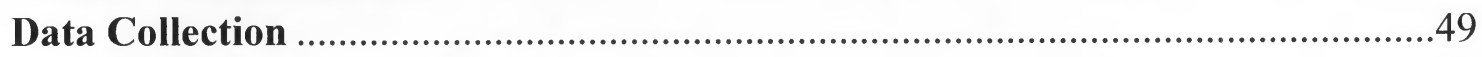

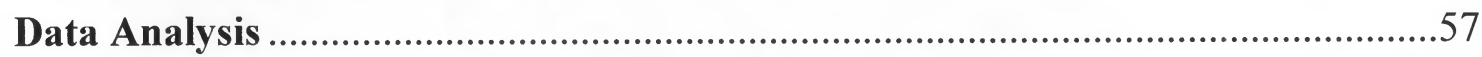

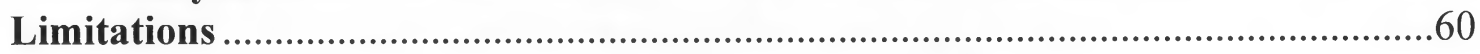




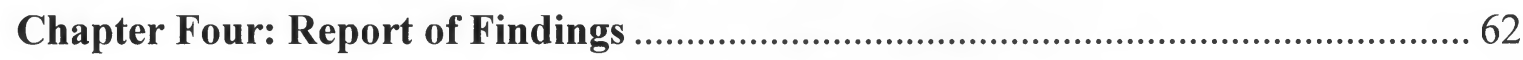

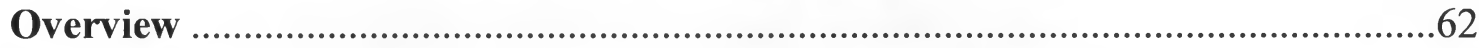

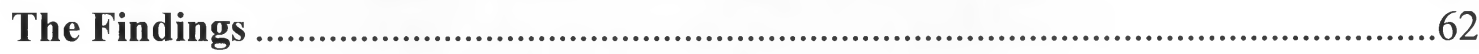

Chapter Five: Discussion and Recommendations........................................................... 96

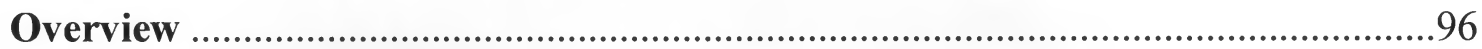

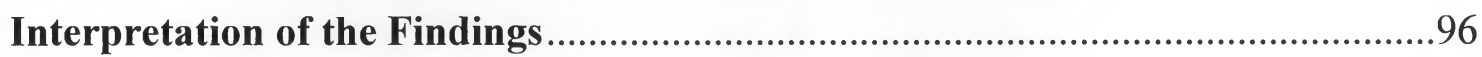

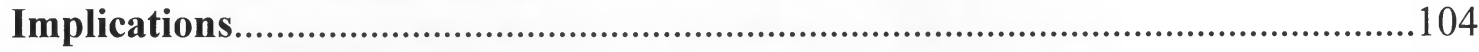

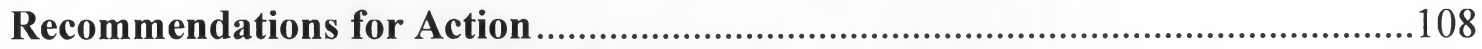

Recommendations for Further Study ........................................................ 116

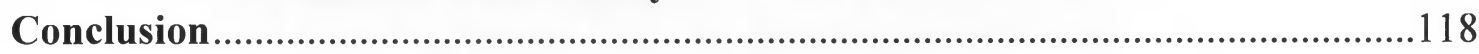

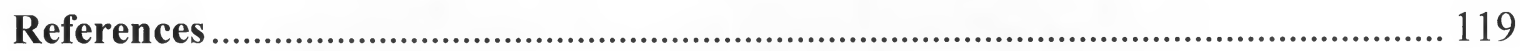

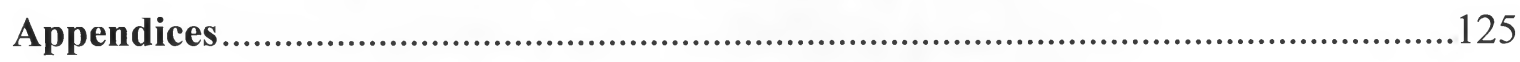




\section{LIST OF TABLES}

Table

Page

3.1: Coding/Desc. of Oper. Measures, and Value from IRADS Dataset....................... 52

3.2: GANAS Year End Survey Operational Measures ............................................ 55

4.1: Demo Characteristics as Numbers/Percentages w/Comparison Groups ................. 68

4.2: Chi-square Test: Graduation Status with Comparison Groups.............................. 69

4.3: Chi-square Test: Time to Degree with Comparison Groups ................................. 71

4.4: Effect of Variables in Model Predicting Impact on East Bay GPA....................... 75

4.5 Transfer GPA Categories by Comparison Groups................................................ 75

4.6: Frequencies/Percentages of Survey Responses by GANAS Participants - Learning

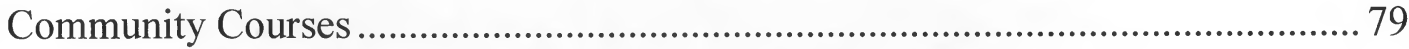

4.7: Frequencies/Percentages of Survey Responses by GANAS Participants - Intrusive Advising 82

4.8: Frequencies/Percentages of Survey Responses by GANAS Participants -

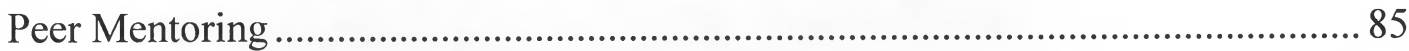

4.9: Frequencies/Percentages of Survey Responses by GANAS Participants - Building Community, Transition, and Confidence 


\section{LIST OF FIGURES}

Figure

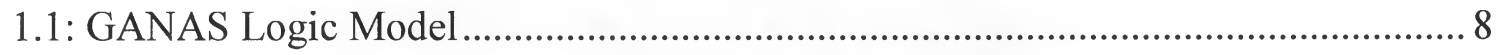

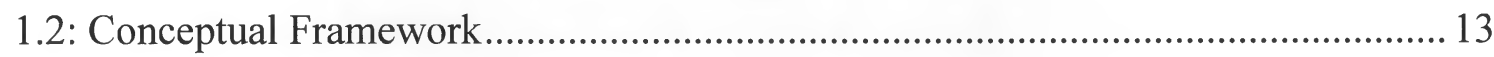

4.1: Average Cumulative Graduation Rates by Comparison Group................................73

4.2: Frequency and Percentages of Herman@ Meetings................................................... 82

4.3: Percentage of Survey Responses - Educational Aspirations...................................... 93 


\section{LIST OF APPENDICES}

$\begin{array}{lll}\text { Appendix } & \text { Page }\end{array}$

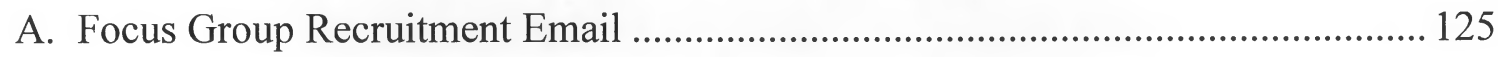

B. Informed Consent to Participate in Research................................................... 126

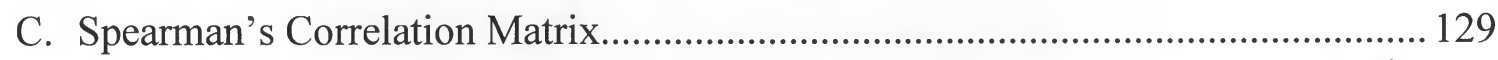

D. Cumulative Graduation Rates by Cohort Year and 4-Year Average...................... 130

E. GANAS Year End Survey Questions pulled from Program Records.................... 131

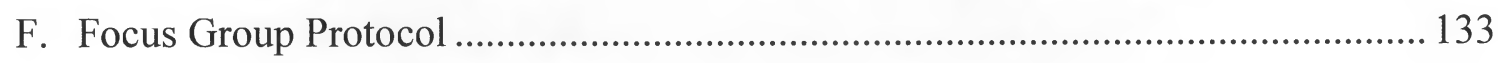




\section{Chapter One: Purpose of the Study}

\section{Introduction}

According to the California Department of Finance, at 39\%, Latinos are the single largest racial or ethnic group in California (2016). One out of every two minors in California is Latino - forecasting out to 2025, Latinos will make up nearly half of the state's college-aged (18-24 years old) population. However, despite this rapidly growing community, Latinos have the lowest rate of college attainment compared to all other ethnic groups in California (Campaign for College, 2013). As the fastest-growing population in the state, there is a responsibility to put equitable educational structures in place for Latino students.

While it has been shown that Latino high school graduates in California enroll in college at a higher rate than that of their non-Latino counterparts, $69.4 \%$ of those that do enroll are entering higher education through the California Community College (CCC) system as first-time freshman (Campaign for College, 2013). As forecasted in the Master Plan, caps on eligibility for the University of California (UC) and California State University (CSU) campuses will further limit enrollment at the four-year university level. These constraints at the CSU and UC level will result in large numbers of Latino California high school graduates being redirected from four-year universities to two-year colleges (Geiser \& Atkinson, 2010). It is evident this is already occurring when looking at Latino enrollment at institutions of post-secondary education for Fall 2015. Nearly $70 \%$ of those students, or 529,300 Latinos, enrolled at a California Community College 
which are open access; compared to $16.7 \%$ who enrolled at the CSU and $5 \%$ at the UC levels (Campaign for College, 2015). These data illustrate how, within the Latino college-going population, attendance is disproportionally high at the CCC level. While it also shows that Latinos are interested in higher education, it is a testament to the challenges Latinos have in accessing direct pathways to the 4-year university.

Although $40 \%$ of Latinos who enroll at community college aspire to transfer to a four-year university, only $14 \%$ of those who begin at a CCC actually end up transferring - leaving thousands of students caught in the community college system without a pathway to a bachelor's degree (Yosso \& Solorzano, 2006; Moore \& Shulock, 2010). As a result, only $11.4 \%$ of Latino adults in the state of California have earned a bachelor's degree or higher, compared to $28.4 \%$ of the overall adult population, and $41 \%$ of white adults (U.S. Census, 2015).

\section{Statement of the Problem}

When looking at transfer student success and baccalaureate attainment, it would be beneficial for both the community college and the four-year university to work together, forming a dual-commitment between institutions. Researchers Jain, Herrera, Bernal, and Solorzano argue that four-year universities need to do more to create pipelines from community colleges to their respective campuses, creating a transferresponsive culture in order to increase the transfer rates of Latinos. At the same time, they suggest community colleges could prioritize the need for preparation and increased push toward transfer for students. A lack of this type of partnership between institutions 
could severely decrease a transfer student's ability to complete the appropriate coursework at the community college; as well as to apply, enroll, and successfully earn a baccalaureate degree from the university in a timely manner (Jain, Herrera, Bernal, \& Solorzano, 2011).

Studies have found that increased support from faculty, peers, and the larger institution can significantly impact Latino students' adjustment to college (Schneider \& Ward, 2003). Creating a campus culture that is committed to ethnic minority groups, providing services and tools to guide their success, while continuing to be supportive of the larger college community provides appropriate support for all students. Promoting a united effort in showing genuine care and putting students first can only strengthen a student's connection to their campus community.

Even though research on the barriers to transfer exist, less is known about the experiences of the few Latino transfer students that do access and matriculate at the fouryear level, or the structures in place that are necessary for this population to achieve baccalaureate attainment. What is clear is that Latino transfer students at the 4-year university level have insufficient services to support their transition and ultimate success (Eggleston \& Laanan, 2001; Miller, 2013). Evaluation of services provided to transfer students at the 4-year university would provide insight on what is lacking and what could be strengthened. Looking at advising practices for example, taking a more holistic view in terms of guiding a student on their path to degree, and of course reviewing systems of support, for Latino students in particular, could be valuable to university administration 
and decision-makers. Results from such an evaluation could inform leadership as they shape services such as advising, tutoring, mentorship, and learning communities that support and guide transfer students campus-wide through to degree attainment; while also urging campus leaders to think about how these services impact the graduation rates of specific populations such as Latinos. With the largest population of Latino students entering higher education at the community college level, many are already working to increase the number of Latinos transferring from California Community Colleges to fouryear universities. It is essential that these efforts extend to the 4-year level and expand, providing meaningful support to those who successfully transition so that they can graduate, thus strengthening the pipeline and defining the pathway for others to follow. California State University, East Bay (CSUEB) decided to take a step in the direction of providing that support in the Fall of 2013 with the launch of the Gaining Access 'N Academic Success (GANAS) Program. That term marked a five years surge of Latino undergraduate enrollment at Cal State East Bay. The total number of Latino undergraduate students enrolled on campus rose from 1,914 to 3,086; a $62 \%$ increase (CSUEB Institutional Research, Analysis, and Decision Support, 2013). With this influx, Latino staff and faculty on campus thought it best to bring this data to recently appointed leadership to discuss how the campus planned to serve this specific demographic. They looked at state-wide data and scholarship on Latino educational attainment and found that a large number of universities, including East Bay, had been unable to graduate Latino students at the same rate as their non-Latino counterparts. Ultimately they came together 
to form a small task force, meeting over a period of two years, and taking a closer look at how the campus could best serve Latino students moving forward. They identified Latino transfer students at Cal State East Bay as the population that would most benefit from specialized services. With a target group in mind, they began to map out a structured program taking into consideration the funds of knowledge, or life experiences that Latino students bring into the classroom. Informed largely by the long-standing, culturally relevant, successful model known as Puente, which serves community college and high school student participants, the task force sought to create similar programmatic space at the four-year level. What developed infused culturally relevant themes and content into existing academic practices; both celebrating the cultural capital Latino students bring with them to the university and enabling them to integrate their home identities into their educational experience. All of these elements were intentionally combined to become what is now known as the Gaining Access 'N Academic Success (GANAS) Program (D. Balgas, personal communication, April, 2013). The program is described as:

An innovative access and retention program that offers integrated academic and cultural programming to welcome and socialize new transfer students while increasing their confidence, engagement, academic success, persistence, and, ultimately, baccalaureate degree attainment rates.

Students participate in a year-long cohort-based learning community paired with a transfer success seminar, intrusive academic counseling, and mentoring. GANAS helps students integrate their home and school identities by creating a sense of familia (family) within the cohort.

Students fulfill upper division G.E. breadth requirements by enrolling and completing the required GANAS courses during the first year. While GANAS is open to all students, our program provides Latino/a-themed academic content and supportive services. (CSUEB WASC Report, 2014) 


\section{Purpose of the Study}

The purpose of this study is to determine if and how services provided by the GANAS Program impact the academic progress of its participants. In particular, this study aims to assess the impact of services on its Latino participants' time to degree and grade point average, as well as highlight the student experience while a participant in the program.

\section{Research Questions and Design}

A mixed methods design to employ a formative program evaluation was used to examine the following research questions:

1. Does participation in the GANAS Program at Cal State East Bay impact the academic progress of its transfer students?

2. How do the services and activities that the program provides result in satisfactory academic progress?

To answer these questions, secondary data gathered from GANAS program records, as well as academic and demographic student data provided by the institutional research office at Cal State East Bay, was collected in order to conduct a quantitative analysis. These data present a better understanding of who participates in the GANAS program, what services they take advantage of, and what their academic progress was during their time at East Bay. Additionally, to expand on the results of my second research question, three focus groups were conducted to incorporate qualitative data into my study. This approach was important to delve deeper into concepts reflected in the logic model, like 
community building and empowerment, which don't have quantitative measures. While some conclusions were gleaned from program records, the focus group data was able to bring the student voice into the narrative, enriching the results specifically for these measures. Qualitative data also helped to clarify relationships to student outcomes when multiple interventions are offered to students combined in one activity, such as with the program courses. Students experience cultural content and a cohorted learning community simultaneously. When trying to attribute a relationship between the course and the GANAS outcomes, it is not possible to determine statistically which intervention it is based upon. Through the focus groups, I was able to more clearly separate the effects of each intervention. It was clear that implementing a mixed methods research design utilizing data from student records, existing program data, and focus groups, was the best approach to triangulate the results of my evaluation.

Below, in Figure 1, is an articulation of the GANAS Program's logic model, which I will use to guide my research and evaluation. When conducting a program evaluation, it is important to conceptualize the programs inputs, activities, outputs, and outcomes. The first column represents the inputs of the program, or the resources that the program uses, which primarily encompasses all those that work within GANAS - the fulltime professional staff, university faculty, and student assistants. Inputs also include the space of the GANAS office itself and gathering areas for the students, as well as the materials provided to enhance the cultural relevancy of programming for students. The next column represents program activities, detailing the services the program offers 
including advising, coursework, peer mentoring, and other forms of academic support.

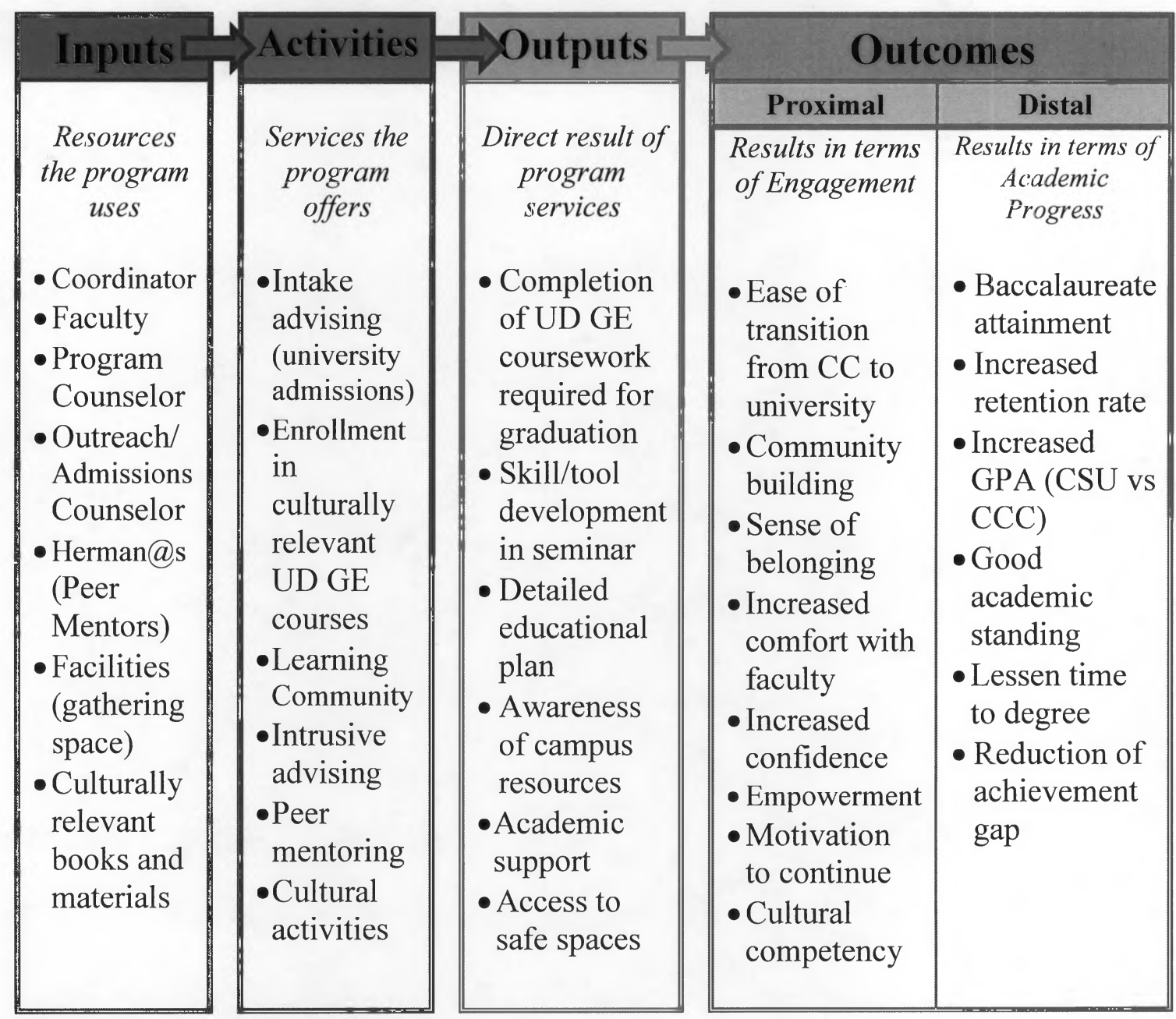

Figure 1.1. GANAS Logic Model

The next column presents the outputs of the program, which are the direct results of program services. The next two columns represent the outcomes of the program, detailing the proximal outcomes that result from engagement in the program and the distal outcomes that address the academic progress of GANAS participants. The arrows illustrate the pathway from input to outcome. There are a few direct one-to-one relationships illustrated here, for example, the enrollment of participants in three upper- 
division general education (UD GE) courses as an activity results in completion of the university UD GE requirement as an output. But for the vast majority of the more important distal outcomes, it is a many-to-one relationship. For example, many of these things work together to have an intended increase in outcomes such as sense of belonging and community building. While the learning community and coursework within the program were built to foster these particular outcomes, it is understood that there are confounding variables in which the program does not have direct control over, such as the non-GANAS courses that participants are enrolled in. This model, paired with the operational measures detailed in Chapter 3, Table 3.1, visually represent the elements that comprised my study.

Hypothesis. It is projected that the GANAS Program will have a positive impact on the academic progress of its participants. The hypothesis of this study suggests that there is a relationship between participation in the GANAS Program and student outcomes. The combination of intrusive advising, peer mentoring, and participation in an academic learning community - the key components of the program - will lead to higher graduation rates, grade point averages, and levels of engagement of participants compared to their counterparts.

Operational Definitions. The following definitions are for terms that will be used throughout the proposed study:

Latino. Reference to people who self-identify as a person of Latin American heritage, origin, or descent. Latino can be used to refer to males or females, whereas the 
term Latina is used to refer to females only. For the purposes of this study, the term Latino will be used to refer to the entire population, regardless of gender.

Transfer students. Students who move from one postsecondary institution to another, primarily originating from community colleges.

Post-transfer. Students who have successfully enrolled at a four-year university after transitioning from a previous postsecondary institution.

Learning community. An intentional linkage or cluster of two or more courses, often around an interdisciplinary theme or problem, which enrolls a common cohort of students.

Culturally relevant pedagogy. The ability to link principles of learning with deep understanding of, and appreciation for, culture. (Ladson-Billings, 2014)

Herman@. In Spanish, the word Hermano translates to brother, and Hermana to sister. In GANAS, the term Herman@ is used to encompass both genders and to refer to the peer mentors who are employed by the program to guide the new incoming students.

\section{Significance of Study}

The GANAS Program at Cal State East Bay is one of the few, if not the only, program within the CSU system that focuses on specifically serving Latino transfer students. Aiming to serve this population in a different way than the general transfer student population has been referred to as innovative by university leadership. With this expectation as well as preliminary successes in its first three years of implementation, a great deal of attention has been drawn to the GANAS program: from within the East Bay 
campus, the community, and even at the national level. Despite no formal evaluation of the GANAS Program, Cal State East Bay launched a sister program in Fall 2015, largely adopting the GANAS model, with the aim to focus on African American transfer students. In Fall 2017, an additional program was launched, also taking pieces of the GANAS model but this time with the intent to serve Asian American and Pacific Islander transfer students. There has been talk of expanding the program to other CSUs as well. While the prospect of replication could be a positive direction for the CSU to move towards in the future, it is concerning that it is a serious consideration at a time when the GANAS program has only been in existence for a little more than four years, has only had three graduating cohorts, and has never been formally assessed outside of looking at its preliminary retention and graduation rates.

A study on the effectiveness of the GANAS program is in order. A program evaluation, even at this early stage, would identify the variables impacting the outcomes of the program and ground its preliminary successes in research. My research and recommendations can inform decisions on how to improve the program at Cal State East Bay, as well as assist leadership in determining what elements could be scaled to serve and benefit all transfer students. A program evaluation can also inform other CSUs with plans for future replications and expansions. Finally, as the Program Coordinator for GANAS, I would also like my research to be a critical evaluation of my own work. 


\section{Chapter Two: Literature Review}

\section{Introduction}

GANAS was developed as a hybrid program that crosses academic instruction with student support services. There are three primary components that serve as the foundational pieces of the GANAS Program. These areas include: a) required coursework, b) intrusive advising, and c) peer mentoring. In conducting a program evaluation for the GANAS Program, it is important to explore each these areas in my review of literature. Additionally, given the focus of the GANAS Program is to serve Latino transfer students, it is also necessary to delve into the literature on the success of transfer students and Latinos in higher education as well. This last area is where the review of literature will begin by introducing the educational pipeline of Latino students pursuing higher education, as outlined by researchers Tara Yosso and Daniel Solorzano.

\section{Conceptual Framework}

Yosso and Solorzano's (2006) leaking pipeline figure, seen in orange in Figure 2, illustrates how the number of Latino students significantly decrease as they progress through their educational path. Out of 100 Latino Elementary school students, the authors indicate that only 8 of those original 100 will complete a baccalaureate degree. Thus producing an educational pipeline that "leaks" students along the way. Building on that concept, I have added an alternate path, shown in purple, which diagrams the GANAS Program intervention for the 17 estimated students who Yosso and Solorzano contend will attend community college out of the original 100 . 


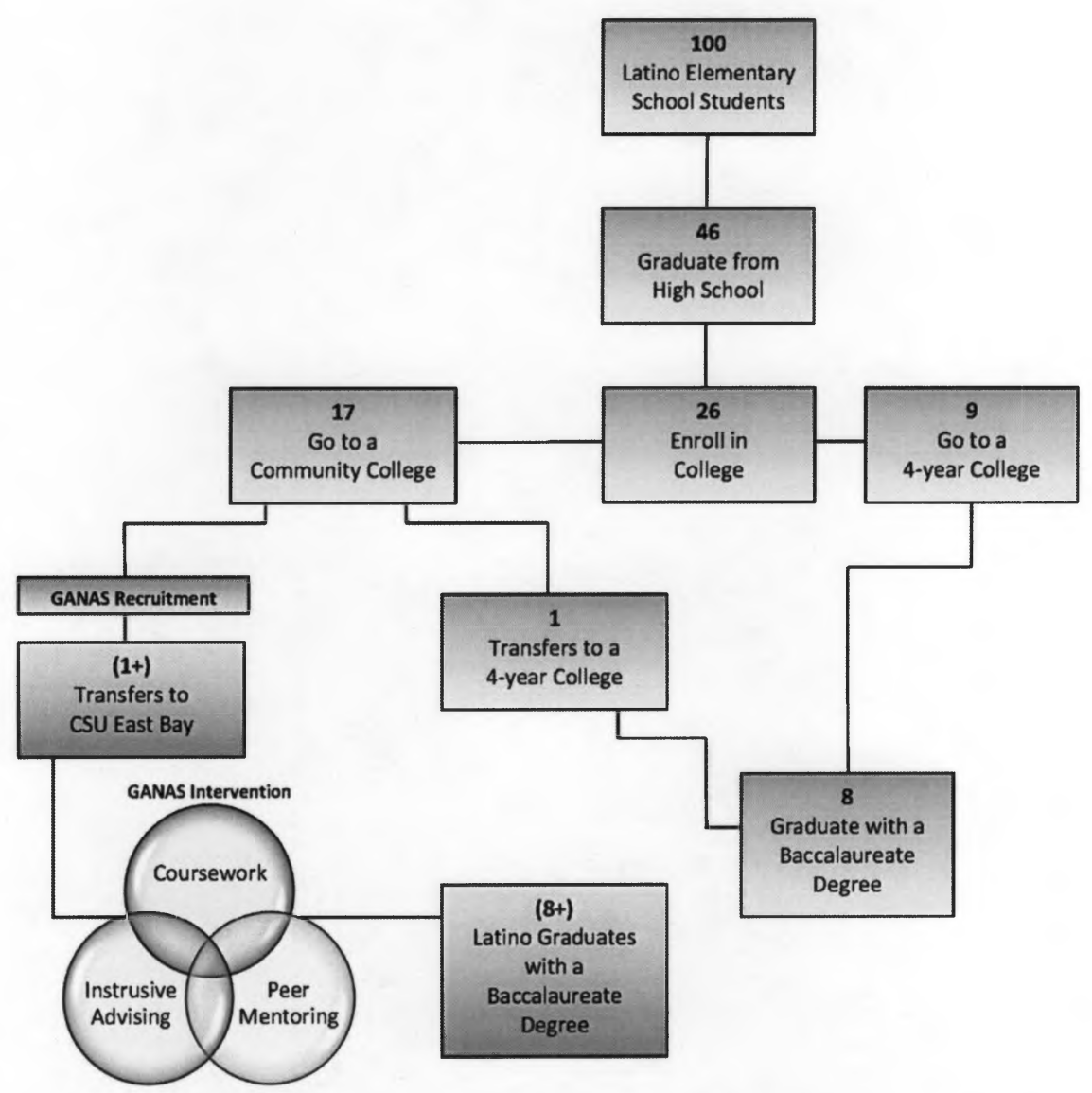

Figure 1.2. Conceptual Framework (adapted from Yosso \& Solorzano, 2006).

Whereas the original pipeline figure shows only one student transferring to a 4year college, when taking into account outreach and recruitment conducted by GANAS staff, the number of transfers to Cal State East Bay could potentially increase. Students that may not have transferred to a 4-year college, through engaging with the GANAS Outreach/Admissions Counselor, now have a liaison that connects them directly to the university through GANAS, helping to guide them in the university application process, advocating for them when roadblocks and challenges arise, and demystifying complicated processes such as enrollment and financial aid. Having this level of 
transitional support could help translate academic language used in communications, ease fears and anxiety in students, thus potentially increasing the number of transfers out of the community college system to 4 -year institutions.

\section{GANAS Program Selection and Participation}

Of those that transfer to Cal State East Bay, a certain number apply and are selected to participate in the GANAS Program. Students must complete a GANAS application to be considered for participation. The application collects basic demographic information on the student (Name, major, institution of origin, gender, self-identified ethnicity, \# of hours worked per week, etc.) and asks two short answer essay questions. The student must first describe a specific challenge that they overcame on their educational path, then tell the staff how they anticipate the GANAS program can help them be successful while at Cal State East Bay. The program also asks that the student provide one letter of recommendation. Each completed application is reviewed and scored based on the student's need for GANAS-specific services. Those determined with a high need for the GANAS intervention are sent an acceptance letter and invited to participate in the incoming cohort. Once selected, a student must confirm with the program staff their interest in participating. Once confirmed, even prior to matriculation, students are immediately referred to the GANAS Academic Counselor for an appointment. This initial meeting is to begin crafting the student's educational plan for their time at the university. Also as part of this first contact, students are reminded that they will be enrolled automatically in two courses each quarter which can fulfill upper- 
division general education requirements to graduate. This introduces the student to the first component of GANAS, intrusive advising, represented by the green circle in Figure 1.2. The second component, coursework, is introduced when the students are automatically enrolled in the courses and the term begins, represented by the blue circle in the framework. Participants will now be spending 6 hours a week together in the classroom for three full quarters, building their community and learning culturally relevant content as a cohort. The third and final component of GANAS, peer mentoring, represented by the yellow circle in Figure 1.2, is also introduced at the beginning of the first academic year when participants are paired with a GANAS Herman@.Herman@s translates to big brother or sister, and serves as the title for the GANAS peer mentors. These three components together - intrusive advising, coursework, and peer mentoring make up the core intervention for transfer students participating in the GANAS program; providing wrap-around support to participants with the aim to increase the baccalaureate attainment of Latino transfer students.

Considering those recruited by GANAS and selected to participate in the program to receive services, Yosso and Solorzano's calculation of only 8 students from the original 100 graduating with a baccalaureate degree can potentially be increased. For this reason, please note that the student numbers represented through the alternate GANAS pathway (purple boxes) have a plus sign and are with parenthesis to highlight the potential to increase the original number in the leaking pipeline. Inserting the alternate pathway that the GANAS program provides into Yosso and Solorzano's original leaking 
pipeline figure, as done in the Figure 1.2, illustrates how the program may propel students onto a different pathway and potentially move the mark in terms of the achievement gap that Latino students are experiencing.

The structure and support system of the GANAS Program is designed to help smooth the transition to the four-year university while attempting to mitigate some of the external challenges that Latino transfer students experience such as poor academic preparation, lack of family support, financial obstacles, competing obligations, time constraints, and the need to work a substantial number of hours. By reconstructing Yosso and Solozano's pipeline framework to include the intervention known as GANAS, I am showing how GANAS can interrupt this leaking pipeline in the students' lives and take them in a different direction. The reason this intervention pathway can be successful for this particular target population is because of how GANAS was designed, based upon the intersection of the following five literatures.

\section{Scope and Structure of Review}

To open the review of literature, I will explore the areas of transfer student success and the Latino experience in higher education. I will then continue with the research that has been conducted within the two areas related to GANAS coursework: cohort-model learning communities and culturally relevant pedagogy. These topics will be reviewed individually as two distinct strands within the third body of literature. The fourth body of literature focuses on intrusive advising and how it differs from traditional concepts of academic counseling. The last body of literature will explore peer mentoring 
and how it is folded into the experiences of university students. The review of these last three core components and their bodies of literature is necessary to lay the foundation for the current research study as they relate to the GANAS model.

\section{Latinos in Higher Education}

In framing the outcomes of the GANAS program, it was important to look at the population of students that was most in need of services. In researching the academic success, retention, and graduation rates of different populations of students, it was decided that Latinos would be the target population for the GANAS program. Data on overall post-secondary enrollment, and by type of institution, as well as overall baccalaureate attainment within the state were key in determining the need for specialized services and programming through the GANAS program.

Research conducted by Yosso and Solorzano (2006) states that Latinos suffer the lowest educational attainment of any major ethnic group in the United States. They claim there are serious and persistent leaks in the educational pipeline that need to be repaired. Using census data, the authors claim that from 100 Latino elementary students that begin together, there are 26 who enroll in college, 17 in community college. Of the 17, only 1 will transfer to a 4-year university. There is clearly a significant "leak" in that transition from the community colleges to four-year universities. Programs like GANAS can help to strengthen those pipelines by reaching out to the community colleges and making connections with programs and students to highlight the benefit of transferring. With program support at the 4-year level, students can be encouraged to apply to the university 
and know that when they transition there is someone to catch them on the other end. In their report, Yosso and Solorzano also make recommendations for policy change. One recommendation is to train multicultural educators to challenge cultural deficit thinking and to acknowledge the cultural wealth of Latino students. This was a core philosophy that GANAS founders kept in mind when selecting the courses and faculty to include as part of the learning community. It was important that participants had the space and opportunity to integrate their home identities with their school identities in the classroom. Through the support services side of the program, there is also an acknowledgement of what can be considered " $21^{\text {st }}$ century" skills that the students bring to the table. Skills like cross-cultural communication that come from living in multicultural homes, translating for immigrant parents, and sharing homes with extended family members; or adaptability, which can come from moving around frequently in their youth or being raised by relatives; innovation, which could come from growing up low-income and having to create toys or games from everyday items; and teamwork, from having a financial responsibility to contribute to the family income by working at a young age. These situations can be viewed as negative experiences, but have manifested in skills that can guide students in the $21^{\text {st }}$ century. These experiences are the cultural wealth that the authors believe these students bring to the classroom and what influence their work ethic as they navigate the university. 


\section{Transfer Student Success}

GANAS aims to serve Latino students who have transferred to the four-year university from a community college and increase the baccalaureate attainment of this population. Program services are provided from the point of application all the way through to graduation. While service begins at the point of transition, it is important for program staff to be aware of the challenges and predictive factors that came before transfer, and what place they hold in the educational pathway of the student.

Wang (2009) explored how precollege characteristics, experiences while matriculating at college, and environmental factors related to the probability of attaining a bachelor's degree for community college students. The author drew on the data from the National Education Longitudinal Study of 1988 (NELS: 88) and the Postsecondary Education Transcript Study (PETS) to measure degree attainment and persistence. The study found the following predictors for higher probability of attaining a bachelor's degree: Females, students with higher SES, high school students with an academic curriculum rather than vocational, students with an expectation to earn a degree since $12^{\text {th }}$ grade, those that were engaged in the campus community, and those that transferred with a high GPA from community college (Wang, 2009).

Similarly, Dennis, Calvillo, and Gonzalez (2008) conducted a quantitative study of 1,130 transfer students to look at the ways in which academic self-efficacy, college commitment, personal and career motivation for attending college, and support of peers, combined with age and first-quarter GPA created profiles of transfer students. The study 
examined these previously identified psychosocial variables that were deemed important predictors of student success and how they were related to the achievement and retention of transfer students. Dennis et al. found that personal characteristics, as well as GPA, are important to consider when determining the success of students who are diverse by many factors other than just ethnicity and gender. Findings also suggest that transfer students, especially those who are ethnic minorities, face other barriers such as poor academic preparation, lack of family support, problems with financial resources, and the need to work more hours (Dennis, Calvillo, \&Gonzalez, 2008).

With so many factors affecting students prior to transfer, it is important to note how Townsend and Wilson (2006) aimed to discover perceptions of current transfer students and factors that influenced a student's fit while attending the four-year institution. The authors interviewed 19 students who transferred to a large researchextensive university, inquired about the transfer process, efforts of the university to orient and assist them, and perceptions of the university versus the community college. Findings indicated that transfer students may need more assistance initially than they are given. Student fit within an institution was found to be a complex matter, influenced by the student's entering characteristics, the culture of the institution, the student's frequency and types of interactions within the institution, as well as the student's desired goals and outcomes of college attendance (Townsend \& Wilson, 2006). In constructing the GANAS program, it was important to ensure that support began during the admission process. 
Students typically apply to several campuses when deciding on their transfer destination, so it was important that Cal State East Bay stand out in regards to being accessible to applicants. GANAS staff become a liaison for students to various departments in addressing admissions issues that may arise. The program aims to engage applicants from the beginning of the process to assure the student that, should they choose to attend East Bay and participate in the GANAS program, they will have continued support and frequent interaction with university staff, faculty, and departments.

While there is clearly research available addressing transfer students, Wawrzynski and Sedlacek (2003) argued that despite this general research, there are still gaps. The authors aimed to fill a void in the transfer student literature by investigating the expectations, self-perceptions, past academic behaviors, and attitudes of students who transferred to a doctoral extensive university on the East Coast. Wawrzynski and Sedlacek (2003) conducted a Transfer Student Survey (TSS) during orientations with 2,492 incoming undergraduate transfer students. Participants represented $66 \%$ of the incoming transfer population that attended orientation. Results demonstrated statistically significant effects associated with both ethnic identity and gender among three categories: expectations, learning outcomes, and academic behaviors. In line with the authors assessment, the literature is limited in addressing the experiences of Latino transfer students specifically at the four-year level. Leaning in that direction, Wawrzynski and Sedlacek's study found that students of color generally expected to become part of their new university community by interacting with faculty and students outside of class. 
Involvement in various aspects of the institution related to becoming successful students, particularly for students of color. More interested with learning outcomes that would provide them with lifelong skills, students of color looked to develop effective written and oral communication skills, acquire technology skills, learn to think and reason, gain an appreciation of cultures different from theirs, and develop leadership skills. Sense of community was also a theme that emerged among students of color (Wawrzynski \& Sedlacek, 2003).

Also attempting to investigate the effect of sense of community on transfer students' engagement in academic activities and post-transfer GPA, Townley, Katz, Wandersman, Skiles, Schillaci, Timmerman, and Mousseau (2013) conducted a crosssectional study of fifty-three undergraduates. Sense of community (SOC), as defined by the authors, is the students' importance of identifying with the institution and feeling welcome. Townley et al. found that greater importance was placed on SOC at the posttransfer institution and suggested that students who reported a strong SOC performed better academically than those with a low SOC. It was concluded that students who feel more emotionally engaged with the campus environment perceive a greater sense of support from faculty and students and are more motivated to succeed academically (Townley, Katz, Wandersman, Skiles, Schillaci, Timmerman, \& Mousseau, 2013). Wawrzynski and Sedlacek's study is important because it was one of the first to begin to disaggregate the data of transfer students post-transfer by race and ethnicity; giving readers a clearer picture of the needs and gaps in the research when it comes to 
this complicated population. While Townsend and Wilson's findings support those of Dennis et al. in that a student's fit within an institution depends on the student's entering characteristics, the authors were also in line with Townley and colleagues who found that the nature of the institution and the student's interactions within the institution are also very important. The authors concluded that transfer students may need more assistance initially than they are given at the four-year level, partly because of the large size of universities, but more importantly so that they can understand how an institution's mission affects faculty and student behavior. Prioritizing students' emotional engagement would prove effective in an institution's attempts to make the transfer process smoother. Likewise, Wang's study has provided an opportunity for four-year institutions to begin to look at the ways that transfer students are served, helping to redefine and expand the missions of their universities.

\section{Academic Coursework}

Within the GANAS Program, students are placed in cohorts and enrolled in required courses as a learning community that moves together through their first year as transfer students at the university. Special sections of courses are created to ensure that only GANAS students are enrolled in a particular course. The courses within the GANAS learning community were intentionally chosen with these things in mind: a) courses would fulfill upper-division general education requirements needed to graduate from $\mathrm{Cal}$ State East Bay, b) content of the courses would apply culturally relevant themes and pedagogy within the curriculum, c) faculty would display authentic care for the GANAS 
participants enrolled in their course, and d) courses would provide tools and resources which are necessary for participants to make academic progress toward graduation.

\section{Learning community model.}

By placing GANAS students into a cohort of 35 students that will enroll and move together through the series of required courses, there is an opportunity for a community to develop and bonding to occur. Students get to know each other well over the period of the academic year and can develop supportive networks among one another. Through this learning community students can begin to integrate into the university, feel connected, and develop a sense of belonging.

While academic institutions cannot control the external stressors that impact transfer students, facilitating students' progress by identifying stressors that impede their academic success and providing tools to intervene where possible is critical. In one study, researchers Coston, Lord, and Monell (2013) aimed to prove that learning communities are designed to provide such tools. As defined by the authors, learning communities are initiatives developed to focus on a small group of students with similar interests. In their study, students were required to take a sequence of two learning community courses in order to assist with their integration into the university. Much like in the GANAS Program, blocks of seats were reserved to ensure that the students would be able to take these courses together, with structured study groups also required. The two sequenced learning community courses exposed students to support services, major-related agencies on and off campus, as well as to career opportunities. The first learning community 
course in the study introduced the students to speakers from university services, including financial aid, registration, and the specific program designed for nontraditional students. These speakers provided information and help to the students as they coped with finding and using different resources. This design bears close resemblance to the Transfer Success Seminar that GANAS students are required to take where resource awareness and career development are key areas of instruction. As a result of participating, students in the study conducted by Coston and colleagues reported a feeling of belonging to their learning community cohort and the university community. The students solved problems, studied together, shared texts, and called each other for support in many areas of their lives (Coston, Lord, \& Monell, 2013).

In an examination of several examples of learning communities designed for underserved populations, authors Fink and Hummel (2015) concluded that the key to success is utilizing theory and research concerning specific target populations in order to address specific issues and barriers. In the development of the GANAS Program, research on the academic success of Latino students in particular was conducted in order to best understand the needs of this population and what specific issues would need to be addressed, as the authors suggest. Fink and Hummel also recommend utilizing core practices of inclusive learning communities. They assert that creating a significant bond among members of the community and to the institution as a whole provides a supportive environment in which to grow, develop, and succeed. They go on to say that boosting positive messages of achievement and success are also important in helping students 
achieve academically and graduate. Finally, the authors emphasize that a focus not only on individual concerns, but also on how the institutional systems can be shifted, is essential so that all students can improve. Through these principles, learning communities can create opportunities for underserved students to participate fully in their educational environment, thereby making excellence inclusive (Fink \& Hummel, 2015).

In their examination of existing learning communities, Fink and Hummel highlight the Transfer2Terp (T2T) Learning Community at the University of Maryland. This particular learning community is designed to alleviate challenges that transfer students encountered transitioning from community college to a large research university. Much like Costen et al. noted, and as is offered in GANAS, the T2T program engages students in a seminar course aimed at equipping students for academic success, while also leveraging the resources of the university, such as the student union and campus life center, to connect students to enriching co-curricular involvement opportunities. The authors argue that learning communities designed for underserved student populations are especially important in fostering a sense of belonging among participants as they often are supplementing some degree of unmet needs for their specific student population (Fink \& Hummel, 2015).

Researchers Firmin, Warner, Firmin, Johnson, and Firebaugh (2013) conducted 24 in-depth interviews with students who participated in a first year learning community at a private, selective Midwestern university. Participants included students of all racial backgrounds and it was the consensus of the interviewees that simply the busyness of 
their schedules limited the time that they felt able to commit to learning community involvement, further explaining that simultaneous extracurricular activities often competed for their time. Firmin et al. found that despite this, most of the students involved in the learning community described their overall experiences as generally positive. Researchers interestingly noted that non-minority students who participated in the learning community reportedly experienced shifts in personal biases and stereotypes, and reported this aspect of the learning community to have significantly impacted their personal viewpoints relating to issues such as diversity. As a whole however, suggestions were shared for improving the learning community, including the importance of faculty interaction. They felt that this was a key component to the learning community's success. Looking back on their experiences as learning community members, most respondents, regardless of ethnicity, reflected on their personal involvement with overall satisfaction (Firmin et al., 2013).

Keeping faculty in mind, Chavez (2007) conducted a semester-long qualitative study of classroom environments facilitated by four college professors. The findings from this study suggest that these four professors, in partnership with students, created multiculturally empowering learning communities that offered a place where individuals worked together to build knowledge and question conventional norms. Chavez suggested six elemental dynamics that are critical to empowering or liberating individual learning communities in higher education: (a) climate of safety, (b) spirit of risk taking, (c) congruence, (d) proactivity, (e) multiplicity, and (f) reciprocity. The author stated that, to 
varying degrees, these elements were present in the learning communities studied. Teachers worked with all students to create collective, empowering learning experiences that utilized and honored multicultural realities within a shared and rigorous academic experience (Chavez, 2007).

In general, these studies seem to agree that learning communities result in positive experiences for students as a whole. Providing an environment of support, resources, empowerment, and sense of belonging are some of the common themes reported by students throughout the studies. These are also themes that are embedded in the design of the GANAS Program.

\section{Culturally relevant pedagogy.}

GANAS coursework supports and strengthens the academic and cultural experience of students by utilizing Latino and multicultural content in courses and providing culturally responsive support services that promote student success and retention. This design enables students to integrate their home identities by creating a sense of familia (family) within the cohort. Faculty tailor the courses to reflect common cultural experiences which creates a dynamic that builds trust, allowing participants to express themselves and relate to one another. Courses like Decolonize Your Diet: Food Justice in Communities of Color allow students to explore the native food ways of their ancestors and bring them into the present. Coursework encourages students to engage with their families to learn treasured recipes and research ingredients native to the land 
they come from. Food is a common element in all cultures, and courses like this offered through GANAS aim to bridge students to one another through common experience.

Gloria Ladson-Billings (2014) argues that by focusing on student learning and academic achievement versus classroom and behavior management, and cultural competence versus cultural assimilation; students will take both a responsibility for, and a deep interest in, their education. She affirms that this is the secret behind culturally relevant pedagogy; the ability to link principles of learning with deep understanding of and appreciation for, culture. The place, she says, where the concept of pedagogy "shifts, changes, adapts, recycles, and recreates" the classroom, shifting marginalized students into a place where they become subjects in the instructional process, not mere objects (Ladson-Billings, 2014). This places students and their lived experiences at the center of the learning, not the periphery.

Through one study, Ladson-Billings (1995) came to focus on eight teachers who she found to be thoughtful, inspiring, demanding, and critical. The teachers were connected to the students, their families, their communities, and their daily lives. She identified three major areas of their work: academic success, which she defined as the intellectual growth that students experience as a result of classroom instruction and learning experiences; cultural competence, defined as the ability to help students appreciate and celebrate their cultures of origin while gaining knowledge of and fluency in at least one other culture; and sociopolitical consciousness, seen as the ability to take learning beyond the confines of the classroom using school knowledge and skills to 
identify, analyze, and solve real-world problems (Ladson-Billings, 1995). She went on to assert that today, researchers and practitioners are moving and evolving in new ways that require educators to embrace a more dynamic view of culture. Such a shift does not suggest that the original view was lacking, but rather speaks to the changing and evolving needs of dynamic systems. GANAS has taken a step in the direction of this shift by incorporating coursework that explores the three areas mentioned by Ladson-Billings. Ladson-Billings argued that "remixing" is vital to innovation in art, science, and pedagogy, and how it is crucial that we be willing to remix what we have created and/or inherited (Ladson-Billings, 2014). While the areas in GANAS of culturally relevant coursework, advising, and mentoring are not new concepts, remixing these services to best support a particular group like Latino transfer students, and serve them well, is necessary as we move forward in educating this ever-growing population.

Even instructors who accept Ladson-Billings' concept of remixing may wrestle with the antiquated notion that only some students should succeed and the more contemporary understanding that, given the right coaching and environment, any student can succeed. Considine, Mihalick, Mogi-Hein, Penick-Parks, and Van Aucken (2014) argue that an increased student success relationship does not necessarily mean standards have been lowered, but could also mean that new strategies raised students up to the level of previous standards. Again, looking at what has been done and shifting it to serve a more contemporary student's needs, so that they can achieve academic success. 
An example of such a strategy was looked at as part of a 2-year ethnographic study of the Havertown Latino community. Researchers Wortham and Contreras (2002), along with two research assistants, observed an ESL room daily over 2 months and interviewed teachers and students as part of the study. Through use of this room, the ESL teacher managed to establish a quasi-familial support group among most of the Latino students at the high school. It was noted that the teacher went beyond curriculum materials that draw on Latino cultures, and beyond the use of Spanish, to incorporate a culturally familiar way of organizing time, space, and student participation. This teacher and the Anglo school staff interpreted her ESL room differently, however. While the teacher saw what she provided as culturally relevant pedagogy, most Anglos teachers saw it as chaotic and unprofessional. By her third year when the ethnographic observations were conducted, most Latino students were interested in each other's lives and were willing to support each other academically and personally (Wortham \& Contreras, 2002). Something that has become an integral piece of the GANAS program is the ability to gather in a common space. Giving the students the freedom to occupy the space within the GANAS office and gather in the surrounding area throughout the day has welcomed conversation, collaboration, and support for one another.

As was clear to the ESL teacher in Havertown, diverse students live complex lives and the many complex issues that affect them cannot be separated from teaching and learning. It is important to allow students to bring the different aspects of their lives into their educational experience. Researchers Ford, Howard, Harris, and Tyson (2000) agree 
and found that culturally responsive teachers often extend themselves beyond their typical, traditional role. Ford et al. argued that the more educators listen to students, especially those who have traditionally been silenced, the more likely they are to recognize the need to create culturally responsive classrooms. The authors' research suggests that putting the opinions of students and resulting implications like these into the hands and minds of educators promotes improved school settings for all students. Applying this shift allows students to thrive in classrooms that are responsive to their academic, cognitive, affective, and cultural needs (Ford, Howard, Harris, \& Tyson, 2000).

Culturally responsive pedagogy essentially places the student, their needs, and their lived experiences at the center of instruction. When an educator constructs their classroom with understanding and appreciation for diverse cultures, utilizing innovative and dynamic strategies of learning, and allowing for home and school identities to interact, an environment where all students can succeed is created. This is the basis for how the GANAS courses were constructed, and how the program aims to operate in its service to students.

\section{Intrusive Advising}

Advising in the GANAS Program is intrusive in that, along with the other wraparound services that the program provides, participants are required to meet with their advisor minimally twice per term, with non-academic factors being taken into consideration when crafting their educational plan. Multiple advising appointments in a 
term allows for the advisor to get to know the participant better and to serve them in a holistic manner. Typical oversight of a student includes academic advising, mid-term progress reports, monitoring GPA and the fulfillment of graduation requirements, as well as basic check-ins to perceive health and well-being. Establishing a rapport through these encounters serves to address a myriad of concerns in the students' lives and apply appropriate interventions as necessary.

This approach of being intrusive, according to Glennen (1976), is contradictory to customary professional counseling. Traditional advising maintains that a counselee should seek counseling on his or her own initiative and that a counselor should not actively recruit clients. In his article, Glennen discusses the establishment of the University College at University of Nevada, Las Vegas. This college served all entering freshmen and transfer students. Once the semester began, the students were called in for intrusive counseling. Counselors began establishing rapport and covering academic regulations, grading systems, probation, attendance regulations, and the curricular options available. Midterm grade reports were turned in to counselors by the faculty and any students receiving low grades were asked to see their counselors. However, the counseling program did not just concentrate on those students who were on academic probation or receiving low grades. Every student was seen at least once each semester. Glennen went on to highlight that through this college, the freshman attrition rate was considerably reduced (from $45 \%$ to $6 \%$ in the first 2 years) and simultaneously, a $9 \%$ increase in the number of students making the dean's list. The author continued in noting 
an increase in academic performance, fewer students on academic probation, fewer students suspended for poor academic performance, and fewer withdrawals from school during this same period. Perhaps the most noteworthy result of the intrusive counseling program was the reduction in the number of freshmen needing assistance from the psychological clinic. Many problems were handled intrusively before they became crisis situations. As a result of these findings, Glennen concluded that colleges and universities must not be passive and wait for students to come for advice and counseling. They must practice intrusive counseling by setting consistent meetings and reaching out to students in need of intervention (Glennen, 1976).

Costen, Lord, and Monell (2013) agree with Glennen that students who are struggling with courses should receive additional counseling and direction to available resources. Equally as important for all students is that a counselor be accessible as well as accurate in their academic advising. Costen et al. continued by referring to counselors as critical liaisons between transfer students and resources. Having an extensive understanding of how to serve the various needs of college students and the ability to refer them to the appropriate resources is vital in addressing the complex issues faced by students today (Costen, Lord, \& Monell, 2013). It is the aim of the GANAS Program that through intrusive advising, issues that arise can be identified early on and addressed prior to becoming a barrier in the academic progress of the student. 


\section{Peer Mentoring}

The component of mentoring was introduced during the second year of the GANAS Program. It was decided that peer mentors, rather than professional mentors, would be introduced so that participants would have support from someone that they can relate to on a more immediate level. GANAS peer mentors, called Herman@s, or big brothers and sisters, are hired to provide an extra layer of support for new incoming participants, and a connection to the experience that only they can provide. Herman@s are chosen from students that have already completed their first year with the GANAS Program, and have successfully transitioned into their second or third year of study at Cal State East Bay. Herman@s are assigned a small caseload of students and meet with them on a bi-weekly basis. In receiving mentoring from Herman@s, GANAS aims for students to increase engagement with peers, faculty and administration; improve communication and networking skills; learn to utilize various student resources on campus; and increase connections with students by getting involved with student organizations and other communities on campus that will support their persistence and help them become a Cal State East Bay graduate.

While professional mentoring is utilized by many programs such as Puente, studies of mentoring suggest that some students prefer mentors closer to them in age (Gándara, Larsen, Mehan, \& Rumberger, 1998). Students who participate in programs like these tend to return upon completion to fulfill different roles, such as mentors. In fact, the notion of giving back to your community is often woven into the philosophy of 
the program itself and passed down as a mantra through participation. Students are reminded of the importance of returning to their community as leaders and mentors for future generations. They intend to give back some of what they received as students (Laden, 1999). Opening the Herman@ position to GANAS students affords them the opportunity to pay forward a positive experience they had with their own mentor, and to give back to the new incoming generation of GANAS participants.

Researchers Good, Halpin, and Halpin (2000) contend that peer mentoring appears to be a viable approach to providing role models and leadership for underrepresented groups within higher education. As noted by Laden (1999) prior participants tend to return in these roles. As such, peer mentoring has been adopted in university settings as a means to assist students as they transition into the university environment. In a study of African American students who were targeted as at risk of possibly leaving an engineering program in the Southeast, and potentially the university, Good et al. found that programs which incorporate upper-division minority students to be involved in peer support and counseling show positive retention results (Good, Halpin, and Halpin, 2000).

Research conducted by Doolen and Biddlecombe (2014) looked at students' interactions with their peers and concluded that both the frequency and the quality of student exchanges with peers is positively associated with student social and academic support. Like Good et al., their study found that development of strong peer relationships is significant in student success and persistence. (Doolen \& Biddlecombe, 2014). 
Crafting the Herman@ position as that of a peer who is just one or two steps ahead of the participant, closer to graduation but still very entrenched in what it means to be a student, has enabled the GANAS Program to introduce a role model to new participants that not only serves as an example of a successful student, but one that is relatable - with similar background, culture, experiences, and interests. In hiring GANAS students to be Herman@s, participants can closely observe and interact with an upper-classman on a regular basis, just like them, that is successfully balancing school, work, and home responsibilities while navigating the complicated path toward baccalaureate attainment. It is the aim of the program that students envision themselves and their success in their experiences with their Herman@, knowing that they too can reach that level.

\section{Conclusions and Implications}

In summary, the literature indicates that the three core components of the GANAS Program - coursework (specifically culturally relevant coursework structured as a learning community), intrusive advising, and peer mentoring - can have positive impacts on university students. The logic model also aligns with this theory of positive impact and easily defines those pathways. Additionally, many of the predictive factors and indicators highlighted in the literature on transfer student success seem to have been taken into consideration in the development of the GANAS Program and its design. Meanwhile the literature on Latinos in higher education helped to highlight where there are gaps and how program services like those provided by GANAS could help fill those areas. 
Assuming GANAS was intentionally designed to follow the most successful strategies described in the literature in executing its core components - using a learning community model to deliver culturally relevant coursework, intrusive advising, and peer mentoring - there is one clear implication for my research: a program evaluation on GANAS and the impact it has on its participants. Results of this study can inform decisions on how to improve the program at Cal State East Bay, as well as assist leadership in determining what elements could be scaled to serve and benefit all transfer students. 


\section{Chapter Three: Methodology}

\section{Introduction}

The purpose of this study is to determine if and how services provided by the GANAS Program impact the academic progress of its participants. In particular, this study aims to assess the impact of services on its Latino participants' time to degree and grade point average, as well as highlight the student experience while a participant in the program. A mixed methods design to employ a formative program evaluation was used to examine the following research questions:

1. Does participation in the GANAS Program at Cal State East Bay impact the academic progress of its transfer students?

2. How do the services and activities that the program provides result in satisfactory academic progress?

To answer these questions, secondary data gathered from GANAS program records, as well as academic and demographic student data provided by the institutional research office at Cal State East Bay, was collected in order to conduct a quantitative analysis. These data present a better understanding of who participates in the GANAS program, what services they take advantage of, and what their academic progress was during their time at East Bay. Additionally, to expand on the results of my second research question, three focus groups were conducted to incorporate qualitative data into my study. This approach was important to delve deeper into concepts reflected in the logic model, like 
community building and empowerment, which don't have quantitative measures. Qualitative data also helped to clarify relationships to student outcomes when multiple interventions are offered to students combined in one activity, such as with the program courses. Students experience cultural content and a cohorted learning community simultaneously. When trying to attribute a relationship between the course and the GANAS outcomes, it is not possible to determine statistically which intervention it is based upon. Through the focus groups, I was able to more clearly separate the effects of each intervention.

This chapter will detail the study methods and explain the data analysis used to answer the aforementioned research questions. It will begin with a discussion of the role of the researcher, followed by the research design. Next, it reviews the setting, sample, and ethical considerations. It will then detail data collection and analysis. Finally, the chapter will conclude with the methodological limitations.

\section{Context and Role of the Researcher}

As the primary researcher, I have chosen this study for both personal and professional reasons. Professionally, I am currently the Coordinator of the GANAS Program at Cal State East Bay, the focus of this program evaluation. Due to my role, I have full access to student data, program records, as well as the student participants. Additionally, I have access to the GANAS staff who work with the students in different capacities and at specific time periods within the application, enrollment, and attendance processes. Being an insider, the data collection process was expected to run fairly 
smoothly. The GANAS Program utilizes online software to track students' academics and participation, it keeps hard copies of application files, as well as responses to completed year-end surveys. All professional staff have secure access to these items so collection was not a problem. I have also developed a strong working relationship with the Associate Provost and Office of Institutional Research, Analysis, and Decision Support (IRADS) on campus which, after IRB approval, granted me access to secondary student data. Additionally, as the program coordinator, it was my charge to make sure that the evaluation was conducted as objectively and with as much integrity as possible. While completely removing bias from the project was impossible, my intent was always to be very critical in my evaluation and analysis of data. It was my intent from the beginning to look to the data to provide critical feedback on my specific role as the coordinator and leader of this program, and to guide my steps as I continue to hold responsibility for executing the vision of the GANAS program.

Personally, I was a community college transfer student and am of Latino decent. The primary mission and vision of the GANAS Program is to serve students with my background and to help propel them to baccalaureate attainment. It is critical that the program serve students' needs effectively, and it is important to my me that I am empowering and elevating my community to the best of my ability with the resources available to me. By taking a critical eye to the program through this evaluation and making decisions moving forward using the results as a guide, I believe I am doing that. 


\section{Research Design}

A mixed methods design employing a formative program evaluation was used to accomplish the study's purpose and answer the research questions. Specifically, a Convergent Parallel approach was taken, designed to synthesize complementary quantitative and qualitative results to develop a more complete understanding of the intervention. The two types of data collection are concurrent but separate, having equal importance in addressing the research questions (Creswell \& Plano Clark, 2011). My data was drawn from three sources:

1. Secondary data provided by the institutional research office at Cal State East Bay which included academic and demographic data on 10,518 transfer students;

2. GANAS Program records from 213 participants including student application files, documentation of participation, and responses from year-end surveys; and

3. Primary data compiled from three separate focus groups totaling 22 participants: two focus groups with current GANAS participants and one with GANAS alumni. The first and second sources of data present a better understanding of who participates in the GANAS program, what services they take advantage of, and what their academic progress was during their time at East Bay. The three focus groups were conducted to discuss the students' experiences with the structured components of the program, but more importantly to delve deeper into those concepts reflected in the logic model. While some conclusions were gleaned from program records, the focus group data was able to bring the student voice into the narrative, enriching the results specifically for these 
measures. Qualitative data also helped to clarify relationships to student outcomes when multiple interventions are offered to students combined in one activity, such as with the program courses. Students experience cultural content and a cohorted learning community simultaneously. When trying to attribute a relationship between the course and the GANAS outcomes, it is not possible to determine statistically which intervention it is based upon. Through the focus groups, I was able to more clearly separate the effects of each intervention. It was clear that implementing a mixed methods research design utilizing data from student records, existing program data, and focus groups, was the best approach to triangulate the results of my evaluation. This also further explains the use of the Convergent Parallel Design and the equal importance of both quantitative and qualitative data collection and analysis for my particular study.

\section{Setting and Sample}

Research took place on the campus of Cal State East Bay and within the GANAS Office. While the campus has taken greater strides to address the specific needs of transfer students over the last few years, particularly by identifying an Executive Director of Transfer Programs in November 2015 and setting ambitious goals in terms of retention and graduation rates, the GANAS Program was one of the earliest initiatives implemented to serve transfers specifically. As the flagship program of its design at Cal State East Bay and the only program to address the educational attainment of Latino transfer students, it is an ideal program to conduct a formative program evaluation to determine how it impacts the academic progress of this population. 
The GANAS Program is currently in its fifth year of implementation and considered a young program, serving 213 students in its initial four years; therefore, my sampling frame will be the entire population of GANAS participants and alumni. All participants of the program are transfer students who were admitted to Cal State East Bay and participated in GANAS between the Fall term of 2013 and the Spring term of 2017. This served as my treatment group $(\mathrm{n}=213)$, which includes 121 current GANAS participants, and 92 graduates. I used a cluster sampling method to create two comparison groups to measure against the study population of GANAS participants: 1) transfer students who applied to GANAS and were accepted, but chose to opt out of participation in the program; and 2) all other students who transferred to Cal State East Bay from a community college in one of the seven terms (F13, W14, F14, F15, W16, F16, W17) in which students entered the GANAS program between Fall 2013 and Winter 2017. Participants were never accepted into the program in Spring or Summer terms.

The first comparison group $(\mathrm{n}=88)$ is the most comparable to GANAS participants because these are students who the GANAS staff, after reviewing their application, felt would benefit from program services, were accepted to participate, but for various reasons chose not to participate in the program. The most popular of those reasons being the scheduling of major courses, which conflicted with the days and times that GANAS courses were offered. Majors such as Nursing and Speech Pathology, which have very structured road maps for coursework or require sequential courses, often did not allow the flexibility for learning community courses like those offered in GANAS. 
Likewise, other majors such as Liberal Studies, provide completion of upper-division GE courses through their major, leaving GANAS coursework to be repetitive and unnecessary for students within those majors. This presents a bias against students in these particular majors to be able to participate in the GANAS program. While students ultimately make the choice to participate or not, it is always the recommendation of the program to take the most effective pathway to graduation.

The second comparison group of other transfers within that time period $(\mathrm{n}=$ $10,217)$ represents the standard achievement of the university and was constructed in collaboration with the office of institutional research at Cal State East Bay. Because this group omits students who matriculated during terms that GANAS did not admit students (Spring and Summer transfers), the group cannot be referred to as "all other transfers." Therefore, I have labeled this group the non-eligible, non-applicant group, but will at times in this dissertation refer to this group as the "larger sample transfer population." Non-eligible refers to any students in this group who may have applied to GANAS but were not accepted by the program to participate. Multiple staff members review each incoming application and can decide that a student is not a good fit for the program. Examples of this could include students coming from a challenging major with little to no flexibility in their course schedule to enroll in GANAS courses, or students who work an abundance of hours preventing the ability to engage in the mandatory components of the program, or simply that the student did not demonstrate need for the services that the program provides. Applicants may be deemed ineligible in some of these cases. The label 
of non-applicant simply refers to the remaining students in the sample who never applied to participate in the GANAS Program. Analysis from both of these comparison groups (GANAS Opt-out and Non-Eligible/Non-Applicant) helped serve in answering my primary and secondary research questions.

It was projected that the GANAS Program will have a positive impact on the academic progress of its participants. The hypothesis of this study suggested that there is a relationship between participation in the GANAS Program and positive student outcomes. The combination of intrusive advising, peer mentoring, and participation in an academic learning community - the key components of the GANAS program - has been said to lead to higher graduation rates, grade point averages, and levels of engagement of participants compared to their counterparts.

It is my plan to use this evaluation as a foundation for continued assessment of the program for years to come. Additionally, while GANAS is currently only implemented at the Cal State East Bay campus, it is conceivable that it could be replicated at other CSU campuses. This evaluation can serve as a resource and model for future implementations.

\section{Ethical Considerations}

This study adhered to all Institutional Review Board (IRB) standards for protection of participants' rights. The San Francisco State University IRB approved this research under an Expedited Review on August 2, 2017. However, there were still ethical considerations to be made, especially given that as the primary researcher, I am the current coordinator of the program being evaluated. 
First, there was a risk of loss of privacy for GANAS participants. As is required by the CSU, I am trained in the Family Right to Privacy Act (FERPA), and have been adhering to this law for over sixteen years. FERPA is a federal law that protects the privacy of student education records (Family Educational Rights and Privacy Act, 1974). As a university employee, I am accustomed to appropriately handling private information with the use of passwords and removal of identifying information from documents where such information is not necessary or not in compliance with FERPA. Therefore, all research data collected as part of the study was stored on a device with full disk encryption and password protection. Individuals focus group excerpts used in narrative of this document have been protected through the use of pseudonyms. Focus group participants were asked to keep everything discussed in the room confidential and reminded to not disclose anything outside. Although the risk of loss of privacy has been mitigated by these steps, the risk could not be eliminated completely.

Second, there was a risk of undue influence or power imbalance because I as the researcher am also the coordinator of the GANAS program. In order to avoid coercion of students to participate, all recruitment communication was sent electronically and as an invitation to participate. Since I interact with the students frequently as the coordinator, the risk of undue influence could compel the participants to respond to questions with what they think I would like to hear, rather than being completely honest about the impact of the GANAS Program. Again, with an aim to be critical of the program that I lead, it was essential to separate any prior knowledge of participants in order to remain as 
objective as possible in my analysis. With that in mind, as part of the opening remarks of the focus group interview, students were encouraged to be honest and critical in their responses, and it was emphasized that there would be absolutely no consequences for seemingly negative feedback or responses. Participants were also reminded that they only need to respond to questions they felt comfortable answering, and that they were allowed to exit the focus group at any time, no questions asked. Focus groups were the only inperson direct contact that I had with students in the data collection process of this study. This method of data collection was selected purposely so that the power, created by the number of participants versus the researcher, falls with the participants and that I would therefore have little to no influence on participant responses. Additionally, participants were given my phone number and email address, as well as that of the dissertation chair, and the IRB Protocol office.

Lastly, there was a risk of bias. It is impossible to completely remove my connection to the program for the purposes of this study. I have a clear stake in the success of the GANAS Program. However, all aspects of the research clearly state that I am the coordinator of GANAS program and the assumption is that this fact will encourage readers to look more critically at the results. With this anticipated additional critique, I was adamant in detailed documentation of the process, as well as in being transparent with the dissertation committee, the research site, and other key stakeholders throughout the process. In addition to the efforts outlined above and my commitment to conduct and produce an ethical evaluation, guidance from the dissertation chair and the 
peer review process of the dissertation committee minimized potential bias from occurring.

\section{Data Collection}

In order to answer the two aforementioned research questions, institutional student data, program records, and focus group interview data were collected. The collection of data from these three resources allowed me to best describe who participates in the GANAS program, what services they take advantage of, and what their academic progress was during their time at East Bay; then to delve deeper into concepts that do not have quantitative measures, like community building and empowerment.

Institutional student data. To best construct and conduct analysis on the students my comparison groups, I submitted a data request to the Office of Institutional Research, Analysis, and Decision Support (IRADS) at Cal State East Bay. To establish the most comparable groups to the GANAS participants, the request asked that only students who matriculated to Cal State East Bay as a transfer during the seven terms in which GANAS admitted students be included. These seven terms were: Fall 2013, Winter 2014, Fall 2014, Fall 2015, Winter 2016, Fall 2016, Winter 2017. GANAS aims to admit a full cohort of students during the Fall term each year, however due to attrition, most years the program opened admissions for the Winter quarter to meet the cohort cap. This also allowed for more students to experience the learning community and to take advantage of program services for the remaining two quarters of the year, equating to the majority of their first academic year. Spring quarter transfers were never admitted to the 
GANAS Program due to the limited interaction and level of intervention that could occur in one 10-week term.

Per my request, the IRADS office compiled a comprehensive dataset supplied with student-level institutional data (demographic, pre-transfer, admissions, enrollment, and graduation), along with student services data extracts from Financial Aid (Pell eligibility) and GANAS (participation).

The dataset included dependent outcome variables (graduation status, time to degree, and East Bay GPA), the independent environmental variable (affiliation with one of three comparison groups), and the independent input variables (demographic backgrounds and pretransfer characteristics). Table 3.1 below provides coding details and descriptions for each of these variables.

Dependent Variables. The dichotomous outcome variable GRADSTAT is defined as graduation within four years before or during summer 2017, for transfer students who matriculated during the seven terms in which GANAS admitted students.

The values of the ordinal outcome variable TMTDEG, or time to degree, is determined by calculating the length of time in years between the term that the student was admitted to Cal State East Bay and the term that their degree was awarded. A second related outcome variable, TMTDEGCL, representing a collapsed version of TMTDEG was created to avoid statistical error when the minimum expected count was not met.

The continuous outcome variable EBGPA represents the calculated grade point average of all courses that the student has taken at Cal State East Bay post-transfer. 
Independent Variables. The nominal independent environmental variable COMPGRPS, was used to identify which of the three comparison groups each student in the IRADS dataset was affiliated with. The three comparison groups are: 1) GNSPTP, representing students who participated in the GANAS Program; 2) GNSACC, representing students who applied to participate in the GANAS Program and were accepted but then chose to opt-out of participation; and 3) NONELGAPP, representing the students in the dataset who either were not eligible or did not apply to participate in GANAS.

The nine independent input variables, both demographic background and pretransfer characteristics, used in this study include ethnic category, Latino heritage, gender, age, citizenship status, Pell eligibility, first generation status, East Bay region, and transfer GPA.

All variables in this study align with the program outputs and outcomes detailed in the logic model, introduced in Chapter 1, Figure 1.1.

All categorical variables were recoded into dummy variables before the dataset was uploaded for analysis. Likewise, continuous variables such as age and transfer GPA were used to build nominal dummy variables to be used for comparison when presenting descriptive statistics in Chapter 4. 
Table 3.1

Coding and Description of Operational Measures, Level, and Value from IRADS Dataset

\begin{tabular}{|c|c|c|c|}
\hline Variable & Operational Measures & Level & Value \\
\hline \multicolumn{4}{|c|}{ DEPENDENT VARIABLES: } \\
\hline GRADSTAT & $\begin{array}{l}2 \text { category dummy variable } \\
\text { representing graduation status. }\end{array}$ & Dichotomous & $\begin{array}{l}0=\text { Not completed } \\
1=\text { Graduate }\end{array}$ \\
\hline TMTDEG & $\begin{array}{l}5 \text { category dummy variable } \\
\text { representing time to degree for } \\
\text { those that have graduated. }\end{array}$ & Ordinal & $\begin{array}{l}0=\text { Not completed } \\
1=1 \text { year } \\
2=2 \text { years } \\
3=3 \text { years } \\
4=4 \text { years }\end{array}$ \\
\hline TMTDEGCL & $\begin{array}{l}3 \text { category dummy variable } \\
\text { representing a collapsed version } \\
\text { of time to degree used in analysis } \\
\text { to avoid statistical error due to } \\
\text { small sample. }\end{array}$ & Nominal & $\begin{aligned} 0= & \text { Not completed } \\
1= & \text { Graduate during } \\
& 1^{\text {st }} / 2^{\text {nd }} \text { year after } \\
& \text { transfer } \\
2= & \text { Graduate during } \\
& 3^{\text {rd }} / 4^{\text {th }} \text { year after } \\
& \text { transfer }\end{aligned}$ \\
\hline EBGPA & $\begin{array}{l}\text { Continuous variable representing } \\
\text { grade point average of East Bay } \\
\text { courses taken. }\end{array}$ & Continuous & \\
\hline \multicolumn{4}{|c|}{ INDEPENDENT VARIABLES } \\
\hline $\begin{array}{r}\text { Environmental: } \\
\text { COMGGRPS }\end{array}$ & $\begin{array}{l}3 \text { Category dummy variable } \\
\text { representing the three comparison } \\
\text { groups within the study }\end{array}$ & Nominal & $\begin{aligned} 0= & \text { Non-Eligible/Non- } \\
& \text { Applicant } \\
1= & \text { GANAS Participant } \\
2= & \text { GANAS Accepted } / \\
& \text { Opted Out }\end{aligned}$ \\
\hline \multicolumn{4}{|c|}{ Input: Demographic Background } \\
\hline ETHNCAT & $\begin{array}{l}7 \text { category dummy variable } \\
\text { representing ethnic category. }\end{array}$ & Nominal & $\begin{aligned} 0= & \text { White } \\
1= & \text { American Indian } / \\
& \text { Alaska Native } \\
2= & \text { Asian } \\
3= & \text { Black } \\
4= & \text { Hawaiian/Other } \\
& \text { Pacific Islander } \\
5= & \text { Hispanic/Latino } \\
6= & \text { Multiple } \\
& \text { Ethnicity } \\
7= & \text { Race/Ethnicity } \\
& \text { Unknown }\end{aligned}$ \\
\hline
\end{tabular}




\begin{tabular}{|c|c|c|c|}
\hline Variable & Operational Measures & Level & Value \\
\hline LATINO & $\begin{array}{l}2 \text { category dummy variable } \\
\text { representing Latino heritage }\end{array}$ & Dichotomous & $\begin{array}{l}0=\text { Non-Latino } \\
1=\text { Latino }\end{array}$ \\
\hline GNDR & $\begin{array}{l}2 \text { category dummy variable } \\
\text { representing gender. }\end{array}$ & Dichotomous & $\begin{array}{l}0=\text { Male } \\
1=\text { Female }\end{array}$ \\
\hline AGE & $\begin{array}{l}\text { Continuous variable representing } \\
\text { age of participant. }\end{array}$ & Continuous & \\
\hline AGECAT & $\begin{array}{l}5 \text { category dummy variable } \\
\text { representing groups of age } \\
\text { ranges. }\end{array}$ & Nominal & $\begin{array}{l}1=18-24 \\
2=25-34 \\
3=35-44 \\
4=45-54 \\
5=55 \text { and over }\end{array}$ \\
\hline CITZ & $\begin{array}{l}3 \text { category dummy variable } \\
\text { representing citizenship. }\end{array}$ & Nominal & $\begin{aligned} 0= & \text { Non-U.S. Citizen } / \\
& \text { Undocumented } / \\
1= & \text { U.S. Citizen } / \\
& \text { Naturalized } \\
2= & \text { Visa Holder or } \\
& \text { Other type }\end{aligned}$ \\
\hline PELLELG & $\begin{array}{l}2 \text { category dummy variable } \\
\text { representing Pell eligibility. }\end{array}$ & Dichotomous & $\begin{array}{l}0=\text { Not Pell Eligible } \\
1=\text { Pell Eligible }\end{array}$ \\
\hline FSTGEN & $\begin{array}{l}2 \text { category dummy variable } \\
\text { representing first-generation } \\
\text { status (parents have not earned a } \\
\text { 4-year degree) }\end{array}$ & Dichotomous & $\begin{array}{l}0=\text { Not } 1^{\text {st }} \text { generation } \\
1=1^{\text {st }} \text { generation }\end{array}$ \\
\hline EBREG & $\begin{array}{l}2 \text { category dummy variable } \\
\text { representing East Bay service } \\
\text { region (Alameda/Contra Costa } \\
\text { County). }\end{array}$ & Dichotomous & $\begin{aligned} 0= & \text { Not from East Bay } \\
& \text { Region } \\
1= & \text { East Bay Region } \\
& \text { Native }\end{aligned}$ \\
\hline \multicolumn{4}{|c|}{ Input: Pre-transfer Characteristic } \\
\hline TRGPA & $\begin{array}{l}\text { Continuous variable representing } \\
\text { transfer grade point average prior } \\
\text { to matriculation at CSUEB }\end{array}$ & Continuous & \\
\hline TRGPACAT & $\begin{array}{l}5 \text { category dummy variable } \\
\text { representing groups of grade } \\
\text { point average ranges. }\end{array}$ & & $\begin{array}{l}0=\text { Less than } 2.0 \\
1=2.0-2.49 \\
2=2.5-2.99 \\
3=3.0-3.49 \\
4=3.5-4.0\end{array}$ \\
\hline
\end{tabular}

Program records. In order to determine the level of activity that each GANAS participant has with the program, I collected data from various program records. I looked at advisor records to determine how often a student came to see the GANAS Academic 
Counselor, I reviewed individual student files to determine how often a student met with their Herman@ (GANAS Peer Mentor), and I collected responses from the year-end surveys that were completed by the majority of students in each of the four cohorts.

The GANAS year-end survey is distributed each year to all student participants and was developed collectively by GANAS staff and founding members of the program. While the program has had the practice of collecting evaluative data every year, it has not systematically analyzed the responses to look for results. The survey consists of ninetynine (99) items: eighty-two (82) questions were close-ended which provided a Likert scale of responses for the student to choose from Strongly Disagree to Strongly Agree. All other questions were open-ended. The survey initially was distributed on paper, but transitioned to an online version in the 2015-2016 academic year. While the survey has generally been consistent through the years, some questions were added in later years. Given this, I have added a value of zero (0) equaling "not applicable" for questions that were not included in earlier surveys.

For the purposes of my study, I collected responses from twenty-two (22) of the survey questions, as these directly connected to the activities, outputs, and proximal outcomes outlined in the GANAS Logic Model, Figure 1.1. The operational measures for these questions are displayed in Table 3.2 below. Levels of measurement for all variables are ordinal. 
Table 3.2

GANAS Year End Survey Operational Measures, Levels, and Possible Responses

\begin{tabular}{|c|c|c|}
\hline Variable & Operational Measures & Response/Score \\
\hline $\begin{array}{l}\text { Intrusive } \\
\text { Advising }\end{array}$ & $\begin{array}{l}\text { The GANAS Counselor was easily accessible } \\
\text { and available to me. } \\
\text { The GANAS Counselor was knowledgeable } \\
\text { about university requirements and procedures. } \\
\text { The GANAS Counselor helped me } \\
\text { understand GE requirements and select } \\
\text { appropriate classes each quarter. } \\
\text { The GANAS Counselor helped me with non- } \\
\text { academic (personal) issues I went through. } \\
\text { The GANAS Counselor showed genuine } \\
\text { concern for me and my academic progress. }\end{array}$ & \\
\hline Peer & My 1-on-1 meetings with my Herman@were & \\
\hline $\begin{array}{l}\text { Learning } \\
\text { Community }\end{array}$ & $\begin{array}{l}\text { helpful. } \\
\text { When I reached out to my Herman@, s/he } \\
\text { was able to answer my questions or help me } \\
\text { find the solution. } \\
\text { I felt comfortable approaching my Herman@ } \\
\text { about academic challenges I was having. } \\
\text { I felt comfortable approaching my Herman@ } \\
\text { about personal challenges I was facing. } \\
\text { In my experience in the Decolonize Your Diet } \\
\text { course, the diverse perspectives and } \\
\text { backgrounds of the students were respected. } \\
\text { In my experience in the Race, Class, and } \\
\text { Body Politics in Dance course, the diverse } \\
\text { perspectives and backgrounds of the students } \\
\text { were respected. } \\
\text { In my experience in the Humans and Sex } \\
\text { course, the diverse perspectives and } \\
\text { backgrounds of the students were respected. } \\
\text { The speakers in the GANAS Seminar Course } \\
\text { this year were engaging and beneficial to have } \\
\text { in the classroom. } \\
\text { The GANAS seminar course familiarized me } \\
\text { with tools and skills I will need for career } \\
\text { exploration and employment searches. }\end{array}$ & $\begin{aligned} 0= & \text { Not applicable } \\
1= & \text { Strongly Agree } \\
2= & \text { Agree } \\
3= & \text { Neither } \\
& \text { Disagree nor } \\
& \text { Agree } \\
4= & \text { Disagree } \\
5= & \text { Strongly } \\
& \text { Disagree } \\
99= & \text { Did not } \\
& \text { respond }\end{aligned}$ \\
\hline
\end{tabular}




\begin{tabular}{|c|c|c|}
\hline Variable & Operational Measures & Response/Score \\
\hline & $\begin{array}{l}\text { I feel that I am part of a community here in } \\
\text { the GANAS Program. }\end{array}$ & \\
\hline $\begin{array}{l}\text { Sense of } \\
\text { belonging }\end{array}$ & $\begin{array}{l}\text { GANAS has provided opportunities for } \\
\text { students to bond and become closer as a } \\
\text { cohort. }\end{array}$ & $\begin{array}{l}0=\text { Not applicable } \\
1=\text { Strongly Agree } \\
2=\text { Agree }\end{array}$ \\
\hline $\begin{array}{l}\text { Ease of } \\
\text { transition }\end{array}$ & $\begin{array}{l}\text { The GANAS program has eased my transition } \\
\text { here to CSUEB. } \\
\text { The GANAS Program has helped me navigate } \\
\text { the university's policies and procedures. }\end{array}$ & $\begin{aligned} 3= & \text { Neither } \\
& \text { Disagree nor } \\
& \text { Agree } \\
4= & \text { Disagree }\end{aligned}$ \\
\hline $\begin{array}{l}\text { Increased } \\
\text { confidence }\end{array}$ & $\begin{array}{l}\text { The GANAS staff motivated and encouraged } \\
\text { me during this year. } \\
\text { GANAS has increased my confidence as a } \\
\text { college student. }\end{array}$ & $\begin{array}{l}\text { = Strongly } \\
\text { Disagree } \\
99=\text { Did not } \\
\text { respond }\end{array}$ \\
\hline $\begin{array}{l}\text { Increased } \\
\text { comfort } \\
\text { with faculty }\end{array}$ & $\begin{array}{l}\text { How many times, on average, did you go to } \\
\text { faculty office hours each quarter (in any } \\
\text { class)? }\end{array}$ & $\begin{array}{l}1=0 \text { times } \\
2=1 \text { times } \\
3=2 \text { times } \\
4=3 \text { times } \\
5=4 \text { times } \\
6=5 \text { times }\end{array}$ \\
\hline $\begin{array}{l}\text { Motivation } \\
\text { to continue }\end{array}$ & $\begin{array}{l}\text { What is the highest level of education you } \\
\text { ever expect to complete? }\end{array}$ & $\begin{array}{c}1=\text { Some college } \\
\text { but less than a } \\
\text { bachelor's degree } \\
2=\text { Bachelor's } \\
\text { degree } \\
3=\text { Master's Degree } \\
4=\text { Doctoral or } \\
\text { Professional } \\
\text { Degree }\end{array}$ \\
\hline
\end{tabular}

Focus group interview data. To collect qualitative data, my primary instrument was a focus group protocol. Only students who participated in the GANAS Program for at least one term were invited to participate in the focus groups. I developed the protocol myself since one does not exist that would recognize the GANAS Program or its components. I used the GANAS Logic Model as my guide to the protocol, and made sure to create 
questions that would allow for students to share their experience in relation to the GANAS Program components, but also to how those components impacted their overall academic experience. I conducted three focus groups - two of current GANAS participants and one of alumni. I pulled from a bank of 25 questions and each focus group ran for approximately 90 minutes each.

Additionally, at the end of each focus group session, participants were invited to complete the following brief writing prompt: What will you remember most about being a GANAS student? Responses provided a more personal, heartfelt understanding of the GANAS student experience and afforded the opportunity for participants to construct a narrative in their own words, in their voice.

\section{Data Analysis}

Quantitative and qualitative data were analyzed concurrently but separately, beginning in August 2017 once data collection was concluded. However, to answer my first research question of whether participation in the GANAS Program at Cal State East Bay impacts the academic progress of its Latino transfer students, I focused on the quantitative analysis. As delineated by Creswell and Plano Clark (2011), the following six procedures for analysis of quantitative data were taken: preparing the data for analysis, exploring the data, analyzing the data, representing the data analysis, interpreting the results, and validating the data and interpretations.

The dataset prepared by the IRADS office was extracted and formatted in a comma-delimited text file in order to be imported into Microsoft Access (database 
management software) and IBM Statistical Package for the Social Sciences (SPSS) version 24.0 for analysis. These data were than reviewed for potential errors or missing data. After careful examination, three records were added for GANAS students who were missing from the original set, and any duplicate records were removed. The original dataset from IRADS consisted of 10,521 records and was narrowed to 10,518 .

To begin, descriptive statistics were computed using SPSS to explore the relationships among variables in Table 3.1 and to compare the demographic characteristics of the population. Specifically, frequencies and percentages were used to describe the overall sample population, broken down by the three comparison groups (GANAS participants, students accepted to GANAS who opted-out, and students who were non-eligible or non-applicants). Next, a Spearmans rho correlation matrix was computed using all variables to determine which may show significance. Dependent and independent variables were selected from the matrix and were further analyzed to assess their significance within the three comparison groups. Explicitly, cross-tabulations and chi-square tests were computed for all selected variables. Two variables particularly relevant to academic progress - graduation status and time to degree - were used as the dependent variables when running the chi-square tests in order to identify a relationship between the variables and GANAS, as compared to the other two groups. Chi square tests of independence were conducted using a $p$ value of $<.10$. In cases where chi-square tests were not useful because there were cells with expected counts less than 5, as was the case 
with the time to degree variable (TMTDEG), categories were collapsed to meet the minimum expected count.

The third outcome (dependent) variable I am using to measure impact on academic progress is East Bay GPA (EBGPA). As it is a continuous variable, a linear regression model was used to analyze the factors influencing the grade point average of students in the dataset. The regression was run using SPSS 24.0. Variables entered were chosen based on their significance in the correlation matrix, chi-square results, and their level of representation in the GANAS Program. For example, demographic variables that showed overrepresentation in the GANAS population (i.e. Latino, Undocumented, etc.) were entered into the regression model. For comparison purposes, the GANAS opt-out group was also entered and served as a point of reference.

Data from GANAS program records were also loaded into SPSS 24.0 to conduct analysis. Frequencies and percentages were computed to explore the responses to the GANAS year-end survey questions. These data, along with the focus group responses, served to answer my second research question: How do the services and activities that the program provides result in satisfactory academic progress?

For the qualitative data analysis, I transcribed the focus group responses and looked for themes in the narrative. These testimonies assisted in filling in the gaps of why and how the quantitative student data analysis revealed the results it did, justification for the year-end survey responses, and ultimately allowed the voice of the GANAS participants to enrich the data with a personal touch. 


\section{Limitations}

One of the major limitations of my study is the small sample size of the GANAS participants, as well as the comparison group of students who opted-out. GANAS served just $2 \%$ of the transfer students that matriculated within the study's given time frame. Even accounting for those that opted-out of participation in the program, the percentage of the two groups combined is just $2.8 \%$ of the population. These small samples resulted in statistical errors, forcing me to adjust variables and run alternate tests that would be useful in my analysis and aid in answering my research questions.

Additionally, because GANAS was home grown at Cal State East Bay and it is the first of its kind, there was no opportunity to compare it to a similar program that serves a comparable population. No regional or state-wide analysis could be done. Two programs on the campus of Cal State East Bay have launched in the last 3 years, taking the model of GANAS, in whole or in part, and focusing it on other ethnic populations; but with less time in implementation and even smaller participation populations than GANAS, comparison to those programs was not possible. Sometime down the line, a cross-evaluation of the three programs would be a very useful study.

The most surprising limitation that I encountered was access to specific studentlevel data that would have served as another dependent variable in my study. As a participant in the GANAS program, students are enrolled in one upper-division general education (UDGE) course each term during their first year. There are three UDGE requirements that need to be completed to graduate. GANAS students have the 
opportunity to complete all three in their first year through the learning community coursework, therefore allowing them to focus solely on major requirements going into their second year, and potentially speeding up time to degree. I had planned to test this as part of my study. Included in my data request to IRADS, I asked that the dataset include the academic term in which each student completed each of the three UD GE requirements. I had planned to run analysis on what percentage of each comparison groups completed all three UDGE courses within the first year of transfer, and then determine if it was significant in time to degree. Unfortunately, that level of data was not available through the university. There was not a report that currently tracked that information and therefore could not be pulled from the system. There is no way to know if the data on these completions would have been useful or significant, but as the learning community coursework in GANAS is a major component of participation, it was something I wanted to explore.

Lastly, in the quantitative analysis of my data, I limited myself to basic inferential statistics that I was familiar with, leaning mostly on univariate analysis, chi-square, and linear regression. Future analysis might include logistic regression on the binary outcome variables of graduation.

As a result of these limitations, especially that of the small sample size, the transferability of the findings from this study could be difficult to substantiate. As the GANAS coordinator, I plan to continue to assess and evaluate program outcomes and measures so that results can possible be not only transferrable, but generalizable 


\section{Chapter Four: Report of Findings}

\section{Overview}

This study was designed to evaluate the GANAS Program and the academic progress of its participants who matriculated full-time to Cal State East Bay between the Fall 2013 and Winter 2017 terms, and then to highlight the services and activities that result in satisfactory academic progress. This chapter describes the results of the mixedmethod analysis conducted, detailing how the three sources of data come together to tell the story of the GANAS Program and its impact on students.

\section{The Findings}

This chapter is organized into four distinct parts, structured in response to this study's research questions. The first section presents descriptive statistics for all independent variables, providing an overview of the characteristics of GANAS participants, alongside the two comparison groups of students: those accepted to GANAS who opted-out, and those who were not eligible or did not apply to GANAS. Detail of how these groups were defined is described in Chapter 3. The second section, research question $\# 1$, details the majority of the quantitative results, which pertain to the academic progress of GANAS students compared to others. The third section, research question \#2, focuses particularly on the GANAS participants and their experience. It details student responses pulled from program record survey data, coupled with focus group testimonies to provide deeper understanding and voice to how the services and activities 
provided in GANAS impact its participants' academic experience. The final section, summary of results, completes the chapter by summarizing the evaluation findings.

Sample overview. The GANAS Program is currently in its fifth year of implementation and considered a young program, serving 213 students in its initial four years of service; therefore, my sampling frame is the entire population of GANAS participants and alumni. All participants of the program are transfer students who were admitted to Cal State East Bay and participated in GANAS between the Fall term of 2013 and the Spring term of 2017. This served as my treatment group $(\mathrm{n}=213)$, which includes 121 current GANAS participants, and 92 graduates as of Summer 2017. I created two comparison groups to measure against the study population of GANAS participants: 1) transfer students who applied to GANAS and were accepted, but chose to opt out of participation in the program; and 2) all other non-GANAS students who transferred to Cal State East Bay from a community college in one of the seven terms in which students matriculated into the GANAS program between Fall 2013 and Winter 2017.

The first group $(\mathrm{n}=88)$ is the most comparable to GANAS participants because these are students who the GANAS staff, after reviewing their application, felt would benefit from program services, were accepted to participate, but for various reasons chose not to participate in the program. As was described in Chapter 3 under Setting and Sample, these reasons could include scheduling conflicts with major coursework, or the option to fulfill upper-division GE courses within the major, rendering the GANAS 
courses unnecessary for the student. This group is labeled the GANAS Opt-out group. The second comparison group of the remaining sample transfers $(n=10,217)$ represents the standard achievement of the university. I have labeled this group the non-eligible, non-applicant group. Non-eligible refers to any students in this group who may have applied to GANAS but were not accepted by the program to participate. As described in Chapter 3, examples of non-eligibility could include students coming from a challenging major with little to no flexibility in their course schedule to enroll in GANAS courses, or students who work an abundance of hours preventing the ability to engage in the mandatory components of the program. It could also be that the student did not demonstrate need for the services that the program provides. Applicants may be deemed ineligible in some of these cases. Non-applicant simply refers to the remaining students in the group who never applied to participate in the GANAS Program. The dataset which included all three groups was constructed by the office of Institutional Research, Analysis, and Decision Support (IRADS) at Cal State East Bay. They compiled a comprehensive dataset supplied with student-level institutional data consisting of 10,518 records. Table 4.1 shows a comparison of characteristics between the comparison groups. While GANAS was implemented to increase the baccalaureate attainment of Latino transfer students in particular, the program is open to all who feel they may benefit from its services to apply. Given its target audience however, it is not surprising that Table 4.1 shows $87.3 \%$ of GANAS participants identify as Latino. Latino heritage is also among the largest percentages in the comparison groups as well, but the percentage in the 
GANAS group is at a much higher margin. While this overrepresentation is by design, it shows that outreach, recruitment, and marketing for the GANAS program has not only been intentional, but successful in attracting the target applicant population of Latino students to the program.

The table also shows that $12.2 \%$ of the GANAS population are Undocumented/Non-U.S. Citizens. Compared to the GANAS Opt-out group and the Non-eligible/Non-applicant group, (9.1\% and $1.7 \%$ respectively), GANAS has an overrepresentation of Undocumented students participating in the program. In fact, looking at the total number of Undocumented students in the entire sample population (n $=211$ ), with GANAS serving 26 of these students, the program has in fact served $12.3 \%$ of the entire population of Undocumented students who matriculated during this time period. Given that GANAS students only represent $2 \%$ of the entire sample, this is a very important finding.

As part of the focus group interviews, one student spoke about the experience of being Undocumented at their community college and what the difference was coming to GANAS:

"Back when I was at [my community college] I didn't know what EOPS was. And also being undocumented, many doors were shut in my face, just (clapped hands). And no support. Like no mentors, no people that could guide me, to educate me on what to do next, right? So staying at a community college and taking random classes and staying there for a long time. So all those years 
completely lost. People that would discourage you constantly, constantly. I would just look around and see, wow, you were born here, you don't know the struggle that I'm going through. Going and asking for help, for financial help, even before DACA got approved. And just people asking you out loud, "Do YOU have a social security number?" for me was humiliating because then I had to say no. And everybody behind me had to listen to my business. And then they would be like, "Oh then I can't help you, you're not on the record. How am I supposed to help you?" You know, “Come back Next!” And you're completely ignored. So coming in to GANAS was like wow, there's hope. There's hope for you. It's not the end of the world. Yes, you're going to pursue a higher education and it's not the end. It's not the end. So just bringing that confidence, that unity, that hope, that support is what makes the difference."

Something of interest is the percentage of GANAS participants that transfer from outside of the East Bay service region. 54.5\% of GANAS participants transferred from institutions outside of Alameda and Contra Costa counties, compared to $43.2 \%$ for the opt-out group and $38.5 \%$ of the larger sample transfer population. One student touched on what it meant to be part of the program, transferring from southern California: “...being away from home and family, everything that I knew and grew up to understand, knowing that I had that big sister, that Hermana, that I could always go to. That really helped me get through." 
It is also important to note, although not by a large margin, that the GANAS program serves female students disproportionately in comparison to the larger transfer sample population. While all three groups consist of a higher percentage of women, the table shows that more female students compared to males clearly apply to participate in GANAS; but of those that apply, a higher percentage of females also opt out of participation.

Finally, other observations show higher percentages of Pell-eligible and first generation students participating in GANAS across the groups, with the GANAS opt-out population percentages coming in closest to the GANAS group. The vast differences appeared in comparison to the larger transfer sample population, where it is shown that the numbers drop by up to 20 percentage points, as is the case with first-generation students $-79.8 \%$ of GANAS students are first-generation whereas the larger transfer sample population is $59.2 \%$.

What these disparities are saying is that the GANAS program is serving the most vulnerable populations at Cal State East Bay. In comparison to the other groups, considerable numbers of the participants in GANAS fall into the categories of Undocumented, Pell-eligible, and first generation, by large margins. This also demonstrates the level of need for services among the GANAS participants. My research will show that GANAS participants, despite coming from historically underserved backgrounds, measure up against that larger transfer sample population in both academic progress and GPA. 
Table 4.1

Demographic Characteristics as Numbers and Percentages with Comparison Groups

\begin{tabular}{|c|c|c|c|c|c|c|}
\hline \multirow[b]{2}{*}{ Demographic characteristic } & \multicolumn{2}{|c|}{$\begin{array}{c}\text { GANAS } \\
\text { Participant } \\
(\mathrm{n}=213)\end{array}$} & \multicolumn{2}{|c|}{$\begin{array}{l}\text { GANAS } \\
\text { Opt Out } \\
(n=88)\end{array}$} & \multicolumn{2}{|c|}{$\begin{array}{c}\text { Non-Eligible/ } \\
\text { Non-Applicant } \\
(\mathrm{n}=10,217)\end{array}$} \\
\hline & $\mathrm{n}$ & $\%$ & $\mathrm{n}$ & $\%$ & $\mathrm{n}$ & $\%$ \\
\hline \multicolumn{7}{|l|}{ Race/Ethnicity } \\
\hline White & 5 & $2.3 \%$ & 8 & $9.1 \%$ & 2355 & $23.0 \%$ \\
\hline American Indian/Alaska Native & 0 & $0.0 \%$ & 0 & $0.0 \%$ & 23 & $0.2 \%$ \\
\hline Asian & 6 & $2.8 \%$ & 14 & $15.9 \%$ & 2729 & $26.7 \%$ \\
\hline Black & 11 & $5.2 \%$ & 9 & $10.2 \%$ & 975 & $9.5 \%$ \\
\hline Hawaiian/Other Pacific Islander & 1 & $0.5 \%$ & 0 & $0.0 \%$ & 86 & $0.8 \%$ \\
\hline Hispanic/Latino & 186 & $87.3 \%$ & 50 & $56.8 \%$ & 2656 & $26 \%$ \\
\hline Multiple Ethnicity & 2 & $0.9 \%$ & 4 & $4.5 \%$ & 618 & $6.0 \%$ \\
\hline Race/Ethnicity Unknown & 2 & $0.9 \%$ & 3 & $3.4 \%$ & 775 & $7.6 \%$ \\
\hline \multicolumn{7}{|l|}{ Gender } \\
\hline Male & 57 & $26.8 \%$ & 19 & $21.6 \%$ & 4056 & $39.7 \%$ \\
\hline Female & 156 & $73.2 \%$ & 69 & $78.4 \%$ & 6161 & $60.3 \%$ \\
\hline \multicolumn{7}{|l|}{ Age } \\
\hline $18-24$ & 84 & $39.4 \%$ & 27 & $30.7 \%$ & 2894 & $28.3 \%$ \\
\hline $25-34$ & 121 & $56.8 \%$ & 46 & $52.3 \%$ & 5912 & $57.9 \%$ \\
\hline $35-44$ & 6 & $2.8 \%$ & 9 & $10.2 \%$ & 932 & $9.1 \%$ \\
\hline $45-54$ & 0 & $0.0 \%$ & 6 & $6.8 \%$ & 358 & $3.5 \%$ \\
\hline 55 and older & 2 & $0.9 \%$ & 0 & $0.0 \%$ & 121 & $1.1 \%$ \\
\hline \multicolumn{7}{|l|}{ Citizenship Status } \\
\hline Non-U.S. Citizen/Undocumented & 26 & $12.2 \%$ & 8 & $9.1 \%$ & 177 & $1.7 \%$ \\
\hline U.S. Citizen/Naturalized & 174 & $81.7 \%$ & 72 & $81.8 \%$ & 9016 & $88.2 \%$ \\
\hline Visa Holder or Other type & 13 & $6.1 \%$ & 8 & $9.1 \%$ & 1024 & $10.0 \%$ \\
\hline \multicolumn{7}{|l|}{ Pell Eligible } \\
\hline No & 72 & $33.8 \%$ & 34 & $38.6 \%$ & 4826 & $47.2 \%$ \\
\hline Yes & 141 & $66.2 \%$ & 54 & $61.4 \%$ & 5391 & $52.8 \%$ \\
\hline \multicolumn{7}{|l|}{ First Generation } \\
\hline No & 43 & $20.2 \%$ & 24 & $27.3 \%$ & 4169 & $40.8 \%$ \\
\hline Yes & 170 & $79.8 \%$ & 64 & $72.7 \%$ & 6048 & $59.2 \%$ \\
\hline \multicolumn{7}{|l|}{ From East Bay Region } \\
\hline No & 116 & $54.5 \%$ & 38 & $43.2 \%$ & 3937 & $38.5 \%$ \\
\hline Yes & 97 & $45.5 \%$ & 50 & $56.8 \%$ & 6280 & $61.5 \%$ \\
\hline
\end{tabular}


Research question \#1. My first research question asked: Does participation in the GANAS Program at Cal State East Bay impact the academic progress of its transfer students? Using the IRADS dataset $(\mathrm{N}=10,518)$, cross-tabulations and chi-square tests were computed for two dependent variables - graduation status and time to degree - to determine if there was a relationship between the variables and GANAS, as compared to the other two groups. Chi-square tests of independence were conducted using a $p$ value of $<.10$.

Chi-square analysis of Graduation Status (GRADSTAT) against the three comparison groups revealed that there was not a significant relationship, $x^{2}(1, \mathrm{~N}=$ $10,518)=1.216, p=.544$. Although GANAS shows a higher percentage of completed students under Graduation Status in Table 4.2, no significant distinction is shown across the groups. This test was a blunt instrument that looked at the entire study population graduating within a four-year opportunity and did not allow for a breakdown of time to degree. While noteworthy in the context of the next analysis that took place, this variable was statistically not significant.

Table 4.2

Chi-square Test: Graduation Status with Comparison Groups

\begin{tabular}{|c|c|c|c|c|c|c|c|}
\hline \multirow[b]{2}{*}{ Academic characteristic } & \multicolumn{2}{|c|}{$\begin{array}{c}\text { GANAS } \\
\text { Participant } \\
(\mathrm{n}=213)\end{array}$} & \multicolumn{2}{|c|}{$\begin{array}{l}\text { GANAS } \\
\text { Opt Out } \\
(\mathrm{n}=88) \\
\end{array}$} & \multicolumn{2}{|c|}{$\begin{array}{c}\text { Non-Eligible/ } \\
\text { Non-Applicant } \\
(\mathrm{n}=10.217)\end{array}$} & \multirow{2}{*}{$\begin{array}{l}p \text { value } \\
\left(x^{2}\right)\end{array}$} \\
\hline & $\mathrm{n}$ & $\%$ & $\mathrm{n}$ & $\%$ & $\mathrm{n}$ & $\%$ & \\
\hline Graduation Status & & & & & & & .544 \\
\hline Not Completed & 121 & $56.8 \%$ & 56 & $63.6 \%$ & 6043 & $59.1 \%$ & \\
\hline Graduate & 92 & $43.2 \%$ & 32 & $36.4 \%$ & 4174 & $40.9 \%$ & \\
\hline
\end{tabular}


Cross-tabulation of the five category variable Time to Degree (TMTDEG) with the comparison groups revealed cells with an expected count less than 5 , increasing the probability of a type 1 error and making it necessary for categories had to be collapsed to meet the minimum expected count. The temporal standards of the original variable were based on California State University metrics of graduation for transfers: completion within two years after transfer equals $100 \%$ time to degree, within three years after transfer is $150 \%$ of time to degree, and within four years after transfer is $200 \%$ of time to degree. The new variable (TMTDEGCL) collapsed the value "graduation within one year after transfer" with "graduation within two years after transfer." Graduation within three and four years after transfer were also collapsed. Analysis of the new variable showed a strong significant relationship between GANAS and Time to Degree, $x^{2}(4, \mathrm{~N}=10,518)=$ $8.267, p<.10$. Unlike when testing Graduation Status, time to degree has been broken out into three categories, two based loosely on the CSU metrics, and in breaking it down and testing it as such, there is statistical significance. Table 4.3 displays this breakdown and shows GANAS students graduating during the first or second year after transfer at a higher rate than both other groups. Coincidentally, both the GANAS Opt-out group and the Non-eligible/Non-applicant group graduate students at the same rate within the same time frame. 
Table 4.3

Chi-square Test: Time to Degree with Comparison Groups

\begin{tabular}{|c|c|c|c|c|c|c|c|}
\hline \multirow[b]{2}{*}{ Academic characteristic } & \multicolumn{2}{|c|}{$\begin{array}{c}\text { GANAS } \\
\text { Participant } \\
\underline{(\mathrm{n}=213)}\end{array}$} & \multicolumn{2}{|c|}{$\begin{array}{l}\text { GANAS } \\
\text { Opt Out } \\
(\mathrm{n}=88)\end{array}$} & \multicolumn{2}{|c|}{$\begin{array}{c}\text { Non-Eligible/ } \\
\text { Non-Applicant } \\
(\mathrm{n}=10,217)\end{array}$} & \multirow{2}{*}{$\begin{array}{l}p \text { value } \\
\left(x^{2}\right)\end{array}$} \\
\hline & $\mathrm{n}$ & $\%$ & $\mathrm{n}$ & $\%$ & $\mathrm{n}$ & $\%$ & \\
\hline Time to Degree & & & & & & & $<.082 *$ \\
\hline Not Completed & 121 & $56.8 \%$ & 56 & $63.6 \%$ & 6043 & $59.1 \%$ & \\
\hline $\begin{array}{l}\text { Graduate during } 1^{\text {st }} \text { or } 2^{\text {nd }} \text { year } \\
\text { after transfer }\end{array}$ & 68 & $31.9 \%$ & 22 & $25.0 \%$ & 2557 & $25.0 \%$ & \\
\hline $\begin{array}{l}\text { Graduate during } 3^{\text {rd }} \text { or } 4^{\text {th }} \text { year } \\
\text { after transfer }\end{array}$ & 24 & $11.3 \%$ & 10 & $11.4 \%$ & 1617 & $15.8 \%$ & \\
\hline
\end{tabular}

With the output of the Chi-square showing significance at $10 \%$, a post-hoc test was conducted. The critical value for 4 degrees of freedom with significance of $<.10$ is 7.78. I then calculated the Chi-square values for each of the 9 cells, $x^{2}=\sum \frac{\left(o_{i}-E_{i}\right)^{2}}{E_{i}}$. This found that the Chi-square terms for the GANAS participants graduating in the combined first and second years after transfer, and in the combined third and fourth year after transfer, produced terms that were larger than $1-3.87$ and 2.65 respectively. When the value is much bigger than 1 , it is significant. The test did not reveal such significant values in either of the other comparison groups.

GANAS participants graduating within the first or second year after transfer have an expected count of 53.6 under the null hypothesis. However, GANAS students are graduating within this time frame at a count of 68 . This means that more students are graduating than expected under the assumption that GANAS has no impact. There is an overrepresentation of graduates within the GANAS group in the combined first and 
second year after transfer, and therefore we must reject the null hypothesis - GANAS does have an impact. For GANAS participants graduating within the combined third or fourth year after transfer, there is an expected count of 33.4, but GANAS students are graduating within this time frame at a count of 24 . This means that there is an underrepresentation of graduates in the combined third and fourth year after transferring, showing that GANAS students are graduating faster than their counterparts.

While the Time to Degree variable had to be collapsed in order to be tested, when correlations were run year by year, tests showed that there was significance in graduating in the second and third year after transfer. This is best displayed by Figure 4.1, where 4year cumulative graduation rates were calculated by cohort year then averaged for each comparison group (full calculations can be found in Appendix D). Clearly all groups begin at nearly the same point with only slight variance in their average 1-year graduation rate. But then looking at the 2-year graduation mark, a large gap is shown to occur with GANAS graduating its participants at $48.3 \%$, GANAS Opt-out at $40.6 \%$, and the larger transfer sample group at $34.3 \%$, a 14 percentage point spread across the groups. The gap continues at the 3-year graduation mark as GANAS then jumps to $78.9 \%$, GANAS Optout goes to $69.7 \%$, and the last group at $65.1 \%$, a 13.8 percentage point spread across groups. Then rates balance out a bit again between GANAS and the GANAS Opt-out group at the 4-year graduation mark, with GANAS slightly above the Opt-out group by $1.1 \%$, but achieving at $12.6 \%$ higher than the larger transfer sample population. 


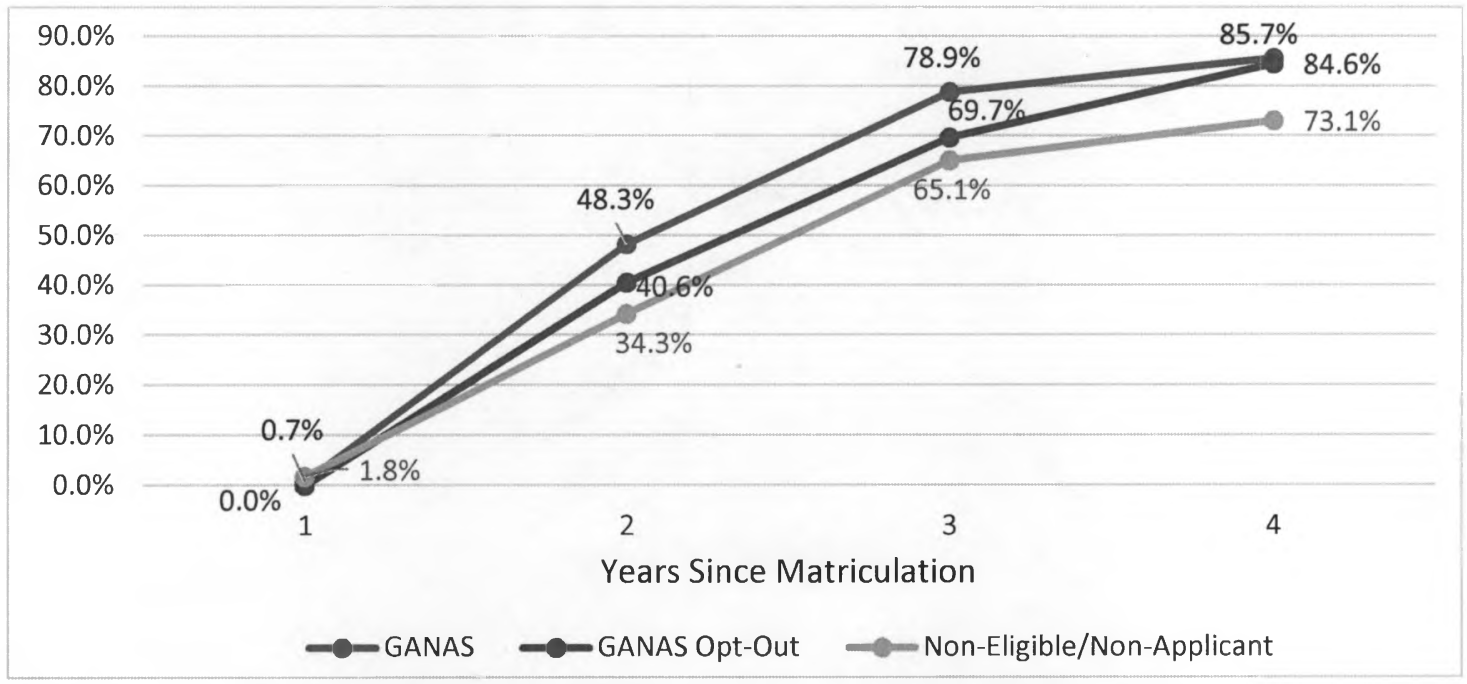

Figure 4.1. Average Cumulative Graduation Rates by Comparison Group

The third dependent variable I used to measure impact on academic progress was East Bay grade point average (EBGPA). As it is a continuous variable, I used a linear regression model to analyze the factors influencing the grade point average of students in the dataset. Variables entered into the model were chosen based on their significance in the correlation matrix, chi-square results, and their level of representation in the GANAS Program. The following predictors were added to the linear regression model: GANAS, GANAS Opt-out, Gender, Latino Heritage, Citizenship, Pell Eligibility, and First Generation status.

The overall model was statistically significant at $p<.001$. All but two of the predictors were found to be significant. Measuring significance at $p<.10$, participation in GANAS was found to be significant with a $p$ value of .076 . The $t$ value is 1.775 and positive, as was the unstandardized beta coefficient, at .097. What this shows is that GANAS does have an impact on the GPA of its participants. All things being equal, 
GANAS participants on average, have a GPA of .097 points higher than the noneligible/non-applicant group of students. Of particular interest, was the high significance of Latino heritage. The $p$ value for Latino heritage was .000 , with a negative $t$ value of 4.40 and a negative unstandardized beta coefficient of .078 . This shows that being of Latino heritage at Cal State East Bay is correlated with a drop in GPA of .078 points. Meaning the average Latino student has a GPA that is .078 less than a non-Latino student. What makes this particularly interesting is that the GANAS Program targets and enrolls Latino students at $87.3 \%$, which logically should point to GANAS students then having lower GPAs than the larger transfer sample population, but results show the contrary.

Similar were the findings of high significance for Pell eligibility $(p<.001)$. With a negative t value of 7.988 and negative unstandardized beta coefficient of .123. Since GANAS is correlated with a slightly increased GPA and serves a higher percentage of Pell eligible students than its counterparts, it is interesting to note that the average Pell eligible student has a GPA that is .123 less than a non-Pell eligible student. As well as the findings for Citizenship, $x^{2}(2, \mathrm{~N}=10,518)=141.010, p<.05$. An increased GPA of .052 is associated with being a U.S. Citizen, so the fact that GANAS serves a disproportionate amount of Undocumented students, also makes the significance of higher GPA among GANAS students that much more remarkable. 
Table 4.4

Effect of Variables in Model Predicting Impact on East Bay GPA

\begin{tabular}{lrrl}
\hline & $\begin{array}{c}\text { Unstandardized Beta } \\
\text { Coefficient }\end{array}$ & $\mathrm{t}$ & \multicolumn{1}{c}{ Sig. } \\
\hline GANAS Participant & .097 & 1.775 & $.076^{*}$ \\
GANAS Accepted/Opt-out & -.035 & -.417 & .677 \\
Latino Heritage & -.078 & -4.400 & $.000^{* * *}$ \\
Citizenship & .052 & 2.308 & $.012^{* *}$ \\
Pell Eligible & -.123 & -7.988 & $.000^{* * *}$ \\
First Generation & -.020 & -1.272 & .203 \\
Female & .099 & 6.389 & $.000^{* * *}$ \\
(Constant) & 2.994 & 101.030 & .000 \\
\hline
\end{tabular}

$p<.10^{*}, p<.05^{* *}, p<.001^{* * *}$

While East Bay GPA, not cumulative GPA, was measured for the purposes of this study, it is also of value to note that $64.3 \%$ of GANAS participants transferred to East Bay with a GPA of 2.99 or below, while $46-50 \%$ of the comparison groups transferred with a GPA of 3.0 and above.

Table 4.5

Transfer GPA Categories by Comparison Groups

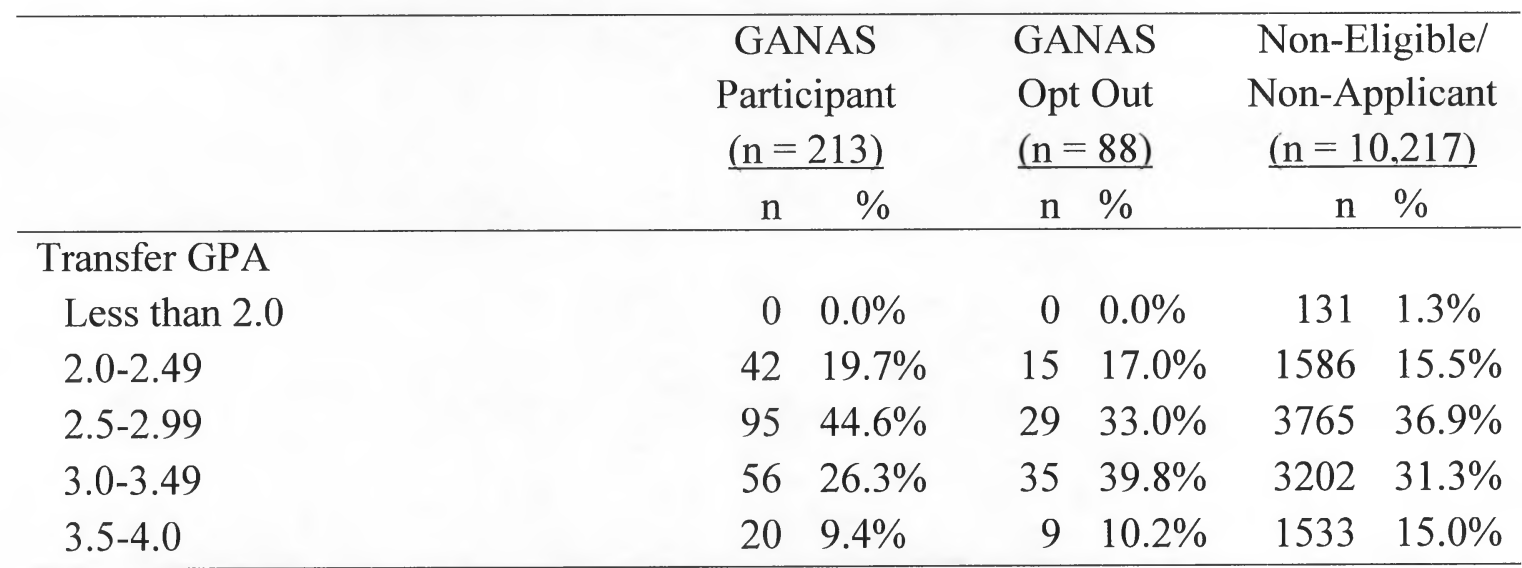

Findings from the statistical analysis of the IRADS dataset provided interesting insight and served to answer my first research question as to if participation in GANAS 
impacts the academic progress of its students. It in fact does. Chi square results revealed that Time to Degree is significant and GANAS students graduate faster than their counterparts. Linear regression analysis revealed that participation in GANAS is correlated with an increase in GPA, on average, of .078 points, despite the correlation of lower GPAs with the demographics of the majority of students that GANAS serves (Latino, Pell Eligible, Undocumented). These statistical tests showed that GANAS has made a positive impact on the academic progress of its participants.

Research question \#2. My second research question asked: How do the services and activities that the program provides result in satisfactory academic progress? To begin to answer this question, I reviewed several program records in the GANAS office to understand the frequency of which students participated in the core components of GANAS - coursework, intrusive advising, and peer mentoring. Some of this was collected from student files, other data was collected from responses to the GANAS yearend survey that is administered each year at the end of Spring. While the survey is distributed to all participants at the end of their first year, only 139 of the 213 GANAS participants choose to take the survey, and of those that did, not every student completed every question. Given this, whenever reference is made to results of the survey, a clear count is provided to frame the size of the response pool.

Learning community coursework. As a participant in the GANAS program, each student is enrolled in one upper-division general education (UDGE) course each term, along with a Transfer Success Seminar course. Participants take these two courses 
together each term as a cohort and move together as a learning community throughout their first year at Cal State East Bay. In order to frame the relationship between the GANAS learning community coursework and outcomes, five questions were pulled from the year-end survey that discuss the GANAS coursework. The questions are listed in Table 4.3 along with frequency of responses and percentages. Students were asked to answer on a Likert scale from Strongly Disagree to Strongly Agree. Of the participants who responded to the questions pertaining to the UD GE courses, most strongly agreed that the diverse perspectives and backgrounds of the students were respected in each of the upper-division classroom. Participants also felt that the Transfer Success Seminar course was engaging and beneficial, with $60.3 \%$ strongly agreeing that the course familiarized them with tools and skills needed for career exploration.

While there has been some slight shifting in terms of the Winter $\mathrm{C} 4$ requirement course, the GANAS coursework for Fall and Spring has remained the same. Dr. Luz Calvo teaches the Decolonize Your Diet (D4) course in the Fall, and Dr. Maria Nieto teaches the Humans and Sex (B6) course in the Spring. In the first and second cohorts, Dr. Carlos Salomon taught an Oral Histories (C4) course, but the Winter course has since changed. As part of the focus group interview sessions, students were asked to comment on their experience in the GANAS learning community. This student in particular was part of one of the initial cohorts and this what she said in regards to the GANAS professors and the courses that they taught: 
"I love, of course, Luz's take on food and be proud of your food and how food is medicine. I mean, never had I really understood that that was what or mothers and our grandmothers had been teaching us this whole time! That food is medicine and I had never verbalized it that way. I had never thought about it that way, and to finally understand that this is what they have been trying to teach us this whole time. This is why you drink this tea, this is why you do that. Like, I had, for some reason it never clicked. ... and to have a teacher to kind of put it on paper and get you to see it and understand it. And appreciate why nopales (cactus) have been shoved down our throats our whole life, right? How important that is and how good that has been for us. I mean, to learn to love in such a way that I had never loved food before. And after Luz's class, I had this new found love and appreciation for the simple foods. The handmade tortillas, you know like, things I had just taken for granted. And then going to Carlos' class and appreciating the stories. The importance in that, to hold on to those oral traditions. Because that means that my kids, and especially my grandkids, they're never gonna know my grandfather's story, it's on me. I have to do this if I want this to stay. And then with Maria, to finally talk about my body and my reproductive system, and our value in our role as the females in humanity. I mean, that was awesome. I had never taken a class where I felt so proud for my eggs, you know...it sounds silly but I was just like, wow. I hold so much power for human existence within me. 
Every single class was just so relevant to who I am as a Latina, as a woman, and as a leader in our community. I could not have chosen better classes."

This excerpt shows not only that this student had a connection with the professors that taught the GANAS courses, but also that the content of the courses was relevant to the student on a cultural and feminine level.

Table 4.6

Frequencies/Percentages of Survey Responses by GANAS Participants - Learning

Community Courses

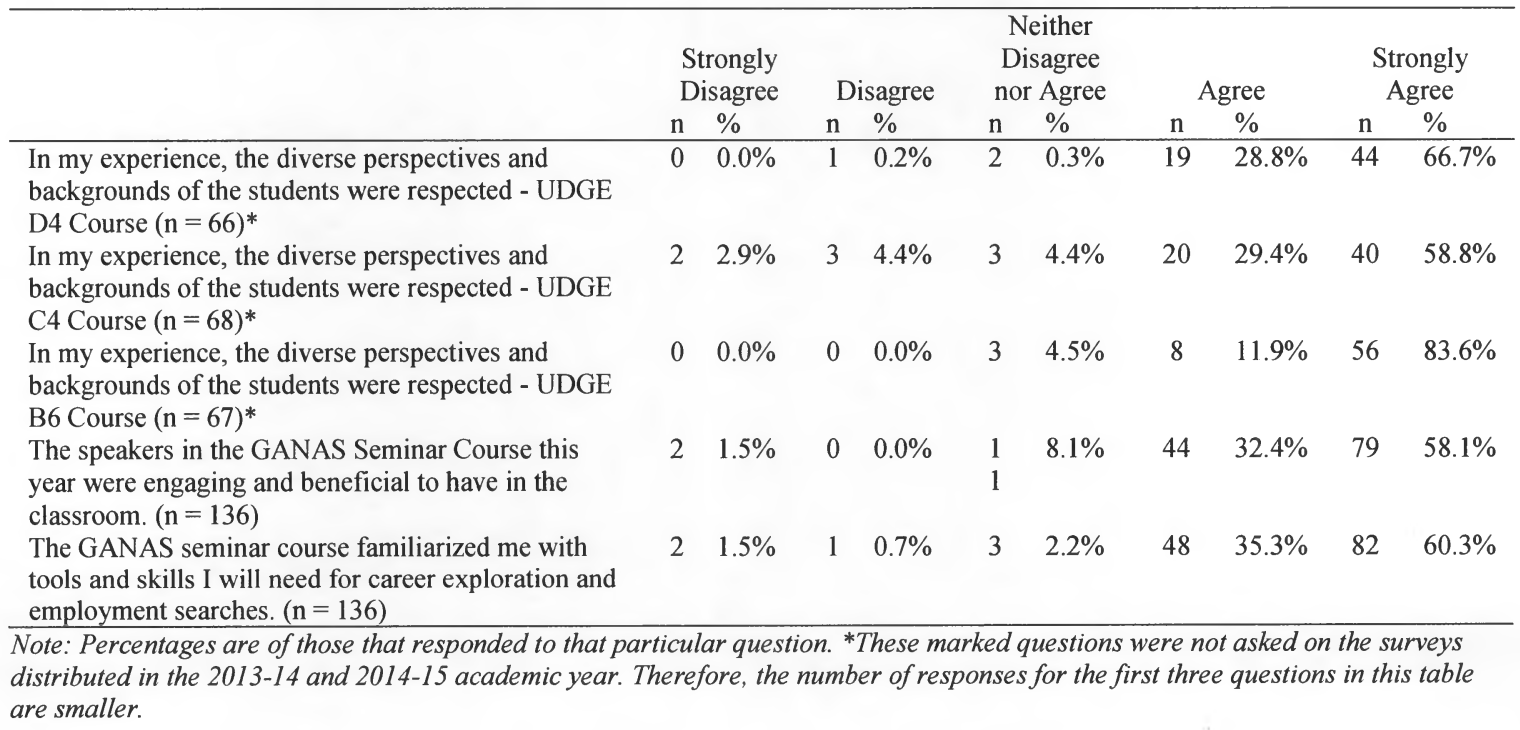

Intrusive Advising. With an Academic Counselor on staff, GANAS participants have a consistent connection to an advisor to assist in tracking progress to graduation.

The counselor should be a knowledgeable resource, help students select courses as part of their educational plan, and provide authentic care in their interactions with the GANAS students. Participants are encouraged to make an appointment with the Academic 
Counselor twice a quarter. This allows for the counselor to develop a relationship with the student and become familiar with their academic history in order to better advise them. It also allows for the counselor to begin to know the student well enough to recognize when there might be an issue, and assign an intervention before it gets to the point that the student is suffering academically.

Information on the number of visits students made to the GANAS office for advising during their first year after transfer was gathered from program records. It was found that on average, GANAS participants visited the Academic Counselor four times within their first academic year. As was done in trying to frame the connection of outcomes to the coursework, five questions in reference to the academic counselor were pulled from the year-end survey and are listed along with frequency of responses and percentages in Table 4.4. Students were asked to respond on a Likert scale ranging from Strongly Disagree to Strongly Agree. $71.9 \%$ of participants strongly agree that the GANAS counselor was easily accessible. Just over $61 \%$ strongly agreed that the GANAS counselor helped them understand GE requirements and assisted in selecting appropriate classes.

In one of the focus group sessions, a student recalled her experience with her GANAS counselor and the emails she would receive at the end of the term:

"At the end of the quarter, [she] would send that email, 'Oh, you got above a whatever.' And those other ones, because she had to send me one of those one quarter - 'What happened? You fell.' Those really helped too because that 
showed, okay they really do care. They do want me to do well. It wasn't just me, you know, back in my first year of community college again, doing whatever I wanted and just dropping out. It was, 'What are you doing? You need to get back on it,' which helped me because I did have a quarter where I had some bad grades. There was a quarter I got C's and D's. So I got an email. All the other quarters were good emails. But that one was not. The good email was like, 'Good job! You had over a 3.0!' and really encouraging, like, 'Keep up the good work.' And the other one was, 'What happened? You were at a 2.0.' Like, you know? And it said, 'What do I need to do? You need to come see me now. Schedule an appointment this week. We're gonna talk about it, figure it out and get you back up.' And I appreciate that. It pushed me more, like, damn they're not kidding they're really going to help me." When referring to intrusive advising and how they felt about that approach, another student said:

'I like him. He's so awesome. I went from like, 'Oh you're just a stranger why should I tell you my life?' to like, 'Let me tell you everything now. Like everything about my life. Like what I did on the weekend.' (laughs). But I think it's definitely by the individual. Some students are just naturally more conservative and you can't push them to the edge. And it's just, some things have a limit and if I don't feel like disclosing that information with you, I don't have to and don't force me to because you're going to deviate students away. So if they 
want to disclose let them and listen to the information to a comfortable boundary.

But I feel like we should never push the student."

Table 4.7

Frequencies/Percentages of Survey Responses by GANAS Participants - Advising

\begin{tabular}{|c|c|c|c|c|c|c|c|c|c|c|}
\hline & \multicolumn{2}{|c|}{$\begin{array}{l}\text { Strongly } \\
\text { Disagree }\end{array}$} & \multicolumn{2}{|c|}{ Disagree } & \multicolumn{2}{|c|}{$\begin{array}{l}\text { Disagree nor } \\
\quad \text { Agree }\end{array}$} & \multicolumn{2}{|c|}{ Agree } & \multicolumn{2}{|c|}{$\begin{array}{l}\text { Strongly } \\
\text { Agree }\end{array}$} \\
\hline & $\mathrm{n}$ & $\%$ & $\mathrm{n}$ & $\%$ & $\mathrm{n}$ & $\%$ & $\mathrm{n}$ & $\%$ & $\mathrm{n}$ & $\%$ \\
\hline $\begin{array}{l}\text { The GANAS Counselor was easily accessible and } \\
\text { available to me. }(n=139)\end{array}$ & 1 & $0.7 \%$ & 1 & $0.7 \%$ & 7 & $5.0 \%$ & 30 & $21.6 \%$ & 100 & $71.9 \%$ \\
\hline $\begin{array}{l}\text { The GANAS Counselor was knowledgeable about } \\
\text { university requirements and procedures. }(n=139)\end{array}$ & 1 & $0.7 \%$ & 1 & $0.7 \%$ & 8 & $5.8 \%$ & 43 & $30.9 \%$ & 86 & $61.9 \%$ \\
\hline $\begin{array}{l}\text { The GANAS Counselor helped me understand GE } \\
\text { requirements and select appropriate classes each } \\
\text { quarter. }(n=139)\end{array}$ & 1 & $0.7 \%$ & 4 & $2.9 \%$ & 15 & $10.8 \%$ & 34 & $24.5 \%$ & 85 & $61.2 \%$ \\
\hline $\begin{array}{l}\text { The GANAS Counselor helped me with non- } \\
\text { academic (personal) issues I went through. } \\
(\mathrm{n}=139)\end{array}$ & 5 & $3.6 \%$ & 3 & $2.2 \%$ & 36 & $25.9 \%$ & 30 & $21.6 \%$ & 65 & $46.8 \%$ \\
\hline $\begin{array}{l}\text { The GANAS Counselor showed genuine concern } \\
\text { for me and my academic progress. }(n=138)\end{array}$ & 2 & $1.4 \%$ & 1 & $0.7 \%$ & 5 & $3.6 \%$ & 32 & $23.0 \%$ & 98 & $70.5 \%$ \\
\hline
\end{tabular}

Peer mentoring. Next, frequency information in reference to the number of times

students met with their Herman@ (peer mentor) was gathered from program records and student files. However, more recently, a question has been added to the year-end survey that asks students to estimate how often they have met with their Herman@, making reporting easier. For those participants who did not have the question on their version of the survey, program records were reviewed and the frequency was calculated by hand.

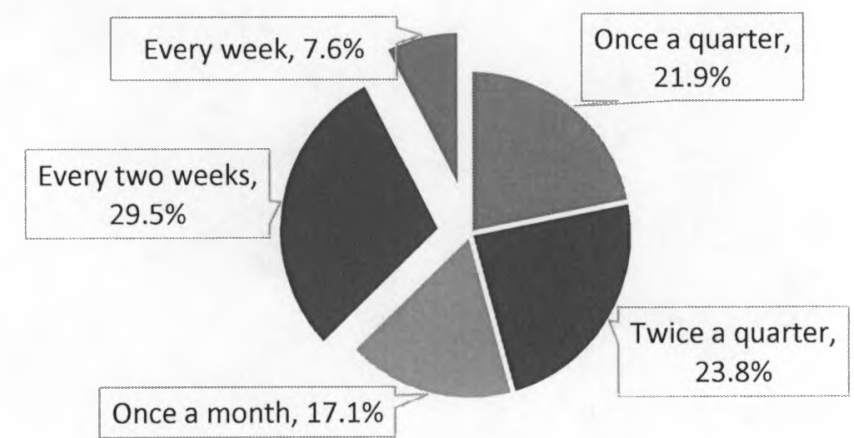

Figure 4.2. Frequency and Percentages of Herman@ Meetings 
Additionally, the first GANAS cohort did not have Herman@s. Peer mentoring was not structured into the GANAS Program until the second year of implementation, Fall of 2014. Therefore, the survey questions regarding mentoring did not exist for the first cohort. This accounts for the smaller $n$ in response to the mentoring questions. Since its inception, GANAS has encouraged participants to meet with their Herman@ every two weeks. It was found that the largest percentage of participants, $29.5 \%$, did indeed meet with their Herman@ that often, with a small percentage (7.6\%) utilizing their Herman@ every week.

Additionally, four survey questions were reviewed in relation to participant contact with their Herman@. While the responses leaned toward the strongly agree end of the scale, no one answer had over $50 \%$ of the responses. The highest percentage was 46\%, where participants felt that when they reached out, their Herman@was able to answer their question or find a solution. There was a fair amount of responses that landed in the Neither Disagree nor Agree category as well, so while responses fell across the scale, most students reported a positive experience. While Herman@s are meant to be support at the peer level, one student in a focus group described the role as "the perfect conduit to the [GANAS] staff”. He said, “They give you the scoop. They've been around longer." The next two students had a clear contrast in the relationships they had with their Herman@, but both also mention their different needs for guidance:

"I feel like the Herman@s work better for other people. I mean, I like my Hermana, but I wasn't like very close with her. It's just because I guess I didn't 
need that, like, extra help. But I mean it was helpful in the sense that like, oh there was somebody that went through this and you know, they have something to speak about, or something to say about what you're going through. It's relatable.

While the next student began with:

"For me I LOVE my Hermana. And I just thought she was so helpful and also so encouraging. Like I told her that I'm very shy and she's like, 'Well, were gonna work on that.' And every time I would get asked if I would go to a conference or if I would be a speaker or anything, I would tell her Hey what do you think? 'Oh! You're going! You're going!' Like every time. Or she would call me, 'Hey, you're going to this, you're going to be a speaker.' I'd be like ahh, why you do this to me? She'd go, 'You have to speak up, you have to participate. You have to be getting involved in more stuff.' I would say, I wish I was more like you, you're so outspoken. And I love that about her. She was always so positive and I just love her help and we could talk about anything, like personal stuff, school-related stuff. Yeah.”

One final student indicated that her relationship with her Herman@ was a positive one, but shared a story that described his approach as somewhat bothersome:

"My Hermano would nag at me sometimes, but I understand now why he would. But it's okay because he helped A LOT. Especially with the transition in going from over there to here. He would be like, 'Come out and do this, come out and do that, let's go study.' So he would try to make me get out of my bubble and 
actually get involved and like find my place in GANAS. So he did help me out in that sense even though he would nag at me sometimes. He meant well and he did help me."

Table 4.8

Frequencies/Percentages of Survey Responses by GANAS Participants - Peer Mentoring

\begin{tabular}{|c|c|c|c|c|c|c|c|c|c|c|}
\hline \multirow[b]{2}{*}{ GANAS Year-End Survey Responses $(\mathrm{n}=106)$} & \multicolumn{2}{|c|}{$\begin{array}{l}\text { Strongly } \\
\text { Disagree }\end{array}$} & \multicolumn{2}{|c|}{ Disagree } & \multicolumn{2}{|c|}{$\begin{array}{c}\text { Neither } \\
\text { Disagree nor } \\
\text { Agree }\end{array}$} & \multicolumn{2}{|c|}{ Agree } & \multicolumn{2}{|c|}{$\begin{array}{l}\text { Strongly } \\
\text { Agree }\end{array}$} \\
\hline & $\mathrm{n}$ & $\%$ & $\mathrm{n}$ & $\%$ & $\mathrm{n}$ & $\%$ & $\mathrm{n}$ & $\%$ & $\mathrm{n}$ & $\%$ \\
\hline $\begin{array}{l}\text { My 1-on-1 meetings with my Herman@ were helpful. } \\
\text { When I reached out to my Herman } @ \text {, s/he was able to }\end{array}$ & 3 & $2.2 \%$ & 1 & $0.7 \%$ & 9 & $6.5 \%$ & 35 & $25.2 \%$ & 58 & $41.7 \%$ \\
\hline $\begin{array}{l}\text { answer my questions or help me find the solution. } \\
\text { I felt comfortable approaching my Herman@ about }\end{array}$ & 2 & $1.4 \%$ & 2 & $1.4 \%$ & 8 & $5.8 \%$ & 30 & $21.6 \%$ & 64 & $46 \%$ \\
\hline $\begin{array}{l}\text { academic challenges I was having. } \\
\text { I felt comfortable approaching my Herman@ about }\end{array}$ & 4 & $2.9 \%$ & 1 & $0.7 \%$ & 11 & $7.9 \%$ & 31 & $22.3 \%$ & 59 & $42.4 \%$ \\
\hline personal challenges I was facing. & 3 & $2.2 \%$ & 6 & $4.3 \%$ & 19 & $13.7 \%$ & 24 & $17.3 \%$ & 54 & $38.8 \%$ \\
\hline
\end{tabular}

Building community, transition, and confidence. The remaining eight questions

selected from the GANAS year-end survey covered the topics of transition from

community college to the university, building community, and areas of confidence and

motivation. While these aren't structured components of the GANAS Program, they are outcomes that program participants experienced.

Two of the survey questions that were looked at focused on the transition to East Bay and the level to which the program helped the student navigate the university. An overwhelming percentage (78.4\%) of students strongly agreed that GANAS eased their transition to Cal State East Bay, as shown in Table 4.8. Similarly, 72.7\% of participants also strongly agreed that the program assisted them in navigating the policies and procedures of the university. As part of the focus group responses, one student shared 
how GANAS played a role in his decision to attend East Bay and how it would support his transition:

"I could've gone to [my local CSU campus] if I wanted to. That was convenient. But I would rather commute from a school where I'm not going to be thrown in a pool of 50,000 other students and I am going to receive that special attention. That will work a lot for students coming from low self-esteem, low confidence. You need that system of enrichment. At [my local CSU campus] I think I just would've been left in the shadows, and just tied along and probably wouldn't have graduated on time."

This student felt that the support system of the program was a valid compromise for having to commute a bit further away for school if it meant he would get the extra support he felt he needed.

In response to the statement: I feel like I am part of a community here in the GANAS Program, the majority of participants (64.7\%) strongly agreed that they did. As a participant, GANAS students are placed in a cohort and move together through their first year after transfer. This allows for time and space to build relationships and community. Similar to the previous response, the majority of respondents (62.6\%) also strongly agreed that the program provided opportunities for the students to bond and become closer as a cohort.

Part of the focus group interview asked students to speak about their experience being placed in a cohort. One student shared how the community was unexpected: 
"What did surprise me though was that it was a lot more community based, like the students became a family... I feel like that was a better outcome for me just because I felt a sense of family at school and it just motivated me to come to school and try more in my academics."

While this student saw the family as a positive aspect which motivated her to try harder, another student shared that the cohort was difficult for her but hinted at a question as to how perhaps growth can come from the experience:

"[It was] challenging. Many of us in the program have strong personalities. It was very challenging to accept each other and to learn, to support each other and really leave every obstacle behind. And it's like we are here with one purpose. One goal to accomplish and move on. And how can we better support each other as Latinos succeeding."

As with any family or group, personalities can create challenges and you have no choice but to address them. For this to happen successfully, it is important to know who you are and where you stand within that family or group. Another student shared about finding his identity within the cohort:

“...Mostly because the fact that I already had, as a student, low self-esteem already and a lot of social anxiety... I feel like having a family [at] this huge university with, like it... creates a safe haven. I feel like the fact that it was a cohort, in a sense, depending on your perspective goals, prepared you for graduate school, like, you're going to be working closely with this group of people. I feel 
like it gives you a reflection of, this is who you are in all these people. Are you the picky one? The chill one? Are you the one that's a leader? You kind of find your identity in a group of people. And it takes that to find it. That the nice part." While clearly challenging for some students and maybe not for others, the structure of the cohort showed to build community and opportunity for growth for the participants, and served as preparation for future endeavors. Whether it be graduate school or career, the experience and interactions with different people and personalities within the cohort gave the students some perspective of how life beyond East Bay might be.

For the next two questions, the survey asked about participants' motivation and confidence. Again, largely positive responses were received in regards to both questions. When asked if the GANAS staff motivated and encouraged its participants, $76.3 \%$ of respondents strongly agreed. And $73.4 \%$ were also in strong agreement that GANAS has increased their confidence as a college student. One student in the focus group said:

"I can definitely say that GANAS taught me so many skills and so many things. Especially giving me that confidence to learn how to advocate for myself, that I need to speak up whenever I need to. It goes back to being confident and knowing that there is more. Knowing that you have to go back for a higher education and that we need to go back to our communities and... help other Latino students that are trying to succeed."

Being able to advocate for herself showed confidence and motivation to reach her goals, which was important to this student. In the Spring term of each year, GANAS first-year 
students complete a project called, Living the Life You Dream. Students are asked to project milestones out up to the age of 65 , highlighting three major events each decade. As the focus group chatted about this assignment, the same student went on to say: “GANAS really helped me to visualize my graduation. To visualize myself getting that degree. I am going to share this personal experience that I used to have. Even though I was attending East Bay and being in GANAS, I had my own struggles and tribulations that I was going through myself. And I just remember walking around campus praying in my mind, ... and I would just say God I don’t know how am I going to graduate. I don't even have a dollar in my purse. I don't know how it's going to happen, but I'm going to do it. [Just] visualizing myself: I'm going to graduate. I'm gonna walk that stage. Its gonna happen... Just knowing that GANAS is there and you can come and vent... So for me, what I can take strongly in my heart from GANAS is visualizing myself doing it. And I did, I did it... And I didn't do it on my own. It was not me. It was people that cared for me and people that loved me and people that really invested their time for me to succeed."

The combination of support and goal setting helped this student visualize her future and motivated her to keep going no matter what her situation was. A second student elaborated on how the program continues to support her after graduation:

"Knowing that we're able to ask for guidance even after years of being away from the program... To be able to achieve the goals makes it easier to know that you 
can obtain them. Because before GANAS, a lot of us... were lost without that guidance from people that really cared. So with GANAS you know you have Melissa, you have Belen, you have Evelia. You have all these people that are advocating for you. Even though you're not their students anymore. So it just makes going out there and achieving your goals even easier.

Table 4.9

Frequencies/Percentages of Survey Responses by GANAS Participants-Building Community, Transition, \& Confidence

\begin{tabular}{|c|c|c|c|c|c|c|c|c|c|c|}
\hline & \multirow{2}{*}{\multicolumn{2}{|c|}{$\begin{array}{l}\text { Strongly } \\
\text { Disagree } \\
\text { n } \%\end{array}$}} & \multicolumn{4}{|c|}{$\begin{array}{c}\text { Neither } \\
\text { Disagree } \\
\text { nor Agree }\end{array}$} & \multicolumn{2}{|c|}{ Agree } & \multicolumn{2}{|c|}{$\begin{array}{l}\text { Strongly } \\
\text { Agree }\end{array}$} \\
\hline & & & $\mathrm{n}$ & $\%$ & $\mathrm{n}$ & & $\mathrm{n}$ & $\%$ & $\mathrm{n}$ & $\%$ \\
\hline $\begin{array}{l}\text { The GANAS program has eased my transition here to CSUEB. } \\
(n=136)\end{array}$ & 1 & $0.7 \%$ & 0 & $0.0 \%$ & 4 & $2.9 \%$ & 22 & $15.8 \%$ & 109 & $78.4 \%$ \\
\hline $\begin{array}{l}\text { The GANAS Program has helped me navigate the universities } \\
\text { policies and procedures. }(n=137)\end{array}$ & 1 & $0.7 \%$ & 1 & $0.7 \%$ & 6 & $4.3 \%$ & 28 & 20.1 & 101 & $72.7 \%$ \\
\hline $\begin{array}{l}\text { I feel that I am part of a community here in the GANAS Program. } \\
(\mathrm{n}=139)\end{array}$ & 1 & $0.7 \%$ & 0 & $0.0 \%$ & 10 & $7.2 \%$ & 38 & $27.3 \%$ & 90 & $64.7 \%$ \\
\hline $\begin{array}{l}\text { GANAS has provided opportunities for students to bond and } \\
\text { become closer as a cohort. }(\mathrm{n}=138)\end{array}$ & 2 & $1.4 \%$ & 1 & $0.7 \%$ & 12 & $8.6 \%$ & 36 & $25.9 \%$ & 87 & $62.6 \%$ \\
\hline $\begin{array}{l}\text { The GANAS staff motivated and encouraged me during this year. } \\
(\mathrm{n}=136)\end{array}$ & 2 & $1.4 \%$ & 0 & $0.0 \%$ & 5 & $3.6 \%$ & 23 & $16.5 \%$ & 106 & $76.3 \%$ \\
\hline $\begin{array}{l}\text { GANAS has increased my confidence as a college student. } \\
(\mathrm{n}=136)\end{array}$ & 1 & $0.7 \%$ & 1 & $0.7 \%$ & 7 & $5.0 \%$ & 25 & $18.0 \%$ & 102 & $73.4 \%$ \\
\hline
\end{tabular}

Along the same lines of building confidence, the survey asked students about visiting faculty office hours. Students reported visiting offices hours, on average, 2-3 times per quarter. In the focus group interviews, when participants were asked if GANAS increased their comfort approaching faculty, students elaborated on the difference between how they interacted with their professors at the community college versus at East Bay: 
"Starting out in the community college, I didn't have a program like GANAS so I would just go to the counselor's office like, what do I need? ... So when it came GANAS, especially with the seminar, when we had the guest speakers come in from the different departments it definitely opened it up. Because at that point it was like, well I'm here to get my stuff done. So this is my problem, or this is working for me and this isn't. So how are you going to help me fix that? It did help me with [my major] department too because it allowed me to become closer to some of my teachers in that department too. I mean, the connection is not quite as strong as it is here in GANAS, but it did help me to be like, You know what? So what if I need the help. I'm gonna go get it. And I used to never go to office hours until I started going to GANAS... After the first year, I knew if I needed to finish I needed to do the same thing I did with GANAS, that was to go to office hours. Go to the tutoring and all those sessions and speak up and say this is what I need. Figure it out and get it done between me and the teachers."

One student also made the comparison between the GANAS professors and other faculty: "So because I wasn't in that last class, I did get to see like how a professor from another upper division GE course kind of interacts with a student. And I felt like I was just, like treated like a number. Whereas like with Luz [and others] ...they actually know my name. They did like take more interest in [me] like, how are you doing at least? And it wasn't just me just like, going to class and like being left off. Just another student in the back of the class. So ... I guess [GANAS 
professors] care more about like their students. Or you felt like they cared more about you and whether you got through the class."

While the program encourages its participants to maintain communication with all of the faculty that teach their courses, in and out of GANAS, there clearly is a special bond that develops between the GANAS faculty and the participants.

"I think we can all agree that the sandwich of Luz and Maria were the best part of the experience and the year together. I think it was perfect to start with someone as dynamic as Luz. To just like, cannonball you into what GANAS is going to be about. And for you to fall in love with everything that is GANAS and everything that is Luz. And then end with someone as equally dynamic and awesome and passionate like Maria. And to introduce you to this topic that you never thought that you would love so much, but it's because of her personality and her passion that is just so infectious and wonderful to be around. So I loved Luz and Maria. They were my favorite part of our first year faculty. Because of their... just love for life and their love for their area of study and love for us. Which was so transparent, too. And I think that was probably what made me love it so much, out of all the professors I've had, and I've had a lot because I've been in school for a long time, their love for us was genuine. And you can feel it, and you can see it, and it was... They would always go above and beyond. Not to just teach us the subject but to teach us to love life, and to love ourselves, to love each other, and to love our culture. Like, THAT is what I loved about them." 


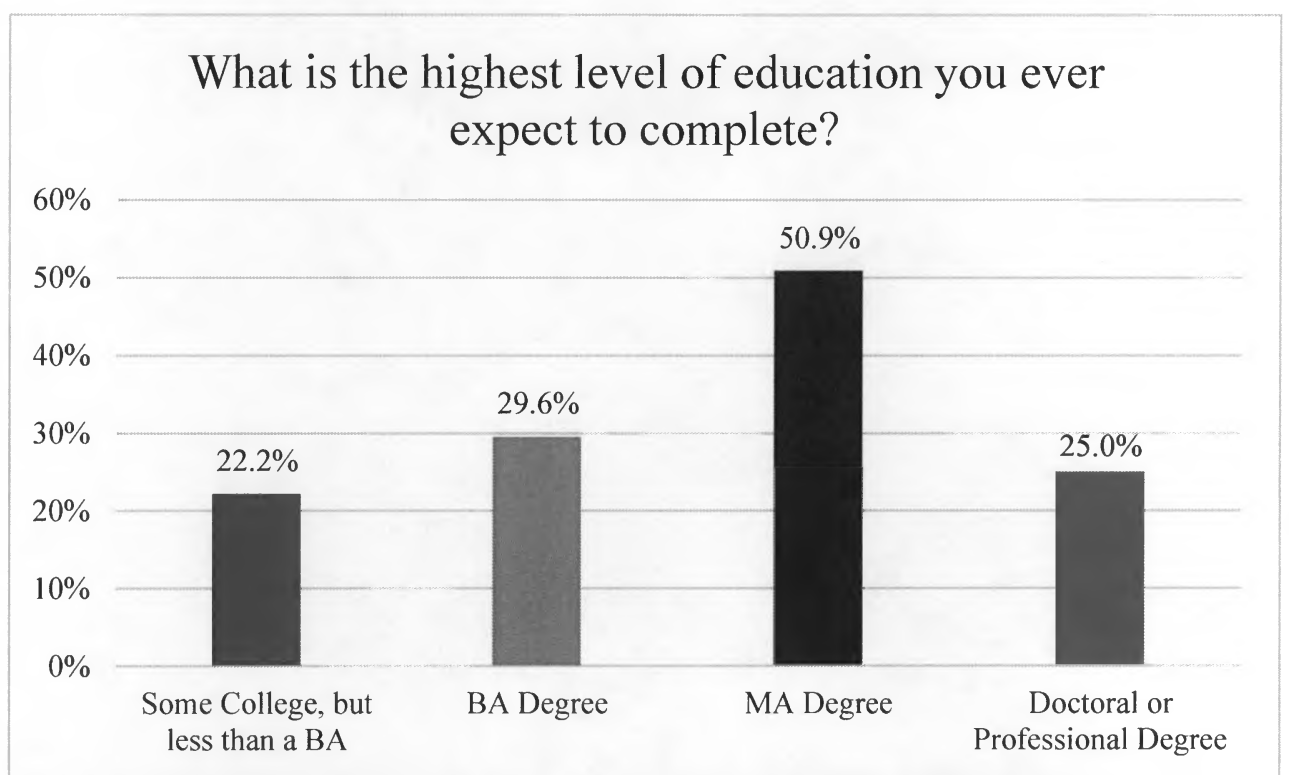

Figure 4.3. Percentage of Survey Responses - Educational Aspirations $(\mathrm{n}=213)$

Finally, the last question pulled from the GANAS year-end survey asked about the students' educational aspirations. As you can see in Figure 4.2, nearly a quarter of the respondents $(22.2 \%)$ expect that they would complete some college but not earn their bachelor's degree. According to program records, only $4.2 \%$ of GANAS participants have left Cal State East Bay without completing a degree, others are still working toward it, and far more have actually earned their baccalaureate degree.

Looking back on Figure 4.1, it is surprising to see this response. With a graduation rate of $85.7 \%$ in four years, and students reporting high instances of confidence and motivation, it is difficult to imagine participants responding in this way and interesting that so many would underestimate their ability to complete their degree.

Summary of findings. This chapter reported the findings from a program evaluation, using a mixed methods design, with the aim of examining the following 
research questions: 1) Does participation in the GANAS Program at Cal State East Bay impact the academic progress of its transfer students? 2) How do the services and activities that the program provides result in satisfactory academic progress?

In response to the first question, the study found that graduates of the GANAS Program are both overrepresented in the combined first and second years after transfer, and underrepresented in the combined third and fourth year after transfer, meaning that GANAS participants graduate faster compared to their counterparts. It was also found that on average, the East Bay GPA of a student in the GANAS program is .097 points higher than their counterparts, despite serving students who identify with several underrepresented populations which are found to be correlated with lower GPAs. Therefore, it was found that the GANAS Program does have an impact on the academic progress of its participants, and it is a positive one.

In response to the second question, the study found that survey responses indicated high frequencies of satisfactory experiences in all aspects of the program. Focus group data highlighted the human connection that students felt as participants in the program. The testimonies of connections to the GANAS staff, faculty, and to each other as predictors of success were endless.

In conclusion, findings from this study indicate that there are some relationships between GANAS participation and successful outcomes, but also that this is not yet a fully matured program. It is only in its $5^{\text {th }}$ year. The fact that there are some positive indications says that the program is on the right track, but that there is room for 
improvement. Conclusions drawn from the findings presented in this chapter are discussed in detail in Chapter 5 . 


\section{Chapter Five: Discussion and Recommendations}

\section{Overview}

The purpose of this study is to determine if and how services provided by the GANAS Program impact the academic progress of its participants. In particular, this study aims to assess the impact of services on its participants' time to degree and grade point average, as well as highlight the student experience while a participant in the program. A mixed methods design to employ a formative program evaluation was used to examine the following research questions:

1. Does participation in the GANAS Program at Cal State East Bay impact the academic progress of its transfer students?

2. How do the services and activities that the program provides result in satisfactory academic progress?

This chapter begins by interpreting the research findings in order to provide recommendations to key stakeholders within the GANAS Program, as well as to leadership who oversee transfer initiatives at Cal State East Bay. A discussion of the implications of these findings follows. The chapter concludes with recommendations for future research and action.

\section{Interpretation of the Findings}

As stated in Chapter 1, it was projected that the GANAS Program would have a positive impact on the academic progress of its participants. The hypothesis of this study 
suggested that there is a relationship between participation in the GANAS Program and student outcomes. The combination of intrusive advising, peer mentoring, and participation in an academic learning community - the key components of the program would lead to higher graduation rates, grade point averages, and levels of engagement of participants compared to their counterparts.

The study did find positive indications in relation to GANAS and the academic progress of its participants, as well as connections to certain structures of the program that showed to be meaningful to students. To first understand why these positive indications are important beyond the fact that these students participated in GANAS, descriptive statistics had to be reviewed. When this was done, it was found that GANAS is serving many of the most vulnerable populations identified on the East Bay campus while its participants are making better academic progress than their counterparts.

While it was expected that GANAS serves high number of Latino transfers in particular $(87.3 \%)$ given this is its target audience, Latino heritage was shown to be correlated with a .078 drop in GPA. The program also had a $12.2 \%$ enrollment of Undocumented students, far exceeding the percentage (1.7\%) within the larger transfer sample group. Undocumented students were also shown to be correlated with lower GPAs than their counterparts. Similar observations and findings were shown for Pell eligible and first generation students as well - higher numbers of these students, correlating to lower achievement. 
As anticipated, there were positive significant statistical relationships between GANAS participation and academic progress. While testing graduation status alone did not reveal any significance, when broken down by time to degree, particular significance was found at the 2-year graduation and 3-year graduation level. So while GANAS did not necessarily impact whether a student graduated or not, it did impact how quickly a student attained their degree.

Further, it was found that on average, the East Bay GPA of a student in the GANAS program is .097 points higher than their counterparts. Of particular interest, was the analysis which showed that being of Latino heritage at Cal State East Bay is correlated with a drop in GPA of .078 points. With an $87.3 \%$ enrollment of Latino students in GANAS, this finding was surprising and seemed to contradict itself. But then in reviewing the focus group data, testimonies of increased confidence and motivation to succeed flooded the data and it becomes increasingly clear how the students manage to beat the odds. The intervention of the GANAS program combats that drop in GPA and over time can begin to move the needle in the opposite direction for a larger population.

Taking into account the analysis and findings of the statistical data, it can be confidently stated that GANAS does in fact impact the academic progress of its participants in a positive direction, answering my first research question. Higher graduation rates and increased GPA are strong arguments for continued if not increased service and support for the GANAS program and its participants. Further, considering the demographic composition of GANAS and all the ways that the participants it serves are 
correlated to low academic achievement, the confirmation of the original hypothesis that GANAS makes a difference, makes the findings that much more meaningful.

Due to the varied services that GANAS provides, it was difficult to statistically define which activities or services are uniquely related to the outcomes and success of the participants. So progressing forward, the review of the program records and focus group responses were critical in answering my second research question in how the academic impact is made and by what services.

The activities and services that were discussed in both the program survey records and the focus groups were: the learning community coursework, intrusive advising, and peer mentoring - which are the foundational pieces of the GANAS structure - along with community building, transition experience, and confidence.

When reviewing the findings related to the GANAS learning community and coursework, responses fell well within the scope of Agree to Strongly Agree in terms of the courses benefitting the participants and providing necessary tools. What was most exciting to learn was the depth of influence and growth that occurred through the coursework, most notably in the interactions with the faculty. Focus group interviews provided some very honest and emotional dialogue around the connections that participants have made with the GANAS faculty. Tying family traditions and history to the classroom, while simultaneously disrupting the patriarchy by empowering certain females to honor their bodies and understand the power that they hold. One student shared so eloquently how she honored her body and its role in humanity and in the same 
breath and thought spoke of the healing medicinal properties of food and the importance of passing those traditions on. In just a short amount of time, she connected the three courses to one another and to herself and her cultural identity. It was both intricate and powerful, but most importantly revealed the utter importance of the human connection that GANAS has provided through its coursework. It was also revealed that students felt that GANAS professors were more invested in them as program participants, versus their experience with outside faculty and how this motivated them to try harder in their academics. Having someone that cared about their success, made it more important to achieve. And having curriculum that related to their culture and spoke to them as individuals caused them to be more engaged and connected to what they were learning, encouraging them to do well in their courses.

It was anticipated that the review of findings within the area of intrusive advising was going to be a difficult task because there has been a staffing change in this role. The program launched in Fall of 2013with one individual in the half-time position of academic counselor, then in Summer of 2015 transitioned to another individual when the position was increased to full-time. Now, in reviewing the survey data around intrusive advising and how it works within the GANAS program, I found that the results again fell heavily in the areas of Agree to Strongly Agree for most statements, presenting that the advising component can be considered successful. Not very surprising however, just as it did with the coursework interpretations, during the focus group discussions around the advising component, dialogue inevitably shifted to who the counselor was, what their 
personality was like, and how that person cared for the participant. Less of the logistics of what their advising appointments entailed or what their educational plans looked like were discussed. Participants spoke of these individuals going "above and beyond" and reaching out in ways that not only surprised the student but made them feel cared for and looked after. One student even expressed her surprise in the extent to which she was supported during the one term she fell into academic probation, declaring in surprise, “...they're not kidding, they're really going to help me." This testimony drove home the fact that the intrusive advising component of the program also contributes directly to the academic progress especially in the case of struggling students - first in taking the time to identify if and when there is a problem, and then by reaching out and recommending interventions to get the student back on track. And in the case of students that are high achieving and making the honor list, they are also being contacted so that their efforts are recognized and encouraged to keep up the good work.

The review of data in connection with the Herman@s did not provide findings as stark as what was found with the other components. Program records show that participants are in fact meeting with their Herman@s as is required by the program however, when looking at the survey data, percentages fell a little more to the center than they did in other sections of the survey. While the responses were still positive, the percentages of agreement with the statements was closer to the $30-40 \%$ range, when other sections saw percentages in the high $50-70 \%$ ranges. Likewise, the focus group responses to the Herman@ component were also somewhat neutral in terms of participants 
benefitting from having a peer mentor. Only a few students in the focus groups chose to contribute to the response in regards to the Herman@ component, and of those that did, most shared an ambivalence toward having an assigned mentor. Although one student did admit that she felt that she was matched well with her Herman@, she didn't particularly feel one way or the other about the relationship. With one student in particular, the pairing was overwhelmingly positive and the student found a true connection to her Hermana and looks back on the relationship very fondly. Either way, as was the case with the other interpretations, most of the conversation and opinions around the Herman@s was based on whether there was a "connection" with that person, or if they were "close" or "got along." While the skills and tools that the peer mentor provided were mentioned, less of the conversation was around these factors, discussion stayed mainly around personal growth and connection. One thing that was clearly not mentioned in terms of this component however, was any relation to the participant's academic progress or achievement. This huge omission shows that this specific service is not directly impacting the outcomes of achievement of the GANAS participants.

Lastly, the non-foundational aspects of the program were reviewed and interpreted. Survey data around community building, transition, and confidence were overwhelmingly positive with most responses falling within the Strongly Agree category, some as high as $78.4 \%$. These elements of the program, while not direct services or activities promised to participants, have been shown to be pleasantly surprising contributors and key factors in what could be considered the "glue" that holds the 
GANAS community together. Again, participants highlighted the people that helped them along the way. The folks that were there for them, that supported them when they were tired or hungry or about to quit. They mentioned the outside folks that GANAS connected them to, in and out of the university, who sometimes led them in a different, more positive direction. There was no shortage of gratitude or appreciation for that human connection in the ways that the participants detailed their struggles and their stories of triumph. Each step of the story had a "thank you" to this person, or a "I couldn't have done it without" another person. Not every outcome can be guaranteed for each GANAS student, but those participants that experienced a connection to staff and faculty, that felt a sense of community, and that they were part of a family within the program, found a way to connect their successes back to GANAS, and to the people that they came in contact with because of the program.

Perhaps the most critical observation that I made as the primary researcher, was for the students to see the recognition of leadership within themselves and one another. As they told their stories and listened to others, sharing their experiences as a community, I was able to see their process of thought and response, of trying to be critical of what they experienced and digging in to tell every side of the story, often reminding one another about an experience or inside story. Sometimes they surprised themselves in their reactions and responses, especially when recognizing the growth and accomplishment that came with their GANAS experience, or the revelations shared by others. A lot of head nodding and smiling occurred, showing agreement when a peer shared a story. 
There was a freedom and healing in the genuine laughter and heartfelt tears that came out during the focus groups. Being able to see themselves clearly, as well as recognizing the struggles and successes in one another and in their shared experiences was a special moment to observe.

So while it is clear statistically that the GANAS Program as a whole makes a positive impact on its participants, in digging deeper into the individual components of the program, it is clear that the culturally relevant curriculum, and the family that is created through the learning community, along with the intrusive advising, are the key contributors to the academic progress of the GANAS participants.

\section{Implications}

As was discovered in running descriptive statistics, GANAS is serving many of the most vulnerable populations identified on the Cal State East Bay campus. The program itself was created to increase the baccalaureate attainment of Latino transfer students. The abysmal attainment rates for Latinos in the state of California has driven research and literature for years. But the needle has yet to move in any significant way. Fortunately, we now have evidence that GANAS is correlated with higher graduation rates and increased GPA. Again, strong arguments for continued service and support for the current GANAS program and its participants. With evidenced research that GANAS is making an impact on the students that it serves, and in a positive way, the implications to serve more students is inevitable. There are three ways that this may manifest. 
Replication. The easy suggestion is typically something around replication of services and or scaling. At Cal State East Bay in particular, GANAS has already been replicated in whole or in part through the Sankofa Scholars Program and the Transfer Asian Pacific American Student Success (APASS) Program, which both feature a learning community model that offers the three culturally relevant upper-division GE courses coupled with a Transfer Success Seminar, as well as advising through the equity programs. There is also a third initiative called EAST, that borrowed from the GANAS academic model in aiming to complete upper-division GE courses in a timely manner, and places transfer students into a cohort, enrolling them in all three UD GE courses together in one term. While all of these initiatives were introduced prior to this evaluation of GANAS being conducted, preliminary retention and graduation rates of GANAS students supported the idea of replication to other populations. Now having conducted this study, I will be able to share with these programs what I have found in terms of the components that directly impact academic progress, but also making sure to impart the degree to which the intentionality of the cultural relevance in both the coursework and the advising contributed to that impact.

Moving from replication to scaling, in particular at the East Bay campus, the notion of introducing more cohorts of transfers into the GANAS program, or any other at this point, is unrealistic and lacks sustainability. With more and more initiatives popping up to serve transfer students in learning communities, the pool of interested applicants from which all of these programs draw is getting smaller. Not all transfer students will 
want to partake in this type of program and some may not need it. Also, taking into consideration fluctuation in enrollment and the instability of state funds from one year to the next, proposing multiple cohorts may not be prudent for East Bay or other campuses. Similarly, there have also been queries from students and community partners as to when the university may provide GANAS-like services for first-time freshman. Most conversations have been just that, speculating. No formal requests or proposals have been made, mainly because there doesn't seem to be a high need nor the resources to move forward. Now that research on GANAS has been conducted, conversations may begin around this idea of what it could mean to serve other groups of Latino students. I am not suggesting that freshman should be the next target, but getting ahead of future conversations now with research and data is necessary. The GANAS Program grew from intentional work, focused and grounded in data and passion to make change. This will need to be done again, using data and a realistic assessment of available resources in order for other groups of students, or more specifically non-transfers, to be served and benefit from the GANAS intervention. But it needs to be explored and well thought out. This also goes for replication across the CSU system. An assessment of campuses who serve large numbers of transfers would have to be conducted to determine if a GANAS intervention would be appropriate, for Latinos or other populations. With this dissertation, one has to tools to make that assessment.

Development. While one suggestion looks to serve other outside populations of Latinos by replication, another way is to look within those that are already with us and 
expand. GANAS is helping to equip Latino students with the tools they need to create and then perform on an equitable playing field. The program is grooming future leaders to go out into the world. More thought should go into staying connected to those leaders and being more intentional as the participants graduate and move on. Building networks outside of GANAS, much like a fraternity or sorority might do, could expand influence and outreach to currently unreachable fields and careers. This could be accomplished through professional development, or workshop style interventions. While this falls somewhat within the category of mentoring, which in the case of the Herman@s wasn't found to be particularly impactful, this would be in the form of career and professional mentoring. Of course a review of literature on professional mentoring would have to be conducted, but with the low educational attainment of Latinos in particular, it can be alluded that the number of Latinos in professional positions are likely also low. By using alumni as conduits of change and creating a larger network, the benefit of community support for Latinos that is experienced within the program is expanded through GANAS to the outside community and larger Latino population.

Expansion. The last way to explore serving more students is by simply creating a tempered model of GANAS that gives students the option to participate or not in different activities. This would provide a low-touch option that can serve larger numbers of students spread over time. This model would remove the academic learning community as it is the most cost-prohibitive component of the original model, as well as the reason that most of the opt-out students in the study decided not to participate (conflict of 
schedule and fulfillment of UD GE within their major). Findings from this program evaluation revealed that the most influential piece of the program is the humanity and passion of the staff, the human connection that is established and supported. As was expressed by the students in the focus groups, having staff and faculty who care, make the students want to care more. And as noted in both the literature review and through focus groups, it is well-known that transfer students have limited time to engage on campus. Providing a less-structured model of GANAS without such a large time commitment, that still allows students to have the human interaction with staff and faculty - again perhaps through professional development or workshop sessions, faculty engagement outside of the classroom, or through culturally relevant community events could provide not only a connection for that student to a robust and caring community, but the opportunity for more students to experience the GANAS intervention.

While all of these options are viable, further conversations and research in terms of available funding, space, and human resources, would be necessary before moving forward.

\section{Recommendations for Action}

While the implications described may take time and research before coming to fruition, there are some actions that can be taken immediately with little to no cost to those involved.

GANAS Program. This study found that, in addition to the academic progress that students experience as a result of participating in the GANAS program, many of the 
areas offered by the program were met with positive responses from its participants. The one area that stands out as not being particularly exceptional is the Herman@ component. Given the ambivalence of the responses to this component, it would be my recommendation to the program that the Herman@s first be scaled back, and then perhaps made an optional aspect of the program in the future. Currently the program employs six Herman@s, with each having a caseload of 12-15 participants. While it is a requirement to meet with your Herman@ throughout your first year of the program, it is inevitable that some participants do not follow through. This leaves the Herman@, frustrated in trying to maintain contact with someone that is unresponsive, and then causes a reduction in work hours that would be spent with those participants. Lack of interest has both an emotional and financial implication for the Herman@. I would make the recommendation to scale back to just three Herman@s, therefore increasing the caseload of each mentor, providing more work hours for them, and giving them the opportunity to work with students that truly want to utilize their support. This would also free up salary funds for student staff, which could perhaps be used to hire a student assistant to focus on specialized projects. Duties could include organizing special interest workshops for participants (student panels, speakers, faculty presentations, film screenings, etc.) as well as other student-centered activities. Reallocating efforts and resources in a direction that better serves the students and their needs would be a smarter way to move forward as a program. 
A second recommendation for the GANAS Program would be to find ways to engage the GANAS faculty beyond their assigned course. Given that the participants expressed such a strong connection to the faculty, it would be beneficial to find ways for the faculty to reconnect with the participants in their second year, or through special activities. Faculty could present to the students on research they have conducted or research interests, or even serve as a speaker to share their stories of graduate school and continuing their education. This places the faculty as a role model and example of what can be accomplished through education. This is also an opportunity for GANAS to seek out other faculty on campus that may relate to the participants. New faculty are hired each year, so it would be the task of the program to learn about what faculty are on campus and how fresh energy and perspective could contribute to the learning process and ultimate academic progress of its participants. Offering the participants more ways to engage with caring and enthusiastic faculty could potentially increase the positive effects that were observed within this study.

A third recommendation for the GANAS Program would be to research and reconsider the language used in connection with describing its advising component. As a researcher I was challenged early on by my committee during the proposal phase of my process, to reconsider using the term "intrusive" in reference to the approach the program uses for advising. The concern stemmed from the seemingly aggressive nature of the word "intrusive" and how a student may react to such a word. Further, it was brought up that even in presenting my research, those outside the program, non-students, may also 
find the word to be particularly harsh or negative without an explanation. Even with context, it was suggested that some may be troubled by the term. While I did consider it, my decision to ultimately move forward in my study using the original phrase "intrusive advising" was for two reasons. First, intrusive advising was the way in which the program itself identified its advising approach. Even as the coordinator I did not see it fit to change the term for the purposes of the study, from what it has been called since the program was founded. Secondly, as it has been the term used up to this point in time, in marketing materials, brochures, websites and reports, I felt that there was a high likelihood that the GANAS participants had already been exposed to the term, and I wanted to present it in its original form to get a genuine reaction from the participants to the term. However, to make sure that the language itself was highlighted in my focus group protocol (Appendix E), when asking the students to share their experience with the advising component I gave a definition for them to consider. This was the exact focus group question: “Advising from GANAS is described as intrusive. This includes an attempt to get to know a student well, digging deeper to get to the heart of what is causing difficulty for them and recommending an appropriate intervention. How did you feel about this approach?" While one participant tangentially addressed this definition (quoted in Chapter 4, pg. 81) by suggesting some students may not want to disclose personal information with the academic counselor and to let the student create their own comfortable boundary, he was the only student to even broach the subject. So while it didn't seem that the term itself had a negative connotation among the GANAS 
participants, I felt at the conclusion of my study was the best time to address the concern. In my attempt to understand the term better and the true intent of what the founding members of the program were trying to accomplish, I spoke to several founding members as well as to other leaders in equity programs. What I found was that the term was mainly chosen because it has been used in the literature, but it also seems to be a word that is commonly used at Cal State East Bay among equity programs. However, what I also found was that the philosophy in terms of the intent behind the approach to advising is more one that is grounded in providing holistic services, in empowerment, in showing genuine care, in giving back, and in fostering resilience. Having those goals in mind and such strong intent behind the both the act of advising, and supporting a student from the role of an advisor, I would call it more revolutionary or transformational, than intrusive. My final recommendation to the program would be to further discuss and research what language others may be using, especially those who may be revolutionizing advising in the some of the same ways that GANAS is, and have a conversation around what terminology is most appropriate. This would of course include feedback and input from students.

The fourth and final recommendation I have for the GANAS Program is to use this evaluation study as a guide to improving its services. While it was found that GANAS participants graduate faster than their counterparts, very little data was collected on the experience of those that do not graduate in two or three years. And very little in terms of critical feedback was offered by participants in the focus group interviews. It is a 
recommendation for further research to gather that feedback, but in the immediate, the program can begin to focus on those students who are not graduating within the two to three years after transfer, or not graduating at all, and implement actionable interventions to assist with the gap. This would include putting a great focus on participants in their second and third year after transfer. The bulk of GANAS services, are offered only in the first year, with the exception of advising which becomes optional moving into the second year. It is my recommendation that participants beyond their first year continue to be required to meet with the GANAS Academic Counselor at least once a term. This would provide an opportunity to check academic progress, discuss any barriers or challenges, and re-evaluate the participant's graduation goal, if necessary. If participants do not comply, I would recommend a hold be placed on their account with an in-person appointment being the only way to remove the hold. Given the caseload of the GANAS Academic Counselor and the intensive first-year advising requirements, it may be necessary to enlist the assistance of a part-time counselor or to incorporate these as additional duties for another staff member in order to accomplish the task of additional required meetings. Providing a more personal connection to students beyond the first year may be a way to impact the academic progress of those graduating in more than two to three years, or not graduating at all. Having conversations with these participants as they move closer to graduation can provide them context they need in terms of not only what is necessary to graduate but what is needed for their career. This information can then help them to make informed decisions and set realistic goals, hopefully preventing them 
from spending unnecessary time and money as an undergraduate. Along the same lines, focusing on the "middle" participants in the program is also important. While the high achieving honors students have been recognized, and those that fall into academic probation get a bit of extra attention, there was no testimony as to whether those participants who fall in the middle of those two groups are recognized in any way. It would be my recommendation for the program to outreach to all students at the end of each term, regardless of academic achievement. This could be a way to continue to encourage all participants to continue the work that is being done, to always strive to do better, and to remind them that the program and its staff are ready and available to help in any instance related to their educational journey.

Cal State East Bay. As a university, Cal State East Bay has definitely increased its commitment to supporting transfer students, especially through its most recent initiatives that have been implemented in the last three years. Given the findings of my study however, and the clear indication that students are looking for the humanity in their interactions with staff and faculty, it would be my recommendation for the university to create a campaign to put students first and make it known that they do so. And while this may already be the philosophy of many staff and faculty on campus, emphasizing it for the student body can only help them to feel the connection to the campus community, and to recognize that as a campus, we are here to help. To start this off, this can be manifested in two particular ways. 
Advising. One of the things about GANAS that participants spoke about frequently was that they felt looked after and cared for, and part of that was the fact that the staff and faculty knew their name. They knew them as a person. They made the connection. Those relationships were established because participants had continued access to both GANAS staff and faculty, and trust grew organically. That can only happen over time with consistent contact. One way that the university could model that and possibly create similar results is through advising. Cal State East Bay students are not assigned academic advisors upon matriculation to the university, and advising is not required to enroll in most courses. My recommendation would be to have the university require students to meet with an academic advisor upon matriculation and have that advisor be that student's assigned advisor for their time on campus. This way a relationship can be built, the student knows that they have a someone they can approach when needed, and the advisor can then serve as that student's advocate because they know the student well. Our work at the university has to be about building relationships so that we can best support our students.

Faculty and staff engagement. The second part of that is in relation to all university employees, but in particular, faculty. Given the findings of GANAS participants' connection to faculty, it would be my recommendation that the university incorporate professional development in regards to modeling student-first behavior and emphasizing students' need to be recognized. This could be accomplished by including student panels in faculty development sessions or new faculty orientations. Students 
could engage more with faculty outside of the classroom in some of the same ways that were suggested within GANAS, by offering presentations on research being conducted, on educational pathways, or common interests. In all of these ways students have greater opportunity for the human connection and personal engagement which has been found to contribute to the success of the GANAS participants.

\section{Recommendations for Further Study}

First and foremost, a more in-depth study and evaluation of GANAS would have included separating out the Latino population from all three populations and assessing the academic progress of those groups against one another. But with such a small sample size to begin with, it would have caused further statistical errors to have to work around. For future evaluations, it will be critical to include a deeper comparison of the Latino population to be able to determine if GANAS is truly making an impact for its target audience. Along that same line, future analysis should include logistic regression on the binary outcome variables of graduation.

Additionally, as statistical analysis revealed significance of GANAS participants graduating in two and three years, it would have been enlightening to have focus group narrative from students who did not meet these milestones and to have them offer suggestions as to how the program could have assisted them in meeting these timelines. Because the focus group protocol was intentionally general in nature and focused on the overall components so as to not influence participant responses, the questions lacked the 
explicitness required to get feedback from this specific population of non-graduates and any critical feedback they could offer about the program.

While focus group interviews also revealed that the Undocumented students who participated in GANAS find higher levels of support than they did at their community colleges, further research would have to be conducted to assess the larger issue of what resources Undocumented students may need and what is lacking so that it can be addressed at the university level.

Also in the years to come, a comparison study of all three of the culturallyfocused transfer programs at Cal State East Bay should be conducted. As both Sankofa Scholars and Transfer APASS programs have components that have been modeled after GANAS, it would be interesting to discover whether the same predictors contribute to the impact the programs make on the students.

Findings and recommendations will be shared with the staff, faculty, and founders of the program, as well as influential leaders and unofficial advisory partners to the program, such as the Student Equity and Success (SEAS) department, the Office of Student Affairs, and the Office of Diversity, Leadership, and Employee Wellness; all at Cal State East Bay, as well as the Puente Statewide office locate at UC Berkeley. In sharing this, it will keep the GANAS Program accountable to its leadership and advisors, and more importantly to its participants, while also offering insight and evidence as to what works and what can be improved upon. 


\section{Conclusion}

GANAS is a young program. And as a young program it is encouraging that has been able to make some change with the students it has served. But there is more to be done. There is always more to be done. We cannot let accolades and editorials make us comfortable and complacent.

Latinos in California are the fastest growing ethnic population in the state, yet continue to have the lowest baccalaureate attainment. We as social justice leaders can no longer stand idly by as our community suffers at the hands of a broken education system and inequitable educational practices. GANAS is one way, one path, one opportunity. But it cannot be the only one. GANAS must be the stone that skips in the water, creating the infinite ripples that are needed to reach the farthest and darkest corners where our gente reside. They see us and they are waiting. We as educators are the gatekeepers. We need to be better, to do better. Together we rise. 


\section{References}

Bensimon, E.A. \& Dowd, A. (2009). Dimensions of the transfer choice gap: Experiences of Latina and Latino students who navigated transfer pathways. Harvard Educational Review, 79 (4), 632-658.

California Department of Finance, Demographic Research Unit. (2013). State and county population projections by race/ethnicity (Report P-1). Retrieved from http://www.dof.ca.gov/research/demographic/reports/projections/view.php

Campaign for College Opportunity. (2013). The state of Latinos in higher education in California. Retrieved from http://collegecampaign.org/wpcontent/uploads/2014/06/State_of_Higher_Education_Latino_FINAL-1.pdf

Campaign for College Opportunity. (2015). The state of higher education in California:

The Latino report. Retrieved from http://collegecampaign.org/portfolio/april2015-state-of-higher-education-in-california-the-latino-report/

Chavez, A. F. (2007). Islands of empowerment: Facilitating multicultural learning communities in college. International Journal of Teaching and Learning in Higher Education, 19(3), 274-288.

Considine, J. R., Mihalick, J. E., Mogi-Hein, Y. R., Penick-Parks, M. W., \& Van Aucken, P. M. (2014). "Who am I to bring diversity into the classroom?" Learning communities wrestle with creating inclusive classrooms. Journal of the Scholarship of Teaching and Learning, 14(4), 18-30. 
Coston, C. T., Lord, V. B., \& Monell, J. S. (2013). Improving the success of transfer students: Responding to risk factors. Learning Communities Research and Practice, 1(1), 22-26.

Creswell, J. W. \& Plano Clark, V. L. (2011). Designing and conducting mixed methods research (2nd edition). Thousand Oaks, CA: Sage.

CSUEB Institutional Research, Analysis, and Decision Support. (2013). Data report run by Institutional Research, requested by CSUEB Office of Student Affairs.

CSUEB WASC Report. (2014). Report submitted to Office of Academic Programs and Graduate Studies, July 24, 2014.

Dennis, J.M., Calvillo, E., \& Gonzalez, A. (2008). The role of psychosocial variables in understanding the achievement and retention of transfer students at an ethnically diverse urban university. Journal of College Student Development, 49(6), 535550.

Doolen, T. L., \& Biddlecombe, E. (2014). The impact of a cohort model learning community on first-year engineering student success. American Journal of Engineering Education, 5(1), 27-40.

Eggleston, L.E. \& Laanan, F.S. (2001). Making the Transition to the Senior Institution. New Directions for Community Colleges, 114, 87-97.

Fink, J. E., \& Hummel, M. L. (2015). With educational benefits for all: Camus inclusion through learning communities designed for underserved student populations. New Direction for Student Services, 149, 29-40. http://dx.doi.org/10.1002/ss.20115 
Firmin, M. W., Warner, S. C., Firmin, R. L., Johnson, C. B., \& Firebaugh, S. D. (2013). Attitudinal outcomes of a multicultural learning community experience: A qualitative analysis. Learning Communities Research and Practice, 1(1), 1-25.

Ford, D. Y., Howard, T. C., Harris, J. J., \& Tyson, C. A. (2000). Creating culturally responsive classrooms for gifted African American students. Journal for the Education of the Gifted, 23(4), 397-427.

Gandara, P., Larson, K., Mehan, H., \& Rumberger, R. (1998). Capturing Latino students in the academic pipeline (Report No. 1). Sacramento, CA: Chicano/Latino Policy Project.

Glennen, R.E. (1976). Intrusive college counseling. The School Counselor, 24(1), 48-50.

Geiser, S. \& Atkinson, R. (2010). Beyond the master plan: The case for restructuring baccalaureate education in California. Research \& Occasional Paper Series (CSHE 16.10). University of California, Berkeley: 2010.

Good, J.M., Halpin, G., \& Halpin, G. (2000). A promising prospect for minority retention: Students becoming peer mentors. Journal of Negro Education, 69(4), 375-383.

Jain, D., Herrera, A., Bernal, S., \& Solorzano, D. (2011). Critical race theory and the transfer function: Introducing a transfer receptive culture. Community College Journal of Research and Practice, 35, 252-266. http://dx.doi.org/10.1080/10668926.2011.526525 
Laden, B. V. (1999). Socializing and mentoring students of color: The Puente project as an exemplary celebratory socialization model. Peabody Journal of Education, $74(2), 55-74$.

Ladson-Billings, G. (1995). Toward a theory of culturally relevant pedagogy. American Educational Research journal, 32(3), 465-491.

Ladson-Billings, G. (2014). Culturally relevant pedagogy 2.0: a.k.a. the remix. Harvard Educational Review, 84(1), 74-84.

Miller, A. (2013). Institutional practices that facilitate Bachelor's degree completion for transfer students. New Directions for Higher Education, 162, 39-50. http://dx.doi.org/10.1002/he.20055

Moore, C., \& Shulock, N. (2010). Divided we fail: Improving completion and closing racial gaps in California's community colleges. Institute for Higher Education Leadership \& Policy. Retrieved from http://eric.ed.gov/?id=ED513824

Schneider, M.E. \& Ward, D.J. (2003). The role of ethnic identification and perceived social support in Latinos' adjustment to college. Hispanic Journal of Behavioral Sciences, 25(4), 539-554. http://dx.doi.org/10.1177/0739986303259306.

Suarez, A. L. (2003). Forward transfer: Strengthening the educational pipeline for Latino community college students. Community College Journal of Research and Practice, 27, 95-117. http://dx.doi.org/10.1080/10668920390128753.

Townley, G., Katz, J., Wandersman, A., Skiles, B., Schillaci, M.J., Timmerman, B.E., \& Mousseau, T.A. (2013). Exploring the role of sense of community in the 
undergraduate transfer student experience. Journal of Community Psychology, 41(3), 277-290. http://dx.doi.org/10.1002/jcop.21529

Townsend, B.K. \& Wilson, K. (2006). "A hand hold for a little bit": Factors facilitating the success of community college transfer students to a large research university. Journal of College Student Development, 47(4), 439-456. http://dx.doi.org/10.1353/csd.2006.0052.

U.S. Census Bureau. (2015). Educational Attainment. Retrieved from https://factfinder.census.gov/faces/tableservices/jsf/pages/productview.xhtml?src=

\section{$\mathrm{CF}$}

U.S. Census Bureau. (2016). Educational Attainment of the Population 18 Years and Over, by Age, Sex, Race, and Hispanic Origin: 2016. Retrieved from https://www.census.gov/data/tables/2016/demo/education-attainment/cpsdetailed-tables.html

Wang, X. (2009). Baccalaureate attainment and college persistence of community college transfer students at four-year institutions. Research in Higher Education, 50(6), 570-588. http://dx.doi.org/10.1007/s11162-009-9133-z.

Wawrzynski, M.R. \& Sedlacek, W.E. (2003). Race and gender differences in the transfer student experience. Journal of College Student Development, 44(4), 489-501.

Wortham, S., \& Contreras, M. (2002). Struggling toward culturally relevant pedagogy in the Latino diaspora. Journal of Latinos in Education, 1(2), 133-144. 
Yosso, T. J., \& Solórzano, D. G. (2006). Leaks in the Chicana and Chicano educational pipeline. Latino Policy \& Issues Brief, Number 13. UCLA Chicano Studies Research Center (NJ1). Retrieved from http://eric.ed.gov/?id=ED493404 


\section{Appendix A Focus Group Recruitment Email}

Email Subject Line: GANAS Focus Group - Invitation to Participate in a Doctoral Research Study on GANAS

Dear Student,

As part of my research toward completing my doctoral dissertation, I will be holding three focus groups as part of the program evaluation I am conducting on the GANAS Program. The discussion that will take place in these groups is aimed at understanding the impact the program has on the academic progress of its participants. As a current or alumni participant in the GANAS program, I would like to invite you to participate in one of the three upcoming focus group gatherings. You and your peers are in a position to give first-hand feedback about your experience in the program, and contribute the voice of the students to this study.

Each focus group will consist of small number of GANAS students and/or alumni, assembled to participate in a discussion about the impact of the program on your academic progress. Questions will be posed to the group as a whole; you can choose which questions you would like to respond to, and you can leave the group at any time. Each focus group will take no more than 75 minutes in length and will be informal.

Your responses to the questions will be kept confidential. Each participant will be assigned an alias to help ensure that personal identifiers are not revealed during the analysis and write up of any findings. There is no compensation for participating in this study.

If you would like to participate, please respond to this email and specify which of following dates is most convenient for you.

Wednesday, August 16, 2017; 5-6:30pm (Alumni only)

Tuesday, August 22, 2017; 5-6:30pm

Wednesday, August 23, 2017; 5-6:30pm

I will confirm your participation by email. If you have any questions, please do not hesitate to ask. I am happy to clarify or elaborate to address any concerns.

Thank you in advance for your consideration, Melissa Cervantes

Doctoral Student in Educational Leadership

San Francisco State University 


\section{Appendix B \\ Informed Consent Form \\ San Francisco State University \\ Informed Consent to Participate in Research \\ Program Evaluation: Gaining Access 'N Academic Success (GANAS)}

\section{A. PURPOSE AND BACKGROUND}

The purpose of this research is to learn how the GANAS Program at Cal State East Bay impacts the academic progress of its participants.

The researcher, Melissa Cervantes, is a graduate student at San Francisco State University conducting research for a doctoral degree in Educational Leadership. You are being asked to participate in this study because at some point in your enrollment at $\mathrm{Cal}$ State East Bay, you were a participant in the GANAS Program.

\section{B. PROCEDURES}

If you agree to participate in this research, the following will occur:

- you will be contacted and invited to participate in the study.

- you will be emailed details regarding time and location of meeting.

- you will sign a consent form and participate in an on-campus focus group, which will last 45-75 minutes.

- the focus group will be audio and video recorded to ensure accuracy in reporting your statements.

- the interview will take place at the Cal State East Bay campus for your convenience.

- the researcher may contact you up to one month after meeting with the focus group for clarification purposes. If clarification is needed, the second meeting will not take any longer than fifteen minutes.

- total time commitment will be no more than two hours

- Data will be collected from the Office of Institutional Research, Analysis, and Decision Support (IRADS) at Cal State East Bay on your academic performance including GPA, terms enrolled, units attempted, upper-division GE course completion, and degree completion (if applicable).

- Program records will also be reviewed to evaluate level of participation in program activities and responses to end-of-year surveys.

C. RISKS

Risks from participation in this study are minor. There is a risk of loss of privacy. To minimize this, no names or identities will be used in any published reports of the research. If a direct quote is used, a pseudonym will replace the participant's name. Only the researcher and the researcher's faculty advisor will have access to the research data. 
Data collection from IRADS also poses a risk to privacy as participant's academic performance records will be included, and will be used to triangulate the data from program records and the focus groups. Risk will be minimized as all quantitative data will be presented as tables in the final report and will not contain any names or identifiable information.

Risks from the focus groups are also minor. There is a risk of a potential loss of privacy due to the use of audio and video recording, however neither medium will be included in any published report of the research. There also may be a risk of undue influence given the researcher is a staff member in the GANAS Program, which is the topic of evaluation; however, participants will be reminded that they only need to respond to questions they feel comfortable answering and can end the interview or exit the focus group at any time.

1. Also, because the focus groups include discussion of personal opinions, extra measures will be taken to protect each participant's privacy. The researcher will begin the focus group by asking the participants to agree to the importance of keeping information discussed in the focus group confidential. The researcher will then ask each participant to verbally agree to keep everything discussed in the room confidential, and will remind them at the end of the research period not to discuss the material outside.

2. Only the researcher and her faculty advisor will have access to the data collected. Any audio/video recordings or transcriptions will be stored for ten years and then will be destroyed. The researcher and faculty advisor will not be keeping any of the information indefinitely.

\section{CONFIDENTIALITY}

The research data will be kept in the secure location of the researcher's faculty advisor's office where only the researcher and faculty advisor will have access to the data. All research data will be stored in a device with full disk encryption and password protection and will be kept in accordance to CSU policy of storing student information for a minimum of three years. However, all data in its de-identified form may be stored indefinitely for future research purposes.

\section{E. DIRECT BENEFITS}

There will be no direct benefits to the participant.

\section{F. COSTS}

There will be no cost to you for participating in this research.

\section{G. COMPENSATION}

There will be no compensation for participating in this research. 


\section{H. ALTERNATIVES}

The alternative is not to participate in the research.

\section{QUESTIONS}

You have spoken with Melissa Cervantes about this study and have had your questions answered. If you have any further questions about the study, you may contact the researcher by email at mcervan2@mail.sfsu.edu or you may contact the researcher's advisor, Professor Gen at sgen@sfsu.edu.

Questions about your rights as a study participant, or comments or complaints about the study, may also be addressed to the Human and Animal Protections at (415) 338-1093 or protocol@sfsu.edu.

\section{J. CONSENT}

You have been given a copy of this consent form to keep.

PARTICIPATION IN THIS RESEARCH IS VOLUNTARY. You are free to decline to participate in this research, or to withdraw your participation at any point, without penalty. Your decision whether or not to participate in this research will have no influence on your present or future status at San Francisco State University.

Signature

$$
\text { Research Participant }
$$

Signature

$$
\text { Researcher }
$$

Date:

Date: 


\section{Appendix C}

Spearman's Correlations Matrix

\begin{tabular}{|c|c|c|c|c|c|c|c|c|c|c|c|c|c|c|c|c|c|c|c|c|c|}
\hline \multirow{4}{*}{$\begin{array}{l}\text { Correlations } \\
\overbrace{}^{\text {Comparison Groups }}\end{array}$} & \multicolumn{4}{|c|}{ Independent Variables } & \multirow{2}{*}{\multicolumn{8}{|c|}{ Dependent Variables }} & \multicolumn{9}{|c|}{ Confounding Variables } \\
\hline & \multirow{3}{*}{$\frac{\text { COMPGRPS }}{1}$} & \multirow{3}{*}{\begin{tabular}{|l|} 
GNGPTP \\
$830^{\circ}$ \\
0000
\end{tabular}} & \multirow{2}{*}{\begin{tabular}{|c|} 
GNSACC \\
$546^{\circ}$
\end{tabular}} & \multirow{2}{*}{\begin{tabular}{|l|} 
NONELGAPF \\
$-1.000^{\prime}$
\end{tabular}} & \multirow{2}{*}{\multicolumn{2}{|c|}{\begin{tabular}{|l|l|} 
GRADSTAAT TMTDEGCL \\
0.001
\end{tabular}}} & & & \multirow{2}{*}{$\frac{Y^{\prime R 3 G R A D}}{-020^{\circ}}$} & \multirow{2}{*}{$\begin{array}{ll}\text { YRAGRAD } \\
0005\end{array}$} & \multirow{2}{*}{$\frac{E B G P A}{-0.013}$} & \multirow{2}{*}{\begin{tabular}{|l|} 
FTCONT \\
$047^{\prime \prime}$
\end{tabular}} & \multirow{2}{*}{\begin{tabular}{|l|} 
ETHNCAT \\
$104^{*}$
\end{tabular}} & & GNDR & & CITZ & FSTGEN & ENTTEAR & TRUNIT & TRGPA \\
\hline & & & & & & & \begin{tabular}{|l|} 
YR1GRAD \\
0.018 \\
\end{tabular} & $\begin{array}{l}\text { YR2GRAD } \\
.025\end{array}$ & & & & & & $195^{\prime \prime}$ & $.049^{\circ}$ & $.040^{\circ}$ & $-059^{\prime \prime}$ & $.063^{\prime \prime}$ & $044^{*}$ & $.038^{\prime \prime}$ & $.027^{2}$ \\
\hline & & & 0.000 & 0.000 & 0.917 & 0591 & 0.059 & 0.011 & 0.040 & 0.616 & 0.171 & 0.000 & 0.000 & 0.000 & 0.000 & 0.000 & 0.000 & 0.000 & 0.000 & 0.000 & 0.005 \\
\hline$\stackrel{\infty}{\infty}$ GANAS Parficipant & $830^{\prime \prime}$ & 1 & -0.013 & $-838^{\prime \prime}$ & 0.007 & 0.000 & -0.014 & $027^{\circ}$ & -0.014 & -0.012 & -0.010 & $.058^{-}$ & $101^{\prime \prime}$ & $.193^{\circ}$ & $.037^{-}$ & $.052^{\prime \prime}$ & $-.057^{*}$ & $059^{-}$ & $030^{\circ}$ & $.034^{-4}$ & $.032^{-}$ \\
\hline & 0.000 & & 0.176 & 0.000 & 0.485 & 0.964 & 0.154 & 0.005 & 0.158 & 0.238 & 0.284 & 0.000 & 0.000 & 0.000 & 0.000 & 0.000 & 0.000 & 0.000 & 0.002 & 0.000 & 0.001 \\
\hline GANAS Accepted/optod Out & $546^{\prime \prime}$ & -0.013 & 1 & $-535^{\prime \prime}$ & -0.008 & -0.010 & -0.012 & 0.003 & -0.015 & 0.009 & -0.008 & -0.003 & $.036^{\circ}$ & $060^{\circ}$ & $.033^{\circ}$ & 0.006 & $-020^{\circ}$ & $.024^{\circ}$ & $033^{\circ}$ & -0.017 & -0.002 \\
\hline & 0.000 & 0.176 & & 0.000 & 0.389 & 0.302 & 0.211 & 0.728 & 0.120 & 0.381 & 0.399 & 0.795 & 0.000 & 0.000 & 0.001 & 0.546 & 0.036 & 0.013 & 0.001 & 0.079 & 0.851 \\
\hline Non-EllgibleNen-Applicant & $-1.000^{\prime \prime}$ & $-838^{\prime \prime}$ & $-.535^{\prime \prime}$ & 1 & -0.001 & 0.005 & 0.018 & $-.025^{\circ}$ & $020^{\circ}$ & 0.005 & 0.013 & $-048^{-}$ & $-.105^{\prime \prime}$ & $-196^{-1}$ & $-.049^{-1}$ & $041^{\prime \prime}$ & $060^{-}$ & $-063^{2}$ & $.044^{\prime \prime}$ & $.038^{-2}$ & 028 \\
\hline & 0.000 & 0.000 & 0.000 & & 0.905 & 0.599 & 0.059 & 0.011 & 0.041 & 0.604 & 0.172 & 0.000 & 0.000 & 0.000 & 0.000 & 0.000 & 0.000 & 0.000 & 0000 & 0.000 & 0.005 \\
\hline Graduation Status & 0.001 & 0.007 & -0.008 & -0.001 & 1 & $968 "$ & $.160^{\circ}$ & $666^{\prime \prime}$ & 478 & $.175^{\circ}$ & $279^{\circ}$ & 0.004 & $-045^{\circ}$ & $-027^{-1}$ & $.052^{\prime \prime}$ & $.105^{\circ}$ & $020^{\circ}$ & 0.015 & $-.577^{\circ}$ & $.070^{\circ}$ & $117^{-}$ \\
\hline & 0.917 & 0.485 & 0.389 & 0.905 & & 0000 & 0.000 & 0.000 & 0.000 & 0.000 & 0.000 & 0.712 & 0.000 & 0.006 & 0,000 & 0.000 & 0.042 & 0.115 & 0.000 & 0.000 & 0000 \\
\hline Time to Degree Collapsed & 0.005 & 0.00 & -00 & 0005 & $968^{-1}$ & 1 & $.114^{-2}$ & $47^{\circ}$ & $659^{\circ}$ & $242^{\prime \prime}$ & $237^{\circ}$ & $-0.05^{\circ}$ & $-042^{\circ}$ & $-035^{"}$ & $.043^{\prime \prime}$ & $.10^{\prime \prime}$ & $.026^{-}$ & 001 & $-604^{-2}$ & $048^{*}$ & $100^{*}$ \\
\hline & 0.591 & 0.9 & 0.3 & 0.599 & 0.000 & & 0.000 & 0.000 & 0.000 & 0.000 & 0.000 & 0.000 & 0.000 & 0.000 & 0.000 & 0.000 & 0.008 & & 0.000 & 0.000 & 0.000 \\
\hline 1 Year Graduato & -0.018 & -0.014 & -0.012 & 0018 & $.160^{\circ}$ & $114^{*}$ & 1 & $.073^{-}$ & -053 & $.019^{\circ}$ & $102^{n}$ & $.069^{\prime \prime}$ & -0.01 & -0.0 & $.049^{-1}$ & $086^{-1}$ & 0 & 3 & - & $169^{-1}$ & $051^{-\prime}$ \\
\hline & 0.059 & 0.154 & 0.211 & 0.059 & 0.000 & 0.000 & & 0.000 & 0.000 & 0.047 & 0.000 & 0.000 & 0.084 & 0.093 & 0.000 & 0.000 & 0.019 & 0.185 & 0.005 & 0.000 & 0.000 \\
\hline 2 Year Graduate & $.025^{\circ}$ & $.027^{\circ}$ & 0.003 & $.025^{\circ}$ & $666^{\circ}$ & $473^{\circ}$ & $-.073^{-1}$ & 1 & $.220^{2}$ & $.081^{2}$ & $266^{2}$ & $.154^{-2}$ & .030 & 0.012 & $.044^{*}$ & .024 & -0.012 & 0.008 & -272" & $.056^{\circ}$ & $.096^{\prime \prime}$ \\
\hline & 0.011 & 0.005 & 0.728 & 0.011 & 0.000 & 0.000 & 0.000 & & 0.000 & 0.000 & 0.000 & 0.000 & 0.002 & 0.212 & 0.000 & 0.014 & 0.216 & 0.405 & 0.000 & 0.000 & 0.000 \\
\hline 3 Year Graduats & $.020^{\circ}$ & -0.014 & -0.015 & $020^{\circ}$ & $.478^{-1}$ & $659^{\prime \prime}$ & $-053^{\prime \prime}$ & $-.220^{\circ}$ & 1 & $-058^{-}$ & $.045^{\circ}$ & $-161 "$ & .021 & $.040^{\circ}$ & -0.001 & $.069^{-}$ & $028^{-1}$ & 0.013 & $-398^{\prime \prime}$ & $.024^{\circ}$ & $042^{*}$ \\
\hline & 0.040 & 0.158 & 0.120 & 0.041 & 0.000 & 0.000 & 0.000 & 0.000 & & 0.000 & 0.000 & 0.000 & 0.032 & 0.000 & 0.933 & 0.000 & 0.004 & 0.188 & 0.000 & 0.014 & 0.000 \\
\hline 4 Year Graduats & -0.005 & -0.012 & 0.009 & 0.005 & $.175^{\prime \prime}$ & $242^{\prime \prime}$ & $-019^{\circ}$ & $-.081^{\prime \prime}$ & $-.058^{\circ}$ & 1 & $.030^{\prime \prime}$ & $-.122^{\prime \prime}$ & 0.001 & -0.018 & 0.006 & $.045^{\prime \prime}$ & 0.015 & 0.010 & $-.198^{\prime \prime}$ & .022 & .031 \\
\hline & 0.616 & 0.238 & 0.381 & 0.604 & 0.000 & 0.000 & 0.047 & 0.000 & 0.000 & & 0.002 & 0.000 & 0.908 & 0.062 & 0.573 & 0.000 & 0.117 & 0.316 & 0.000 & 0.023 & 0.002 \\
\hline East Bay GPA & -0.013 & -0.010 & -0008 & 0013 & $277^{\prime \prime}$ & $237^{\prime \prime}$ & $.102^{n}$ & $266^{\circ}$ & $045^{\prime \prime}$ & $.030^{\circ}$ & 1 & $.085^{\prime \prime}$ & $-090^{\prime \prime}$ & $-062^{\prime \prime}$ & $.074^{n}$ & $081 "$ & $.027^{-1}$ & $-048^{*}-2>3$ & -0.002 & $107^{-1}$ & $475^{\prime \prime}$ \\
\hline & 0.171 & $022-2>$ & 0.399 & 0.17 & 0.00 & 0.000 & 0.000 & 0.000 & 0.000 & 0.002 & & 0.000 & 0.00 & 0.00 & 0.00 & 0.000 & 0.005 & 0.000 & 0.811 & 0.000 & 0.000 \\
\hline Full-Time Cont Enrollment & $047^{n}$ & $.058^{\prime \prime}$ & -0.003 & $-.048^{\prime \prime}$ & 0.004 & $-.055^{\circ}$ & $.069^{-}$ & $.154^{-}$ & $-.161^{\circ}$ & $-.122^{-}$ & $085^{\circ}$ & 1 & 0.018 & 0.006 & -0.011 & $-157^{\circ}$ & $.038^{-1}$ & -0.005 & $162^{-}$ & -0.016 & $.025^{-}$ \\
\hline & 0.000 & 0.000 & 0.795 & 0.000 & 0.712 & 0.000 & 0.000 & 0.000 & 0.000 & 0.000 & 0.000 & & 0.058 & 0.559 & 0.261 & 0.000 & 0.000 & 0.642 & 0.000 & 0.109 & 0.009 \\
\hline Ethnic Category & $104^{-}$ & .10 & $.036^{-}$ & $-105^{\prime \prime}$ & $-.045^{\prime \prime}(x-3)$ & $-042^{*}$ & -0.017 & $.030^{-1}$ & $-021^{\circ}$ & 0.001 & $.090^{\prime \prime}$ & 0.018 & 1 & $502^{\prime \prime}$ & $050^{-}$ & $-026^{4}$ & 0.003 & $108^{\prime \prime}$ & $023^{\circ}$ & $.054^{-}$ & $.085^{\prime \prime}$ \\
\hline & 0.000 & 0.000 & 0.000 & 0.000 & 0.000 & 0.000 & 0.084 & 0.002 & 0.032 & 0.908 & 0.000 & 0058 & & 0.000 & 0.000 & 0.008 & 0.756 & 0.000 & 0.020 & 0.000 & 0.000 \\
\hline Latino Heritage & $195^{\circ}$ & $.193^{\circ}$ & $060^{\circ}$ & $-.196^{\circ}$ & $-027^{\prime \prime}$ & $-035^{\circ}$ & -0.016 & 0.012 & $.040^{-}$ & -0.018 & $.062^{\prime \prime}$ & 0.006 & $.502^{\prime \prime}$ & 1 & $.072^{-}$ & $.071^{\prime \prime}$ & $-.152^{-}$ & $202^{\circ}$ & $.049^{\prime \prime}$ & $-.050^{-1}$ & $.043^{\prime \prime}$ \\
\hline & 0.000 & 0.000 & 0.000 & 0.000 & 0.006 & 0.000 & 0.093 & 0.212 & 0.000 & 0.062 & 0.000 & 0.559 & 0.000 & & 0.000 & 0.000 & 0.000 & 0.000 & 0000 & 0.000 & 0.000 \\
\hline Gendor & $.049^{*}$ & $.037^{\prime \prime}$ & $033^{\circ}$ & $.049^{n}$ & $.052^{*}$ & $.043^{-1}$ & $049^{\circ}$ & $.044^{\circ}$ & -0.001 & 0.006 & $.074^{-}$ & -0.011 & .050 & $.072^{\prime \prime}$ & 1 & $034^{\circ}$ & -0.004 & $.096^{\prime \prime}$ & $-020^{\circ}$ & -0.018 & $.103^{\circ}$ \\
\hline & 0.000 & & 0.001 & 0.000 & 0.000 & 0.000 & 0.000 & 0.000 & 0.933 & 0.573 & 0.000 & 0261 & 0.000 & 0.000 & & 0.001 & 0.656 & 0.000 & 0.040 & 0.059 & 0.000 \\
\hline CurrantAge & $.040^{-1}$ & $-.052^{\circ}$ & 0.006 & .04 & $.105^{5}$ & $.110^{\circ}$ & $.086^{*}$ & $.024^{\circ}$ & $.069^{\circ}$ & $.045^{\prime \prime}$ & $081^{-}$ & $-.157^{-}$ & $-026^{\circ}$ & .07 & $.034^{\prime \prime}$ & 1 & $.043^{-}$ & $.019^{\circ}$ & $-258^{-1}$ & $318^{-2}$ & 0.016 \\
\hline & 0.000 & 0.000 & 0.5 & 0.0 & 0.000 & 0.000 & 0.000 & 0 & 0.000 & 0.0 & 0.000 & 0.000 & 0.008 & 0.000 & 0.001 & & 0.000 & 0.048 & 0.000 & 0.000 & 0.095 \\
\hline Clizenship & $.059^{-}$ & $-057^{-1}$ & $.020^{\circ}$ & $.060^{\circ}$ & $020^{\circ}$ & $026^{-1}$ & $023^{\circ}$ & -0.012 & $028^{\circ}$ & 0.0 & $027^{\circ}$ & $038^{\prime \prime}$ & 0.00 & $.152^{\prime \prime}$ & -0.004 & $043^{\circ}$ & 1 & $.034^{-}$ & $.020^{\circ}$ & $.025^{\prime \prime}$ & $046^{-}$ \\
\hline & 0.000 & 0.000 & 0.036 & 0.000 & 0.0 & 0.008 & 0.019 & 0.21 & 00 & 0.1 & 0.005 & 0.000 & 0.7 & 0000 & 0.656 & 0.000 & & 0.000 & 0.042 & 0.009 & 0.000 \\
\hline First Generation & $063^{*}$ & .05 & $024^{\circ}$ & $.063^{3}$ & $=$ & 0. & -0.0 & & & 0.0 & -.04 & -0.0 & .10 & 202 & $.096^{-1}$ & $.019^{\circ}$ & $-.034^{-}$ & 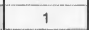 & $.030^{\circ}$ & & 0.013 \\
\hline & 0.000 & 0.000 & 0.013 & 0.000 & 0.115 & 0.078 & 0.185 & 0.405 & 0.1 & 0.3 & 0.0 & 0.642 & 0.00 & 0.000 & 0.000 & 0.048 & 0.000 & & 0.002 & 0.944 & 0.191 \\
\hline Year of Entry & $.044^{*}$ & 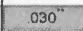 & 03 & & & $-604^{4}$ & & -27 & -39 & $.198^{\circ}$ & -0.002 & .162 & .02 & $.049^{\prime \prime}$ & $.020^{\circ}$ & $.258^{\circ}$ & $-020^{\circ}$ & $.030^{-1}$ & 1 & $.034^{\prime \prime}$ & -0.018 \\
\hline & 0.000 & 0.002 & 0.0 & 0.0 & 0.0 & 0.0 & 0.005 & 0.0 & 0.0 & 0.0 & 0.8 & 0. & 0.0 & 0.00 & 0.040 & 0.000 & 0.042 & 0.002 & & 0.000 & 0.062 \\
\hline Transtior Units & $.038^{\prime \prime}$ & .03 & -0.017 & .0 & .07 & .04 & $.169^{\circ}$ & .o & -0.2 & -.022 & $107^{-2}$ & -0.016 & .05 & .05 & -0.018 & $318^{\prime \prime}$ & $.025^{\circ}$ & 0.001 & $-034^{\prime \prime}$ & 1 & $.030^{\circ}$ \\
\hline & 0.000 & 0.000 & 0.079 & 0.000 & 0.000 & 0.000 & 0.000 & 0.000 & 0.014 & 0.023 & 0.000 & 0.109 & 0.00 & 0.000 & 0.059 & 0.000 & 0.009 & 0.944 & 0.000 & & 0.002 \\
\hline Transter GPA & $.027^{-}$ & $-032^{\prime \prime}$ & -0.002 & $028^{\prime \prime}$ & $.117^{\circ}$ & $103^{n}$ & $051^{-}$ & $096^{\prime \prime}$ & $.042^{-1}$ & $-031^{\circ}$ & $475^{\circ}$ & $026^{-}$ & $.085^{\prime \prime}$ & $.043^{-}$ & $103^{\prime \prime}$ & 0.016 & $046^{\prime \prime}$ & 0.013 & -0.018 & $030^{\circ}$ & 1 \\
\hline & 0.005 & 0.001 & 0.851 & 0.005 & 0.000 & 0.000 & 0.000 & 0.000 & 0.000 & 0.002 & 0.000 & 0.009 & 0.000 & 0.000 & 0.000 & 0.095 & 0.000 & 0.191 & 0.062 & 0.002 & \\
\hline
\end{tabular}




\section{Appendix D}

Cumulative Graduation Rates by Cohort Year and 4-Year Average

\begin{tabular}{|c|c|c|c|c|c|c|c|c|c|c|c|c|c|}
\hline \multirow[b]{2}{*}{$\begin{array}{l}\text { Cohort By } \\
\text { Year }\end{array}$} & \multirow[b]{2}{*}{$\begin{array}{c}\text { Cohort } \\
\text { Total } \\
\end{array}$} & \multicolumn{3}{|c|}{ 1st Year } & \multicolumn{3}{|c|}{ 2nd Year } & \multicolumn{3}{|c|}{ 3rd Year } & \multicolumn{3}{|c|}{ 4th Year } \\
\hline & & $\begin{array}{c}\# \\
\text { Comp } \\
\end{array}$ & Calculation & $\begin{array}{c}\text { Gra } \\
d \\
\text { Rate } \\
\end{array}$ & $\begin{array}{c}\# \\
\text { Comp } \\
\end{array}$ & Calculation & $\begin{array}{l}\text { Grad } \\
\text { Rate } \\
\end{array}$ & \# Comp & Calculation & $\begin{array}{l}\text { Grad } \\
\text { Rate } \\
\end{array}$ & $\begin{array}{c}\# \\
\text { Comp } \\
\end{array}$ & Calculation & $\begin{array}{l}\text { Grad } \\
\text { Rate } \\
\end{array}$ \\
\hline \multicolumn{14}{|l|}{ GANAS } \\
\hline 2013-2014 & 35 & 0 & $0 / 35=0$ & $\begin{array}{l}0.0 \\
\%\end{array}$ & 22 & $22 / 35=0.6285$ & $62.9 \%$ & 6 & $28 / 35=0.8$ & $80.0 \%$ & 2 & $30 / 35=0.8571$ & $\begin{array}{c}85.7 \\
\%\end{array}$ \\
\hline $2014-2015$ & 36 & 1 & $1 / 36=0.0277$ & $\begin{array}{l}2.8 \\
\% \\
\end{array}$ & 11 & $12 / 36=0.3333$ & $33.3 \%$ & 16 & $28 / 36=0.7777$ & $77.8 \%$ & & & - \\
\hline 2015-2016 & 70 & 0 & $0 / 70=0$ & $\begin{array}{l}0.0 \\
\%\end{array}$ & 34 & $34 / 70=0.4857$ & $48.6 \%$ & & & -- & & & - \\
\hline $2016-2017$ & 72 & 0 & $0 / 72=0$ & $\begin{array}{l}0.0 \\
\%\end{array}$ & & & -- & & & -- & & & -- \\
\hline AVG 2013-17 & & & & $\begin{array}{l}0.7 \\
\%\end{array}$ & & & $48.3 \%$ & & & $78.9 \%$ & & & $\begin{array}{c}85.7 \\
\% \\
\end{array}$ \\
\hline \multicolumn{14}{|c|}{ GANAS Opt-Out } \\
\hline $2013-2014$ & 13 & 0 & $0 / 13=0$ & $\begin{array}{l}0.0 \\
\%\end{array}$ & 4 & $4 / 13=0.3076$ & $30.8 \%$ & 4 & $8 / 13=0.6153$ & $61.5 \%$ & 3 & $11 / 13=0.8461$ & $\begin{array}{c}84.6 \\
\% \\
\end{array}$ \\
\hline 2014-2015 & 9 & 0 & $0 / 9=0$ & $\begin{array}{l}0.0 \\
\% \\
\end{array}$ & 4 & $4 / 9=0.4444$ & $44.4 \%$ & 3 & $7 / 9=0.7777$ & $77.8 \%$ & & & - \\
\hline $2015-2016$ & 30 & 0 & $0 / 30=0$ & $\begin{array}{l}0.0 \\
\% \\
\end{array}$ & 14 & $14 / 30=0.466$ & $46.7 \%$ & & & - & & & - \\
\hline $2016-2017$ & 36 & 0 & $0 / 36=0$ & $\begin{array}{l}0.0 \\
\% \\
\end{array}$ & & & - & & & - & & & - \\
\hline AVG 2013-17 & & & & $\begin{array}{l}0.0 \\
\% \\
\end{array}$ & & & $40.6 \%$ & & & $69.7 \%$ & & & $\begin{array}{c}84.6 \\
\% \\
\end{array}$ \\
\hline \multicolumn{14}{|c|}{ Non-Eligible/Non-Applicant } \\
\hline 2013-2014 & 2511 & 57 & $57 / 2511=0.0227$ & $\begin{array}{l}2.3 \\
\% \\
\end{array}$ & 780 & $\begin{array}{c}837 / 2511=0.333 \\
3\end{array}$ & $33.3 \%$ & 785 & $1622 / 2511=0.6459$ & $64.6 \%$ & 214 & $1836 / 2511=0.7311$ & $\begin{array}{c}73.1 \\
\%\end{array}$ \\
\hline 2014-2015 & 2049 & 41 & $41 / 2049=0.020$ & $\begin{array}{l}2.0 \\
\%\end{array}$ & 685 & $\begin{array}{c}726 / 2049=0.354 \\
3\end{array}$ & $35.4 \%$ & 618 & $1344 / 2049=0.6559$ & $65.6 \%$ & & & -- \\
\hline 2015-2016 & 2785 & 43 & $43 / 2785=0.0154$ & $\begin{array}{l}1.5 \\
\%\end{array}$ & 911 & $\begin{array}{c}954 / 2785=0.342 \\
5\end{array}$ & $34.3 \%$ & & & - & & & -- \\
\hline $2016-2017$ & 2872 & 40 & $40 / 2872=0.0139$ & $\begin{array}{l}1.4 \\
\%\end{array}$ & & & - & & & - & & & -- \\
\hline AVG 2013-17 & & & & $\begin{array}{l}1.8 \\
\%\end{array}$ & & & $34.3 \%$ & & & $65.1 \%$ & & & $\begin{array}{c}73.1 \\
\%\end{array}$ \\
\hline
\end{tabular}

Used to create Figure 4.1 - Average Cumulative Graduation Rates by Comparison Group 


\section{Appendix E \\ GANAS Year-End Survey Questions pulled from Program Records}

1. The GANAS Counselor was easily accessible and available to me. $(n=139)$

2. The GANAS Counselor was knowledgeable about university requirements and procedures. $(n=139)$

3. The GANAS Counselor helped me understand GE requirements and select appropriate classes each quarter. $(n=139)$

4. The GANAS Counselor helped me with non-academic (personal) issues I went through. $(n=139)$

5. The GANAS Counselor showed genuine concern for me and my academic progress. $(n=138)$

6. On average, I met with my Herman@ $(n=139)$

7. My 1-on-1 meetings with my Herman@ were helpful. $(\mathrm{n}=106)$

8. When I reached out to my Herman@, s/he was able to answer my questions or help me find the solution. $(n=106)$

9. I felt comfortable approaching my Herman@ about academic challenges I was having. $(n=106)$

10. I felt comfortable approaching my Herman@ about personal challenges I was facing. $(n=106)$

11. In my experience, the diverse perspectives and backgrounds of the students were respected (UDGE D4 Course)

12. In my experience, the diverse perspectives and backgrounds of the students were respected. (UDGE C4 Course)

13. In my experience, the diverse perspectives and backgrounds of the students were respected. (UDGE B6 Course)

14. The speakers in the GANAS Seminar Course this year were engaging and beneficial to have in the classroom. 
15. The GANAS seminar course familiarized me with tools and skills I will need for career exploration \& employment searches.

16. I feel that I am part of a community here in the GANAS Program.

17. GANAS has provided opportunities for students to bond and become closer as a cohort.

18. The GANAS program has eased my transition here to CSUEB.

19. The GANAS Program has helped me navigate the universities policies and procedures.

20. The GANAS staff motivated and encouraged me during this year.

21. GANAS has increased my confidence as a college student.

22. How many times did you visit the GANAS Academic Counselor? $(n=139)$

23. How many times, on average, did you go to faculty office hours each quarter (in any class $) ?(n=137)$

24. What is the highest level of education you ever expect to complete? $(n=108)$ 


\section{Appendix F \\ Focus Group Protocol}

Introductory questions:

1. What are some of the reasons you made the choice to attend a community college?

2. What was your academic experience as a community college student?

3. Why did you apply to the GANAS Program?

4. When selecting your transfer destination, did the GANAS Program have any influence on that decision?

5. Prior to being admitted to GANAS, did you feel that you had a solid understanding of what GANAS was about? If not, what surprised you?

There are three components that make up the basic structure of GANAS: the coursework, the academic advising, and the mentoring.

6. Tell me about your experience in Transfer Success Seminar series.

7. As a GANAS student you were automatically enrolled in these courses which formed a learning community that moved together as a cohort for your entire first year. Tell me what that experience was like.

8. What is your overall impression of the faculty who teach the GANAS courses?

9. How did the environment of your GANAS courses differ, if at all, from your nonGANAS courses at Cal State East Bay?

10. Advising from GANAS is described as intrusive. This includes an attempt to get to know a student well, digging deeper to get to the heart of what is causing difficulty for them and recommending an appropriate intervention. How did you feel about this approach?

11. As a GANAS participant, you are assigned a peer mentor, called an Herman@. Please comment on that experience.

12. As a GANAS participant, you have access to a PASS Leader for tutoring assistance. Please comment on that experience if it applies. 
13. Outside of advising appointments, would you say you spent a lot of time in and around the GANAS office?

14. Did you take advantage of the student space known as the "Community Room"? What was that experience like?

15. Please discuss any barriers that you encountered as a student at Cal State East Bay. Was GANAS able to assist you in overcoming these barriers? Explain.

16. GANAS aims to provide a family-like environment for its students. Would you agree? Why or why not?

17. Has your participation in GANAS increased your confidence or comfort approaching faculty? How?

18. Do you feel more comfortable moving forward in pursuit of your goals?

19. Would you say participating in GANAS has changed your sense of empowerment?

20. Do you feel more comfortable speaking out or speaking up?

21. GANAS coursework is described as being culturally relevant. This means professors display cultural competence and skill in teaching in a multicultural setting which enables each student to relate course content to their cultural context. How did the GANAS courses relate to you and your culture?

22. If you had to choose one of the three main components of GANAS that we discussed today - the coursework, the advising, or the mentoring - which would you say impacted your academic progress the most and why?

23. Is there any aspect of GANAS, that we have not discussed, that impacted your academic progress?

24. Is there any aspect of GANAS, that we have or have not discussed, that impacted you in any other way, outside of academics?

25. Is there anything that we have not covered that you would like to add? 